\title{
Benzophenone Schiff Bases of Glycine Derivatives: Versatile Starting Materials for the Synthesis of Amino Acids and Their Derivatives
}

\author{
Martin J. O’Donnell \\ Department of Chemistry and Chemical Biology, Indiana University Purdue University \\ Indianapolis, Indianapolis, IN 46250 USA
}

\begin{abstract}
This review focuses on the introduction and early development, in solution, of phase-transfer catalyzed (PTC) reactions to afford racemic or enantioenriched natural and unnatural amino acids. To form monosubstituted amino acids alkylation reactions are performed on the benzophenone Schiff base of glycine. For $\alpha, \alpha$-disubstituted amino acids the activated intermediate is an aldimine derivative of the monosubstituted amino acid. Enantioenriched products are produced by organocatalysis using derivatives of Cinchona alkaloids as the phasetransfer catalyst. Selectivity for monoalkylatation and lack of product racemization depend on the acidities of the glycine imines, and dialkylated products are formed from aldimine esters of monoalkyl amino acids. The racemic and catalytic enantioselective reactions of a cationic glycine equivalent with organoboranes, organometallics and malonate anion are discussed as are other reactions of these versatile Schiff bases derivatives.
\end{abstract}

\section{Keywords}

Amino Acid Synthesis

Unnatural Amino Acids

Phase-Transfer Catalysis (PTC)

Asymmetric Synthesis

Benzophenone Schiff Bases

Imines of Amino Acid Derivatives

Organocatalysis

Racemic and Stereoselective Reactions

Glycine and Other Amino Acid Anion Equivalents

Glycine Cation Equivalents

\section{Contents}

1. Introduction

2. Protected glycine equivalents for amino acid synthesis 1903-1985 4

3. Preparation of Schiff bases of amino acid and dipeptide esters 5

4. Phase-transfer alkylations of the Schiff base esters of glycine and aminoacetonitrile 7

5. Large-scale synthesis by ion-pair extraction 8

6. Difluorocarbene aziridination of an imine by ion-pair extraction 8

7. Monoalkylation: Ketimine (IPE) vs. aldimine (PTC) glycine ethyl esters 9

8. Dialkylation of aldimines as a route to $\alpha, \alpha$-dialkyl amino acids 10

9. Synthesis of $\alpha$-methyl histidine by two complementary routes 11

10. PTC mono- or dialkylation with potassium carbonate 12

11. Intra- and intermolecular PTC dialkylations of a glycine equivalent 12

12. Acidities (pKa) of imine derivatives of glycine: Insights into alkylations 13

This is the author's manuscript of the article published in final edited form as:

O’Donnell, M. J. (2019). Benzophenone Schiff bases of glycine derivatives: Versatile starting materials for the synthesis of amino acids and their derivatives. Tetrahedron. https://doi.org/10.1016/j.tet.2019.03.029 
ODonnell Benzophenone Schiff Bases MS Ghosez Revd 031419.doc

13. Amino acid amide PTC alkylations

14. Phenylation and diphenylation for the preparation of aryl amino acids

15. Selective alkylation of dipeptides by PTC

16. First enantioselective PTC alkylation and Cinchona alkaloid organocatalysts 21

17. Enantioselective PTC monoalkylation of benzophenone imines of glycine esters 22

18. Mechanistic and molecular recognition studies of enantioselective PTC 24

19. Enantioselective PTC dialkylation of an $\alpha$-substituted aldimine ester 24

20. A new active catalyst species for enantioselective alkylation by PTC 25

21. Optimization of the catalytic enantioselective alkylation by PTC 27

22. Third generation Cinchona-based catalysts for enantioselective alkylations 27

23. Homogeneous enantioselective alkylation of the Schiff base ester of glycine 28

24. Homogeneous catalytic enantioselective Michael additions 29

25. Allylic acetates for the enantioselective synthesis of glutamic acids 30

26. Recrystallization of enantiomerically enriched products to higher optical purity 32

27. Amine diastereomer separations by conversion to their benzophenone imines 33

28. Other quaternary ammonium salts and Schwesinger-type catalysts 33

29. Large-scale synthesis of an optically active amino acid in $>99 \%$ ee 34

30. Glycine cation vs. glycine anion equivalents 35

31. Cationic glycine: $\alpha$-Acetates of the benzophenone imines of glycine esters 36

32. Cationic glycine: Reactions with neutral heteroatom nucleophiles 36

33. Cationic glycine: Reactions with organoboranes 37

34. Cationic glycine: Enantioselective syntheses with organoboranes 38

35. Cationic glycine: Enantio- and diastereoselective synthesis with organoboranes 39

36. Cationic glycine: Reactions with neutral carbon nucleophiles 40

37. Cationic glycine: Reactions with organometallics 41

38. Cationic glycine: Malonate anions with palladium catalysis 42

39. Cationic glycine: Malonate anions and bis-phosphine tether length 43

40. Cationic glycine: Malonate anion enantioselective (BPPM) and $\beta$-alkylation 44

41. Cationic glycine: Malonate anion enantioselective (BINAP) and recrystallization 44

42. Cationic glycine: Reaction with vinyl anions to $\beta, \gamma$-unsaturated amino acids 45

43. Preparation and reactions of a cationic aminophosphonate equivalent with organoboranes 46

44. Preparation and alkylation of the Weinreb amide of the benzophenone imine of glycine 47

45. $\alpha$-Keto Schiff base esters for preparation of $\alpha, \beta$-didehydroamino acids 48

46. Transesterification of Schiff base esters of amino acids and dipeptides 49

47. Nitrogen alkylation for the preparation of N-alkyl amino acids and a total synthesis $\quad 50$

48. Conclusions 53

Reflections 53

Acknowledgements $\quad 54$

References $\quad 54$ 
ODonnell Benzophenone Schiff Bases MS Ghosez Revd 031419.doc

\section{Introduction}

The biochemical and medicinal importance of amino acids, the "building blocks of life," and the consequent need for new methods for the asymmetric synthesis and utilization of both natural and unnatural $\alpha$-amino acids ${ }^{1,2}$ cannot be overstated. The 20 proteinogenic $\alpha$-amino acids have diverse physical properties governed by the structure and nature of their side chains: polar (hydrophilic) vs. nonpolar (hydrophobic); neutral, acidic or basic; aromatic vs. nonaromatic; essential vs. nonessential; achiral vs. chiral. The chirality of "natural" amino acids and their stereoisomers is identified either by the classical terms L (natural), D (unnatural) or D,L (racemic) or by the Cahn-Ingold-Prelog (CIP) sequence rules where 19 of the 20 have the $S$ absolute configuration while cysteine contains an $R$ stereogenic center. These 20 amino acids are the monomers used by living systems for the construction of all peptides and proteins. The 20 varied side chains in these amino acids impart unique 3-dimensional and functional properties to the peptide/protein depending on their placement in the polymer sequence.

Three examples demonstrate a range of biologically important natural compounds that contain amino acids or their metabolites: penicillin (from microbes), an antibiotic mimicking with a bicyclic structure the D-Ala-D-Ala dipeptide motif present in a key intermediate in bacterial cell wall synthesis; insulin, a two chain, 51 amino acid peptide regulating glucose metabolism; and hemoglobin, a large tetrameric protein in which a single replacement of glutamic acid by valine is responsible for sickle cell anemia. In addition, amino acids are the biochemical precursors for many hormones, neurotransmitters and other metabolites in humans, and innumerable natural products occurring in plants, animals and microbes. ${ }^{3,4}$

The asymmetric synthesis of amino acids and their analogs has been the focus of numerous studies over the past forty years. Examples of earlier classical methods for the synthesis of racemic $\alpha$-amino acids (bond formed to the $\alpha$-carbon) include: $\underline{C}_{\alpha}-C_{\beta}$, alkylation of ethyl acetamidomalonate (vide infra); $\underline{\mathrm{C}_{\alpha}} \underline{-} \underline{\mathrm{H}}$, hydrogenation of various amino acid precursors; $\underline{\mathrm{C}}_{\alpha}-\mathrm{CO}_{2} \underline{\mathrm{H}}$, Strecker reaction of iminium ions from aldehydes and $\mathrm{NaCN} / \mathrm{NH}_{4} \mathrm{Cl}$ then hydrolysis, (facile route to arylglycines); and $\underline{\mathrm{C}}_{\alpha}-\mathrm{NH}_{2}$, amination of $\alpha$-haloesters. More recently, each of these bond constructions, in addition to the chiral protonation of amino acid enolates, has been employed to prepare optically active $\alpha$-amino acids by asymmetric synthesis. ${ }^{1}$

The nitrogen to carbon to carbonyl $\left(\mathrm{N}-\mathrm{C}_{\alpha}-\mathrm{C}=\mathrm{O}\right)$ motif of amino acids is present in many pharmaceuticals and other products: DOPA (Levodopa, L-3,4-Dihydroxyphenylalanine), Parkinson's disease; Plavix (Clopidogrel), platelet inhibitor; Valium (Diazapam), antianxiety; Enalapril (Vasotec), antihypertensive; Thyroxine (Levothyroxine), thyroid hormone; Humalog (Insulin Lispro), regulates glucose metabolism; Prilocaine (Citanest), local anesthetic; and Nutrasweet (Aspartame, Asp-PheOMe), artificial sweetener.

In addition to their importance in the chemical synthesis of amino acids and other molecules (vide infra), the imine functionality plays a key role in biochemistry. The imines/iminium ions formed between pyridoxal-5'-phosphate and various enzymes are involved in numerous biochemical reactions: racemization, decarboxylation, transamination, $\alpha$-cleavage, $\beta$-elimination, $\beta$-replacement, $\gamma$-elimination and $\gamma$-replacement. ${ }^{5}$

This review focuses on the introduction and development, in solution, of phase-transfer catalyzed (PTC) reactions to afford racemic or enantioenriched natural and unnatural amino acids using the imines (Schiff bases) of glycine and other amino acids. The construction of the $\mathrm{C}_{\alpha}-\mathrm{C}_{\beta}$ bond by asymmetric organocatalysis or metal-catalyzed reactions of anionic and cationic glycine equivalents (2-azaallyl anions and 2-azaallyl cations) ${ }^{6}$ and various additional 
transformations of these substrates will be discussed. The extension of this methodology for industrial large-scale syntheses will also be covered.

A review of the main synthetic equivalents for the simplest amino acid, glycine, will highlight the history of this field. The focus of this article is a review of the solution-phase methodology involving Schiff base derivatives of glycine developed in the O'Donnell lab since our first publications in $1978 .{ }^{7,8}$ Relevant reviews by the author:

$\alpha$-Amino Acid Synthesis. ${ }^{9 a}$

Asymmetric Phase-Transfer Reactions. ${ }^{9 \mathrm{~b}}$

Ethyl N-(Diphenylmethylene)glycinate. ${ }^{9 \mathrm{c}}$

Ethyl N-(Diphenylmethylene)-2-acetoxyglycinate. ${ }^{9 \mathrm{~d}}$

$\mathrm{N}$-(Diphenylmethylene)aminoacetonitrile. ${ }^{9 \mathrm{e}}$

Benzophenone Imine. ${ }^{\text {of }}$

Diethyl Acetamidomalonate. ${ }^{9 \mathrm{~g}}$

A New Interfacial Mechanism for Asymmetric Alkylation by Phase Transfer Catalysis. ${ }^{\text {gh }}$

Amino Acid and Peptide Synthesis Using Phase Transfer Catalysis. ${ }^{9 i}$

Asymmetric Phase-Transfer Reactions. ${ }^{9 j}$

The Preparation of Optically Active $\alpha$-Amino Acids from the Benzophenone Imines of Glycine Derivatives. ${ }^{9 \mathrm{k}}$

The Enantioselective Synthesis of $\alpha$-Amino Acids by Phase-Transfer Catalysis with Achiral Schiff Base Esters. ${ }^{91}$

O’Donnell Amino Acid Synthesis. ${ }^{9 \mathrm{~m}}$

O’Donnell Amino Acid Synthesis. ${ }^{\text {9n }}$

\section{Protected glycine equivalents for amino acid synthesis 1903-1985}

For the first seventy years of the last century, the classical chemical synthesis of the $\alpha$ amino acids was the method reported by Sörensen in 1903, which involved deprotonation of diethyl acetamidomalonate (1, Figure 1$)^{9 \mathrm{~g}, 10}$ followed by alkylation, hydrolysis and in situ decarboxylation $\left(\mathrm{Na}, \mathrm{EtOH} ; \mathrm{RX} ; \mathrm{H}^{+}\right)$to add a new side-chain $\mathrm{R}$ to glycine to give racemic amino acids derivatives. 
<smiles>CC(=O)NC(C(=O)O)C(=O)O</smiles>

1

"Glycine Anion"

Sörensen (1903)

$\mathrm{PhCH}=\mathrm{N} \smile \mathrm{CO}_{2} \mathrm{Et}$

4a

"Glycine Anion"

Stork (1976)

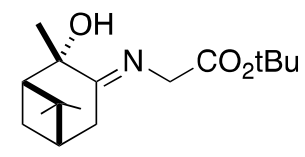

2

"Glycine Anion" Yamada (1976)<smiles>CCOC(=O)CN=Cc1ccccc1</smiles>

$5 a(6 a)$ "Glycine Anion"<smiles>O=C1CCN2C(=O)c3ccccc3C3(ON2C1)N(c1ccccc1)C(=O)C1CCCN13</smiles>

3

"Glycine Anion"

Belokon (1983)<smiles>CCOC(C)OC(C)=O</smiles>

$7 a$

"Glycine Cation"

O’Donnell (1985)

Figure 1. Glycine Anion Equivalents and a Glycine Cation Equivalent.

Chemistry of carbon-nitrogen double bond formation (imines or Schiff bases) dates to 1864 when Hugo Schiff in Pisa reported their first synthesis. ${ }^{11}$

In 1976 Yamada alkylated the chiral Schiff base of glycine 2, which contains the built-in chiral auxiliary derived from the natural product $\alpha$-pinene, to produce optically active amino acid products. $^{12}$ In 1983 Belokon' introduced the glycine imine equivalent into a chiral metal complex of general structure $\mathbf{3}$, which, on deprotonation and alkylation, gave a variety of optically active products. ${ }^{13}$ More recently this methodology has been extended by Soloshonok et. al. ${ }^{14}$

Other early reports of amino acid syntheses involving starting materials containing a carbon-nitrogen double bond include isocyano acetates (Schöllkopf ${ }^{15 a}$ Matsumoto $^{15 b}$ ), oxazol-5ones/azlactones (Steglich ${ }^{15 \mathrm{c}}$ ), $\alpha$-[bis(alkylthio)methyleneamino] acid esters (Hoppe ${ }^{15 \mathrm{~d}}$ ), and amidino esters (Gschwend ${ }^{15 e}$ ).

In 1976 the Stork group reported alkylation and Michael addition of the achiral aldimine of glycine ethyl ester (4a) with strong base under anhydrous conditions at low temperature (LDA, anhydrous THF, $-78^{\circ} \mathrm{C}, \mathrm{RX}$ ) to obtain good yields of racemic amino acids. ${ }^{16}$

Our efforts in the field began with two 1978 publications that used, as the glycine anion equivalent, the benzophenone imine of glycine ethyl ester $(\mathbf{5 a})^{7,9 \mathrm{c}}$ or acetonitrile $(\mathbf{6 a}){ }^{8,9 \mathrm{e}}$ Room temperature alkylation of $\mathbf{5 a}$ or $\mathbf{6 a}$ using phase-transfer methods under basic conditions introduced a promising new method for the alkylation to form racemic amino acids. The "glycine cation equivalent" (7a) that inverts the polarity of the glycine moiety and allows reactions with a variety of neutral or charged nucleophiles, was introduced in $1985 .{ }^{9 \mathrm{~d}, 17}$ The stereoselective synthesis of amino acids from a glycine anion equivalent $\mathbf{5}$ was reported in 1989. ${ }^{18}$ These and a number of other synthetic transformations of the benzophenone imines and aldehyde imines from glycine amino esters will be described in the following pages.

\section{Preparation of Schiff bases of amino acid and dipeptide esters}


Synthesis of the starting benzophenone imines of glycine ethyl ester $(\mathbf{5 a})^{7,9 \mathrm{c}}$ or acetonitrile $(\mathbf{6 a})^{8,9 \mathrm{e}}$ and other amino acid esters was accomplished by condensation of glycine ethyl ester (8) (released from its hydrochloride salt prior to reaction) or aminoacetonitrile (9) with benzophenone imine in refluxing xylene in the presence of freshly distilled boron trifluoride etherate (Scheme 1A). ${ }^{7}$ The crude reaction mixture was flame-distilled under vacuum and then recrystallized. Starting materials $\mathbf{5}$ and $\mathbf{6 a}$ are stable for extended periods when stored at room temperature under argon. In contrast, the aldimine $\left(\mathrm{PhCH}=\mathrm{NCH}_{2} \mathrm{CO}_{2} \mathrm{Et}, \mathbf{4 a}\right)$ is stable in the freezer for several months. ${ }^{16}$

\section{A. Condensation (1978)}

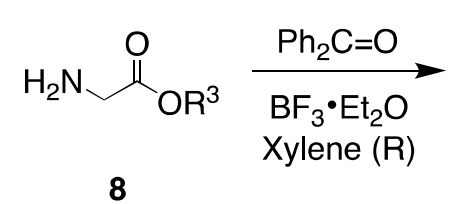

8

or

$\mathrm{H}_{2} \mathrm{~N} \smile \mathrm{CN}$

9<smiles>O=C(O)CN=Cc1ccccc1</smiles>

$5(76-97 \%)$

or

$\mathrm{Ph}_{2} \mathrm{C}=\mathrm{N} \smile \mathrm{CN}$

$6 a(70 \%)$

\section{B. Transimination (1982)}

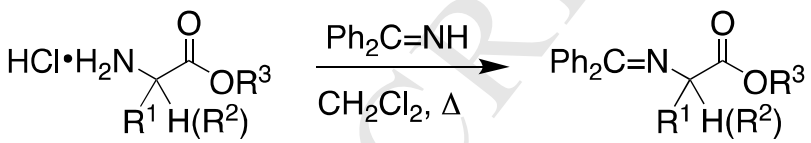

$10(11)$

$12(13)$

Products from Transimination Route<smiles>O=C(CN=Cc1ccccc1)O[18O]</smiles>

5a-5e (76-97\%)

$\mathrm{R}^{3}=\mathrm{Et}, \mathrm{Me}, \mathrm{tBu}$

$\mathrm{CH}_{2} \mathrm{Ph}, \mathrm{CHPh}_{2}$<smiles>[R]C(N=Cc1ccccc1)C(=O)OCC</smiles>

12a-12g (90-93\%) $\mathrm{R}^{1}=\mathrm{Me}, \mathrm{CH}_{2} \mathrm{Ph}, \mathrm{Ph}$

(See Row 2)<smiles>CCC(C)(C)N(C)C(C)(C)C(C)=O</smiles>

13a $(60 \%)$<smiles>COC(=O)C(Cc1ccc(O)c(O)c1)N=Cc1ccccc1</smiles>

$12 \mathrm{e}(84 \%)$<smiles>COC(=O)C(Cc1c[nH]c2ccccc12)N=Cc1ccccc1</smiles>

$12 f(91 \%)$<smiles>COC(=O)C=NC(=O)CN=Cc1ccccc1</smiles>

$14 \mathbf{a}$ or $15 \mathbf{a}(91,94 \%)$

$(\mathrm{n}=1$ or 2$)$<smiles>COC(=O)C(Cc1cnc[nH]1)N=Cc1ccccc1</smiles>

$12 \mathrm{~g}(89 \%)$

Scheme 1. Preparation of Schiff Bases of Amino Acids and Dipeptide Esters.

Fortunately, a milder, more efficient and easier synthesis of these Schiff bases involves the transimination of benzophenone imine with the hydrochloride salts of glycine, monosubstituted amino acid esters, aminoacetonitrile or dipeptide esters in methylene chloride at room temperature for $24 \mathrm{~h}$ followed by recrystallization to give products 12a-g (Scheme 1B). ${ }^{19}$ The Schiff base 13a, derived from an $\alpha, \alpha$-disubstituted amino ester $\left(\mathrm{R}^{1}=\mathrm{R}^{2}=\operatorname{Me}, \alpha\right.$ aminoisobutyric acid, Aib) was prepared in refluxing 1,2-dichloroethane and the crude product was purified by chromatography. The dipeptide ester Schiff bases (14a and 15a) from Gly-Gly$\mathrm{OMe}$ and Gly-GABA-OMe (GABA $=\gamma$-aminobutyric acid) were also prepared in excellent yields.

The stereochemical outcome from product hydrolysis of an optically active Schiff base ester 12b $\left(\mathrm{R}^{1}=\mathrm{PhCH}_{2}\right)$ under reaction conditions was studied starting from commercially 
ODonnell Benzophenone Schiff Bases MS Ghosez Revd 031419.doc

available L-phenylalanine. ${ }^{19}$ The ethyl ester hydrochloride of $(S)$-Phe was prepared by standard methods follow by transimination with benzophenone imine to yield $(S)-\mathbf{1 2} b\left(\mathrm{R}^{1}=\mathrm{PhCH}_{2}, \mathrm{R}^{2}=\right.$ Et). Hydrolysis of this product gave either:

(a) the amino ester salt $\left\{\left(1 \mathrm{~N} \mathrm{HCl} / \mathrm{ether}, 0{ }^{\circ} \mathrm{C}\right.\right.$ to ambient temperature, overnight $)$ to yield $(S)$ phenylalanine ethyl ester $\bullet \mathrm{HCl}:\left\{[\alpha]^{25}{ }_{\mathrm{D}}+35.6^{\circ} \pm 0.5^{\circ}\right.$, average of three readings, $(c 2$, EtOH); lit. $\left.[\alpha]^{20}+33.5^{\circ}(\mathrm{EtOH})\right\}$ or

(b) the amino acid $(S)$-phenylalanine: $(6 \mathrm{~N} \mathrm{HCl}$, reflux under argon, $6 \mathrm{~h})$ to give $(S)$ phenylalanine $\bullet \mathrm{HCl}\left\{[\alpha]_{\mathrm{D}}^{25}-6.3^{\circ} \pm 0.4^{\circ}\right.$, average of three readings, $(c 2,1 \mathrm{~N} \mathrm{HCl}) ;$ lit. $[\alpha]_{\mathrm{D}}^{25}$ $4.47^{\circ}(c 1-2,5 \mathrm{~N} \mathrm{HCl}) ;$ lit. $\left.[\alpha]^{25}{ }_{\mathrm{D}}-7.4^{\circ}(5 \mathrm{~N} \mathrm{HCl})\right\}$.

Thus, the hydrolyses of the benzophenone imine of $(S)$-phenylalanine ethyl ester, occurs with retention of configuration to give either $(S)$-phenylalanine hydrochloride or $(S)$ phenylalanine. ${ }^{19}$

To date, the benzophenone imines of either glycine ethyl ester (5a) or, in the case of stereoselective syntheses, glycine t-butyl ester $(\mathbf{5 c})$ have been the most popular of these starting materials (vide infra).

\section{Phase-transfer alkylations of the Schiff base esters of glycine and aminoacetonitrile}

The alkylation of the benzophenone imine of glycine ethyl ester (5a) can be accomplished in good yield using strong base under anhydrous conditions (LDA, HMPA, THF, $\left.-78^{\circ} \mathrm{C}\right){ }^{7}$ However, a milder procedure was developed using the phase-transfer technique of ionpair extraction (IPE) developed by Brändström, ${ }^{20}$ which uses a full equivalent of the phasetransfer reagent. Since the ethyl ester would be saponified under the normal phase-transfer conditions employed at the time $(50 \% \mathrm{NaOH})$, IPE, which uses milder base $(10 \% \mathrm{NaOH})$ together with tetrabutylammonium hydrogen sulfate was an ideal solution that led to good to excellent yields of $\mathbf{1 2 h}-\mathbf{k}, \mathbf{1 2 b}$ (Scheme $2 \mathrm{~A}){ }^{7}$

A. Ion-Pair Extraction (IPE)

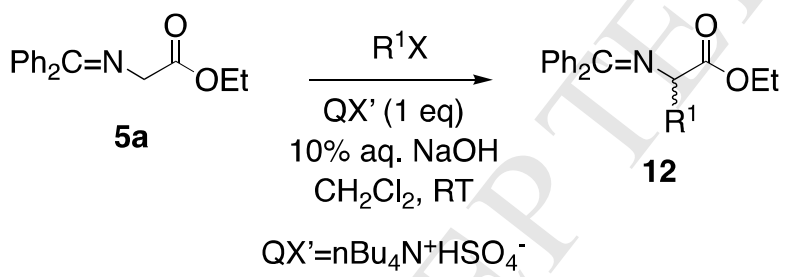

B. Phase-Transfer Catalysis (PTC)

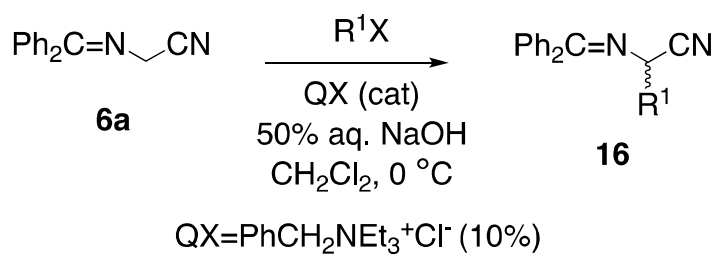

Products: Ester (IPE) or Nitrile (PTC) / Yields / $\mathbf{R}^{\mathbf{1}} \mathbf{X}$<smiles>CCOC(=O)C(C)N=C=Cc1ccccc1</smiles><smiles>CCOC(OCC)N(C)C=Nc1ccccc1</smiles>

(IPE/PTC)

12i (16b)

$(89 \%, 95 \%)$

Etl, EtBr<smiles>CCOC(=O)C(N=Cc1ccccc1)C(C)C</smiles>

(IPE/PTC)

12j (16c) $(60 \%, 79 \%)$

iPrl, iPrBr<smiles>CCOC(=O)C(N=Cc1ccccc1)C(C)CC</smiles>

(IPE/PTC)

12k (16d)

(59\%, 82\%)

sBul, sBuBr

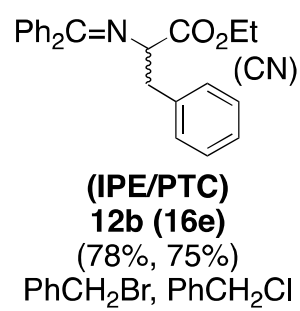

Scheme 2. Alkylations by Ion-Pair Extraction and Phase-Transfer Catalysis.

Phase-transfer catalysis (PTC, Scheme 2B) was developed as a practical synthetic procedure by Makosza, ${ }^{21}$ Dehmlow, ${ }^{22}$ Starks $^{23}$ and others. ${ }^{24}$ The first PTC alkylation of 
protected amino acid substrates was accomplished using the benzophenone imine of aminoacetonitrile $(\mathbf{6 a})$, which is stable to $50 \% \mathrm{NaOH}$, with a catalytic amount of TEBA (triethylbenzylammonium chloride) in toluene at $0{ }^{\circ} \mathrm{C}$ (Scheme 2B). Chemical yields and alkylating agents for the procedures to prepare products $\mathbf{1 2}$ and $\mathbf{1 6}$ are compared (Scheme 2). ${ }^{7,8}$

In many cases, especially with expensive catalysts, procedures that use a catalytic amount of a reagent are preferable to those that involve a full equivalent of a phase-transfer reagent. However, IPE can offer several advantages: cost of the tetraalkylammonium salt for racemic synthesis, ease of operation and use of more reactive alkyl halides in IPE (iodides with IPE vs. bromides or chlorides with PTC, since iodides poison the catalyst). The lipophilicity of alkyl iodides is responsible for this catalyst poisoning because the product quaternary iodides are extracted into the organic phase and are not readily available at the interface for catalyst recycling. $^{20-24}$

\section{Large-scale synthesis by ion-pair extraction}

In a collaboration with the late Jim McCarthy and Master's student Charlotte Barney, then at Merrell Dow in Indianapolis, the practicality of ion-pair extraction was demonstrated by the large scale reaction of $\mathbf{5 d}(57 \mathrm{~g}, 0.17$ mole) with $\mathrm{PhCHBrF}$ to give the racemic erythro- and threo-3-fluorophenylalanine diastereomers $\left(\boldsymbol{t}-17\right.$ and $\boldsymbol{e}$-17) (Scheme 3). ${ }^{25}$ Since the achiral quaternary ammonium salt $\left(\mathrm{nBu}_{4} \mathrm{NHSO}_{4}\right)$ is relatively inexpensive, use of a full equivalent was not problematic. The procedure involved a simple reaction setup and procedure and the mild basic $(10 \% \mathrm{NaOH})$ avoided hydrolysis of the benzyl ester, thus allowing isolation of either of the amino ester diastereomers. Amino acid e-17a was prepared by ester deprotection with trimethylsilyl iodide followed by mild acid hydrolysis and isolation. ${ }^{26}$

Note: A "large scale" reaction means different things to different people and will be used in its loosest terms ( $15 \mathrm{~g}$ to $\geq 1.8 \mathrm{~kg}$ starting material) by this "discovery chemist"!

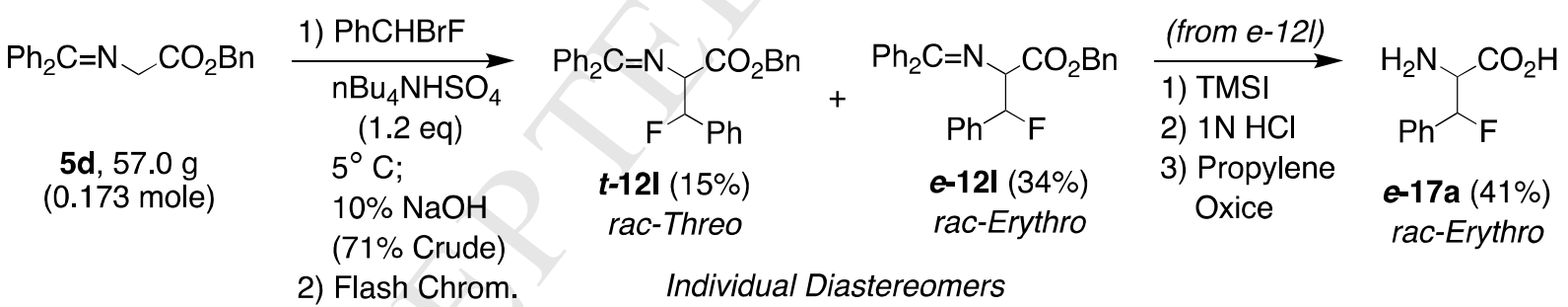

Scheme 3. Large-Scale Synthesis of 3-Fluorophenylalanine Diastereomers by Ion-Pair Extraction.

\section{Difluorocarbene aziridination of an imine by ion-pair extraction}

In a continuation of the McCarthy collaboration, 5a was reacted with difluorocarbene under ion-pair extraction conditions to give the $N$-difluoromethyl aziridine $\mathbf{1 8}$ (Scheme 4). ${ }^{27,28}$ Structure 18 was confirmed by X-Ray. Overall this transformation involves construction of both a new carbon-carbon bond and the exocyclic carbon-nitrogen bond. The mechanism of the reaction is believed to involve the final intermediacy of an azomethine ylide, which forms the carbon-carbon bond between an $\pi 01 \sigma 0 v$-carbon anion and the original imine carbon. 
ODonnell Benzophenone Schiff Bases MS Ghosez Revd 031419.doc

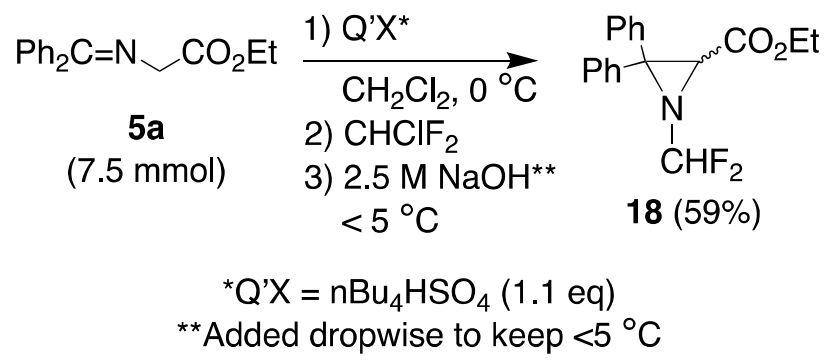

Scheme 4. New Pathway for the Reaction of a Difluorocarbene with Imines.

\section{Monoalkylation: Ketimine (IPE) vs. aldimine (PTC) glycine ethyl esters}

In collaboration with the Ghosez group, ${ }^{29}$ a head-to-head comparison of monoalkylation of ketimine 5a (Scheme 5A) and aldimine 4b (Scheme 5B) was carried out with various alkyl halides by either the ion-pair extraction procedure (5A, full equivalent of QX) (Scheme $5 \mathrm{~A})^{7,20}$ or two catalytic phase-transfer (liquid-liquid or solid-liquid) methods (5A, 1 equiv. QX; 5B, $10 \%$ QX) (Scheme 5B). ${ }^{8,21-24}$ The Schiff base $4 \mathbf{b}$ from 4-chlorobenzaldehyde and glycine ethyl ester was chosen over the Schiff base of benzaldehyde and glycine ethyl ester (4a) because the former is crystalline.

A. Ketimine Starting Substrate

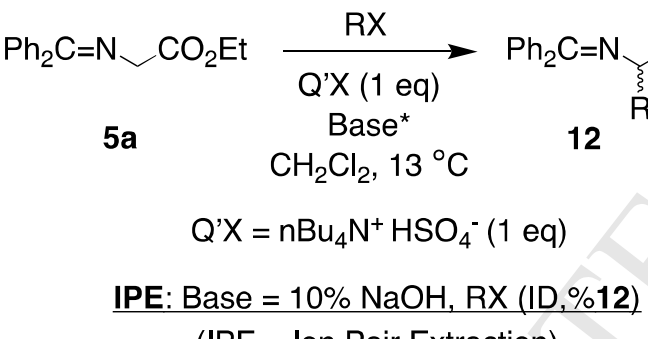

$$
\begin{aligned}
& \text { (IPE = Ion Pair Extraction) } \\
& \text { 4- } \mathrm{ClPhCH}_{2} \mathrm{Br}(\mathbf{1 2 m}, 94 \%) \\
& \text { 1-NaphCH }{ }_{2} \mathrm{Br}(12 \mathrm{n}, 91 \%) \\
& \text { AllyIBr }(120,76 \%) \\
& \text { Etl (12i,76\%) }
\end{aligned}
$$

LL PTC: Base $=50 \% \mathrm{NaOH} ; \mathrm{RX}(\mathrm{ID}, \% 12)$ : 4- $\mathrm{ClPhCH}_{2} \mathrm{Br}(12 \mathrm{~m}, 73 \%)$$$
\text { nHexl (12p, 18\%) }
$$

S/L PTC: Base - grnd. KOH; RX (ID,\%12): 4- $\mathrm{CIPhCH}_{2} \mathrm{Br}(\mathbf{1 2 m}, 71 \%)$ nHexl (12p, 47\%)

\section{B. Aldimine Starting Substrate}

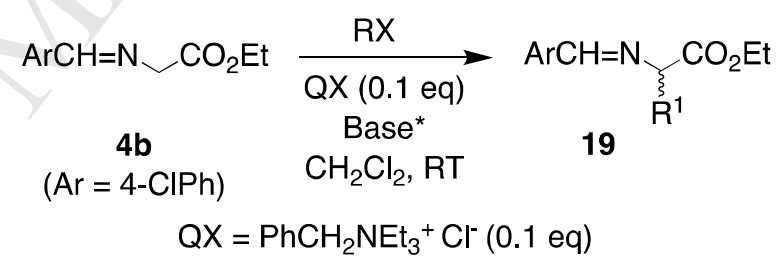

PTC: Base, RX (ID,\%19); ( $L / L=$ Liquid/Liquid or $S / L=$ Solid-Liquid)

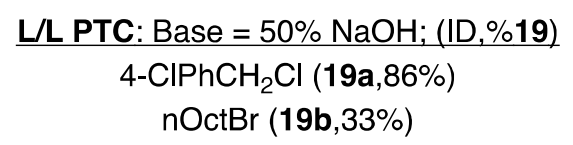

S/L PTC: Base $=\mathrm{KOH}$ (Ground): (ID,\%19); 4- $\mathrm{ClPhCH}_{2} \mathrm{Cl}(19 \mathrm{a}, 80 \%)$ $\mathrm{nOctBr}(\mathbf{1 9 b}, 74 \%)$

Scheme 5. Monoalkylation of Ketimine and Aldimine Schiff Bases Under Various PTC Conditions.

The ion-pair extractive alkylation of 5a resulted in good to excellent yields of both active (benzylic, 91-94\%, allylic, 76\%) and less reactive alkyl (EtI, 76\%) halides except when an alkyl iodide (nOctBr) was used. When comparing the liquid-liquid and solid-liquid PTC procedures 
for $\mathbf{5 a}$ and $\mathbf{4 b}$, overall the ketimine $\mathbf{5 a}$ gave better results $\left(\mathrm{ArCH}_{2} \mathrm{Cl}, 80-86 \%\right.$; $\left.\mathrm{RI}(\mathrm{Br}), 33-74 \%\right)$ than the aldimine $\mathbf{4 b}\left(71-73 \% \mathrm{ArCH}_{2} \mathrm{Br}\right.$; RI, 18-47\%) and the catalyst-poisoning effect with alkyl iodides was noted in both series.

\section{Dialkylation of aldimines as a route to $\alpha, \alpha$-dialkyl amino acids}

Extension of the monoalkylation PTC route to a dialkylation procedure led to $\alpha, \alpha$-dialkyl amino acids and their derivatives. The targets for this study were the $\alpha$-methyl derivatives of three biologically important amino acids: tyrosine (Tyr), m-Tyrosine (m-Tyr) and 3,4dihydroxyphenylalanine (DOPA). Two routes (Scheme 6) were envisioned: benzylations of the Schiff base ethyl ester of alanine (19c) (Route A) or methylation of the benzylic aldimine ester of tyrosine analogs with phenolic protection (19d-f) (Route B). ${ }^{30}$

The O-benzyl protected tyrosine 19d was prepared by condensation of $\mathrm{p}$ chlorobenzaldehyde with Tyr-OEt $\bullet \mathrm{HCl}\left(\mathrm{Et}_{3} \mathrm{~N}, \mathrm{CH}_{2} \mathrm{Cl}_{2}, \mathrm{MgSO}_{4}\right)$ and then the phenol was protected $\left(\mathrm{PhCH}_{2} \mathrm{Br}, \mathrm{K}_{2} \mathrm{CO}_{3}\right.$, acetone). Application of this procedure for preparation of the DOPA analog resulted in isolation of the tetrahydroisoquinoline 21 by a Pictet-Spengler cyclization of the initially formed imine 20. This undesired result was prevented by using the sterically demanding aldehyde, mesitaldehyde, to form starting material 19f, which was converted to the product 11c $\left(\mathrm{R}^{1}=\mathrm{R}^{2}=\mathrm{Bn}\right)$ by methylation in $55 \%$ yield.

Route A

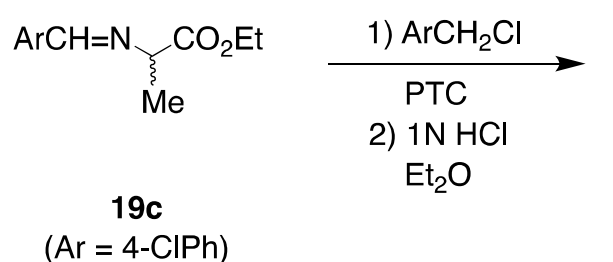

\begin{tabular}{c}
$\begin{array}{c}\text { Benzylation } \\
\text { (all from 19c) }\end{array}$ \\
\hline $84 \%$ \\
$93 \%$ \\
$79 \%$
\end{tabular}
Route B

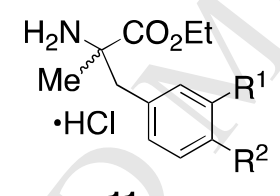

11a-c

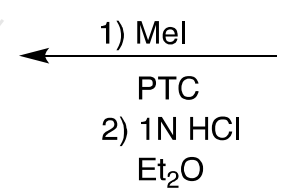

$86 \%$ (from 19d)

11a: $R^{1}, R^{2}=H, O B n(T y r)$

11b: $R^{1}, R^{2}=O B n, H(m-T y r)$

11c: $R^{1}, R^{2}=O B n, O B n(D O P A)$

\section{Methylation}

$55 \%$ (from 19f)<smiles>[R7]c1ccc(C[C@H](N=C[CH2])C(=O)OCC)cc1[R]</smiles>

19d-19f (below)

$(\mathrm{Ar}=4-\mathrm{CIPh})$

Undesired Cyclization (20 to 21) of

Unprotected DOPA Starting Material

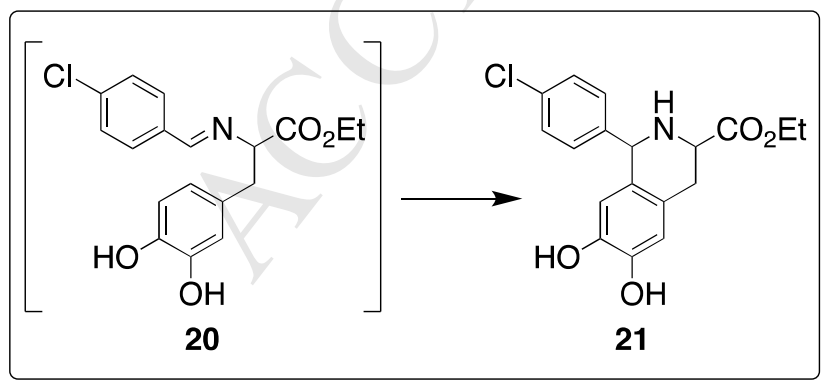

Solution: Use a Sterically-Hindered Schiff Base

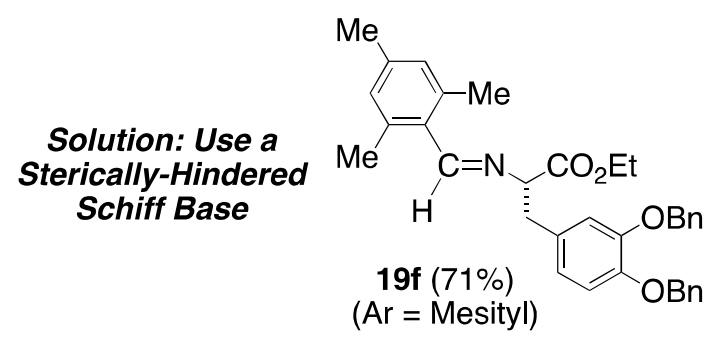

Undesired In Situ Pictet-Spengler Cyclization

Scheme 6. Dialkylation of the 4-Chlorophenyl Schiff Base of Amino Esters. 
The remaining alkylations were carried out as described above. Yields are for the amino ester hydrochloride salt products (11a-c) by either the benzylation or methylation routes (because of the expense of m-Tyr, product 11b was not pursued by methylation). These products were subjected to deprotection and hydrolysis to give the final dialkylamino acid products in 47-54\% overall yield from their parent amino acids.

\section{Synthesis of $\alpha$-methyl histidine by two complementary routes}

Construction of $\alpha$-methylhistidine (24a) was also accomplished by the benzylation and methylation routes (Scheme 7). ${ }^{31}$ Starting material $\mathbf{1 9 g}$ was prepared in a one-pot procedure from histidine methyl ester dihydrochloride by condensation of the free amino ester (generated in situ) with 4-chlorobenzaldhyde followed by protection of the imidazole nitrogen with tosyl chloride/triethylamine (83\%).

The solid-liquid PTC alkylations (Routes 7A and 7B) used powdered $\mathrm{KOH}$ in acetonitrile with catalytic tetrabutylammonium bromide at $5{ }^{\circ} \mathrm{C}$ with inverse addition (Schiff base ester added last). The reaction was monitored by HPLC for the disappearance of starting material (30$60 \mathrm{~min}$ ). Following an aqueous workup, the crude products (23a, $47 \%$ and $\mathbf{2 3 b}, 70 \%$ ) were hydrolyzed $(1 \mathrm{~N} \mathrm{HCl}, \mathrm{RT} ; 6 \mathrm{~N} \mathrm{HCl}$, reflux) to yield $\alpha$-methylhistidine $2 \mathrm{HCl}(\mathbf{2 4 a}, 27-47 \%$, respectively).

Route A

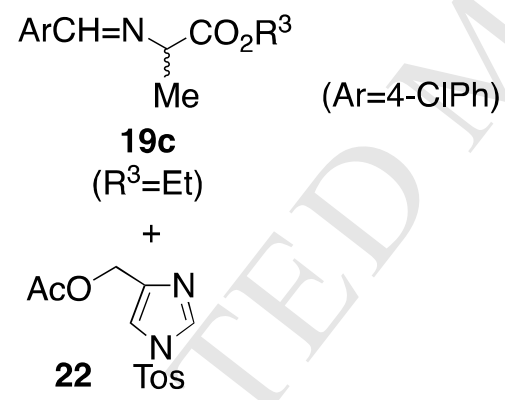

Route B

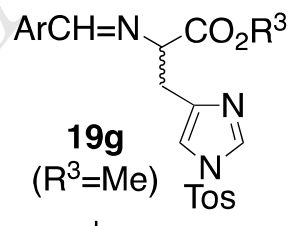

Mel

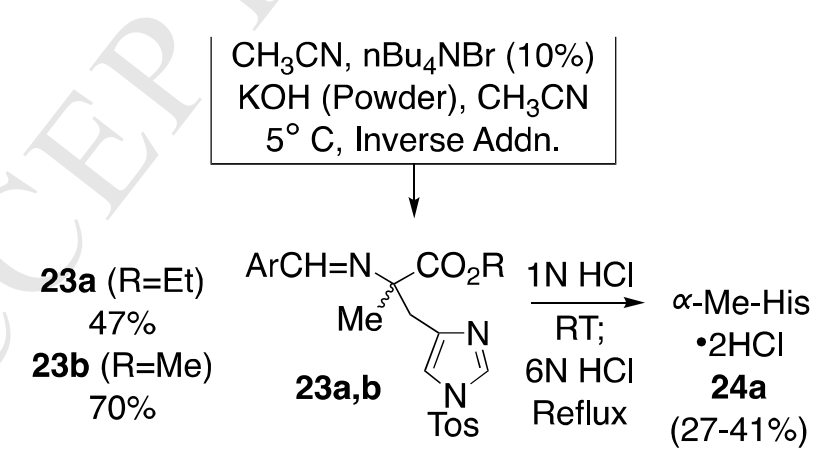

Scheme 7. Preparation of $\alpha$-Methyl Histidine using PTC Dialkylations. 


\section{PTC mono- or dialkylation with potassium carbonate}

Monoalkylation of the benzophenone imine of glycine ethyl ester (5a) with active and less reactive alkyl halides in refluxing acetonitrile in the presence of potassium carbonate occurs in good yield to give 12. Both mono- and subsequent dialkylation of the aldimine esters $(\mathbf{4 b}$ or 19c) occur at room temperature with the same base in dichloromethane to yield products $19 \mathbf{a}, \mathbf{h}, \mathbf{i}$ or 23c,d (Scheme 8). ${ }^{32}$

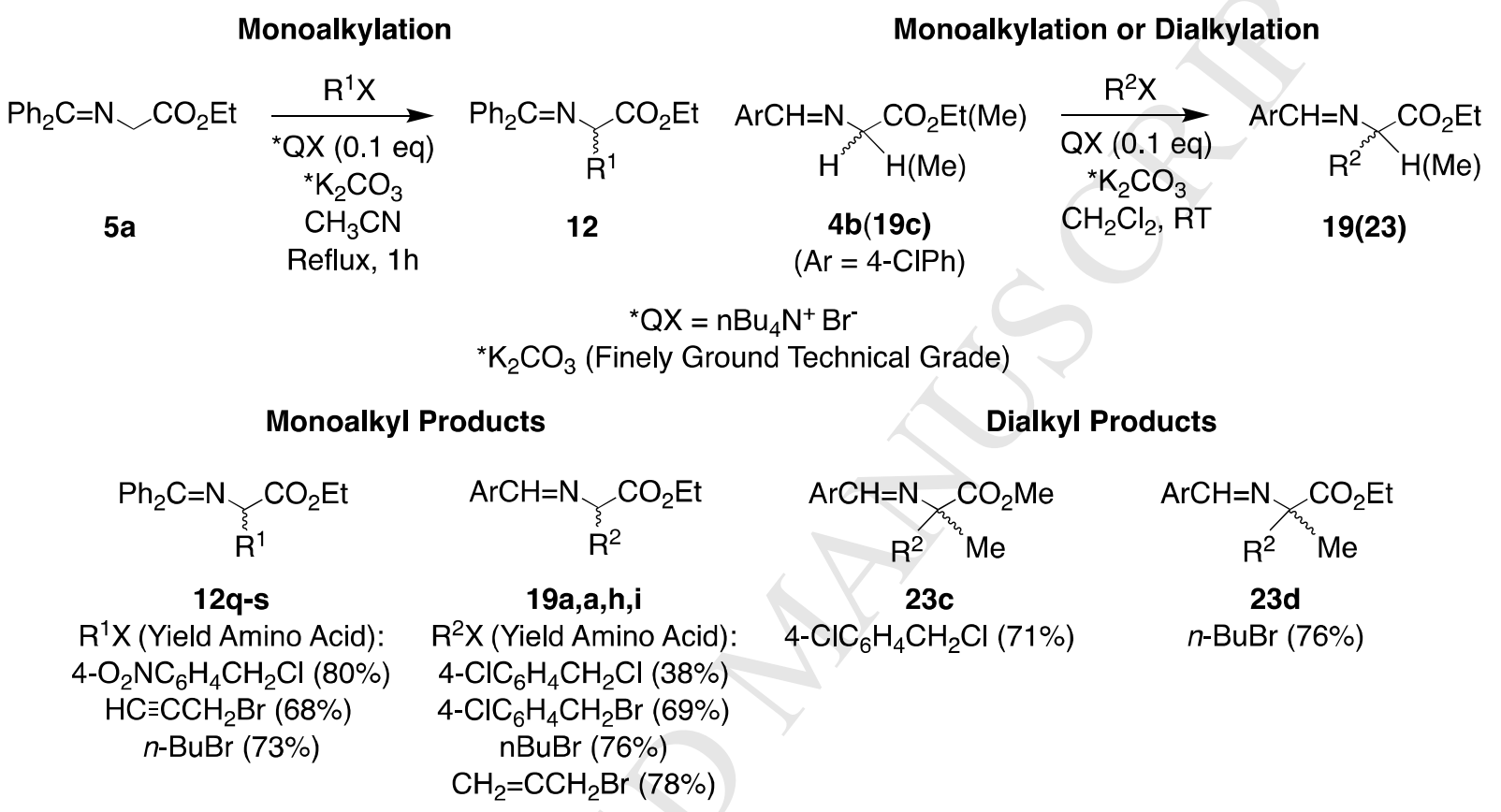

Scheme 8. Mono- and Dialkylation with Potassium Carbonate.

\section{Intra- and intermolecular PTC dialkylations of a glycine equivalent}

Each of the three amino acids shown below: 1-aminocyclopropane-1-carboxylic acid, ACC (24b) ${ }^{33}$ cycloleucine (24c) and 2,6-diaminopimelic acid, DAP (25) is of considerable biological interest (Scheme 9). ${ }^{34}$ Structurally each can be viewed as a dialkylated amino acid. ACC and cycloleucine are formed by an intermolecular followed by a intramolecular ring closure alkylation at the $\alpha$-carbon of glycine with either 1,2-dibromoethane or 1,4dibromobutane. Since the electrophile, 1,3-dibromopropane, would form a strained, disfavored four-membered ring in an analogous reaction, it underwent a dialkylation by reaction with two equivalents of $\mathbf{6}$ to attach an amino acid at each end of the three carbon tether and give DAP. 
ODonnell Benzophenone Schiff Bases MS Ghosez Revd 031419.doc

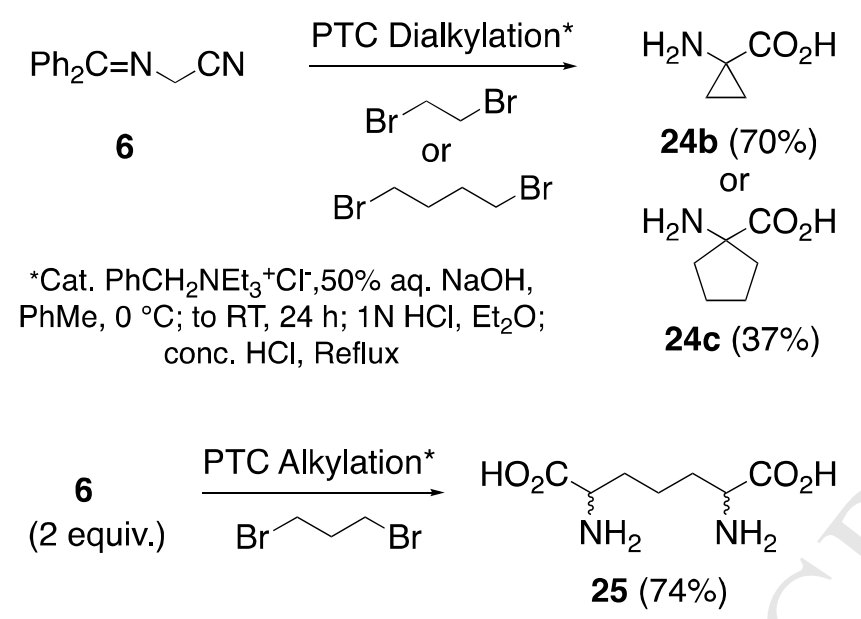

Scheme 9. Intra- and Intermolecular Dialkylations.

The three products were prepared using the two-phase PTC procedure shown with only the stoichiometry of the starting Schiff base 6a varied. The alkylation was followed by the typical two-step hydrolysis to yield the target amino acids.

Schiff base nitrile 6a was also alkylated with 1,2-dibromoethane $\left(\mathrm{Bu}_{4} \mathrm{~N}^{+} \mathrm{Br}^{-}, \mathrm{K}_{2} \mathrm{CO}_{3}\right.$ (finely ground technical grade), $\mathrm{CH}_{3} \mathrm{CN}$, reflux, $12 \mathrm{~h}$ ) under solid-liquid conditions to give the Schiff base nitrile of ACC (75\%). However, a mixture of products was obtained when these solid-liquid reaction conditions were attempted to prepare the corresponding products for cycloleucine (24c) or DAP (25).

\section{Acidities (pKa) of imine derivatives of glycine: Insights into alkylations}

The benzophenone imine of glycine ethyl ester is selectively monoalkylated using various basic two-phase systems (5a to 12, Scheme 10). In contrast and with the exception of select intramolecular dialkylations (Scheme 9), the dialkylation of these substrates does not occur under typical PTC conditions with the benzophenone imines of amino acid esters. The acidities in the two systems (5a vs. 12) are responsible for this dichotomy. The Schiff base ester of glycine (5a) is $10^{4}$ more acidic than its monoalkylated derivative (12). Thus, provided a "mild" basic system is used, $\mathbf{5 a}$ will be selectively deprotonated to $\mathbf{1 2}$ without further deprotonation leading to $\mathbf{1 3}$ (vide infra). ${ }^{35}$

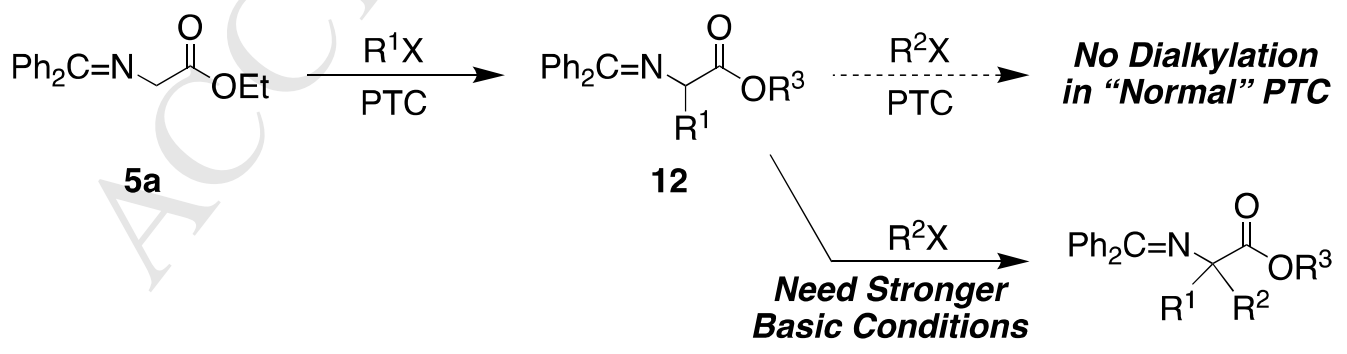

13

Scheme 10. Selective Monoalkylation of the Benzophenone Imines of Glycine Ethyl Ester. 
Dialkylation from the monoalkylated products is possible by using the aldimines of monosubstituted amino acid esters (previous Schemes 6-8). Alternatively, dialkylation could be accomplished by employing stronger bases in conjunction with anhydrous conditions at low temperature.

The acidities (pKa, DMSO) for these Schiff base (ketimine vs. aldimine) amino acid ethyl esters was determined in collaboration with F. G. Bordwell (Figure 2). ${ }^{35 a}$ Somewhat surprisingly, the acidities of members of this table span $4.5 \mathrm{pKa}$ units. Tables of $\mathrm{pKa}$ values of a variety of structural classes from the Evans and Reich groups are informative. ${ }^{36}$

Glycine

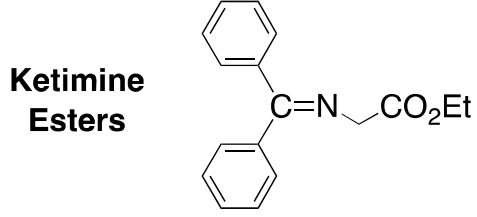

$5 a(p K a ~ 18.7)$ (X-Ray, Fig. 3)

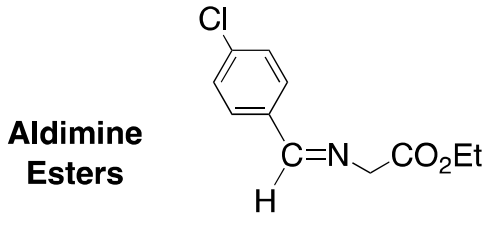

4b (pKa 18.8)

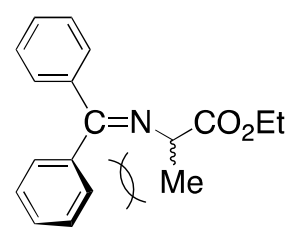

12a (pKa 22.8)

$\mathrm{Cl}$

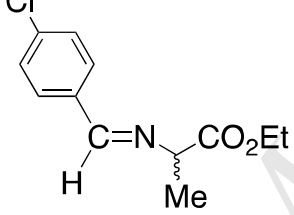

19c (pKa 19.2)

Monoalkyl and Monoaryl Derivaties

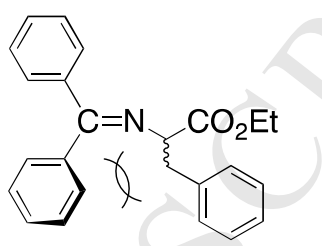

12b (pKa 23.2)

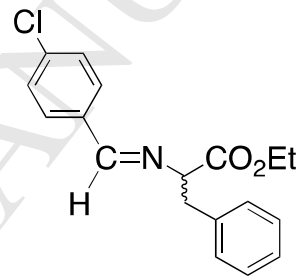

19j (pKa 19.0)

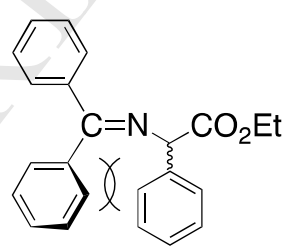

12c (pKa 21.2) (X-Ray, Fig. 3)

Cl

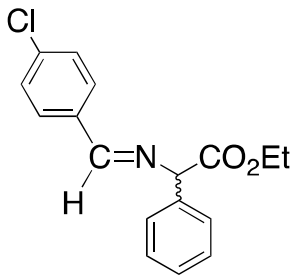

19k (pKa 17.2)

Figure 2. Acidities (pKa, DMSO) of Benzophenone- and 4-Chlorobenzaldehyde Imines of Glycine Ethyl Ester and Monoalkylated Amino Acid Esters.

Comparison of the column and row pairs in this figure is instructive. The acidity of the parent glycine derivatives $(\mathbf{5 a}, \mathrm{pKa}=18.7$ and $\mathbf{4 b}, \mathrm{pKa}=18.8)$ are essentially the same. Comparing the 4-Cl-benzaldehye Schiff base (4b) with the unsubstituted benzaldehyde derivative [4a, $\mathrm{PhCH}=\mathrm{NCH}_{2} \mathrm{CO}_{2} \mathrm{Et}^{16}(\mathrm{pKa}=19.5)$ ] demonstrates that the 4-chloro derivative is approximately eight times more acidic than its unsubstituted parent. ${ }^{35 a}$

The difference in acidity between starting imine and monoalkylated imine in the ketimine series is striking. There a substantial acid weakening effect (4.1 pKa units) in going from 5a $(\mathrm{pKa}=18.7)$ to its monomethylated derivative 12a $(\mathrm{pKa}=22.8)$. While this large acid-weakening effect is observed in the ketimine series, in the aldimine series the difference in acidity between the starting material $(\mathbf{4 b}, \mathrm{pKa}=18.8)$ and its monomethyl derivative $(\mathbf{1 9 c}, \mathrm{pKa}=19.2)$ is quite small. Similar results occur in the ketimine benzylated series 5a $(\mathrm{pKa}=18.7)$ and 12b $(\mathrm{pKa}=23.2)$ vs. the aldimine one $\mathbf{4 b}(\mathrm{pKa}=18.8)$ and $\mathbf{1 9 j}(\mathrm{pKa}=19.0) .{ }^{35 \mathrm{a}}$

The reason for the substantial acid weakening effect in going from the ketimine ester of glycine ethyl ester (5a) to its monoalkylated (12a or 12b) or monoarylated (12c) products is primarily steric in nature. The imine phenyl group cis to the alkyl substituent in these three products (12a-c) is forced out of planarity with the trans phenyl - by the methyl, benzyl or phenyl groups, respectively, by allylic $(1,3)$-strain. ${ }^{37}$ This decreases resonance delocalization in their 2- 
azaallyl anions ${ }^{6}$ and, consequently, increases their pKa's (decreases their acidities). In the aldimine series $(\mathbf{1 9 c}, \mathbf{1 9} \mathbf{j}$ and $\mathbf{1 9 k})$, such strain is not present because of the small imine hydrogen. ${ }^{35 a}$

The phenylglycine Schiff bases $12 \mathrm{c}$ and $\mathbf{1 9 k}$ are of further interest. Normally introduction of an $\alpha$-phenyl group is, in the absence of steric crowding, acid strengthening [ $\mathrm{PhCH}_{2} \mathrm{CN}$, pKa 21.9 vs. $\mathrm{Ph}_{2} \mathrm{CHCN}$, pKa $\left.17.5 ; \Delta \mathrm{pKa}=4.4\right]$. The 4 pKa units difference between the ketimine 12c (pKa 21.2) and its more acidic aldimine 19k (pKa=17.2) substantiates the allylic (1,3)-strain crowding of the cis-phenyls in $\mathbf{1 2 c}$, which is absent in $\mathbf{1 9 k}$ for a phenylation reaction (see later Scheme 12). ${ }^{35 a}$

In summary, it is possible to (a) monoalkylate/monophenylate the benzophenone imine of glycine esters $\mathbf{5 a}$ to obtain products $\mathbf{1 2 a - c}$, without concomitant dialkylation and (b) there is a second crucial feature accompanying the selective monoalkylation of ketimine 5a. Since dialkylation does not occur in this series, provided mild base is used, the racemization of a monoalkylated product prepared by an enantioselective alkylation should not undergo occur racemization but, rather should maintain its stereochemical integrity under the reaction conditions (vide infra).
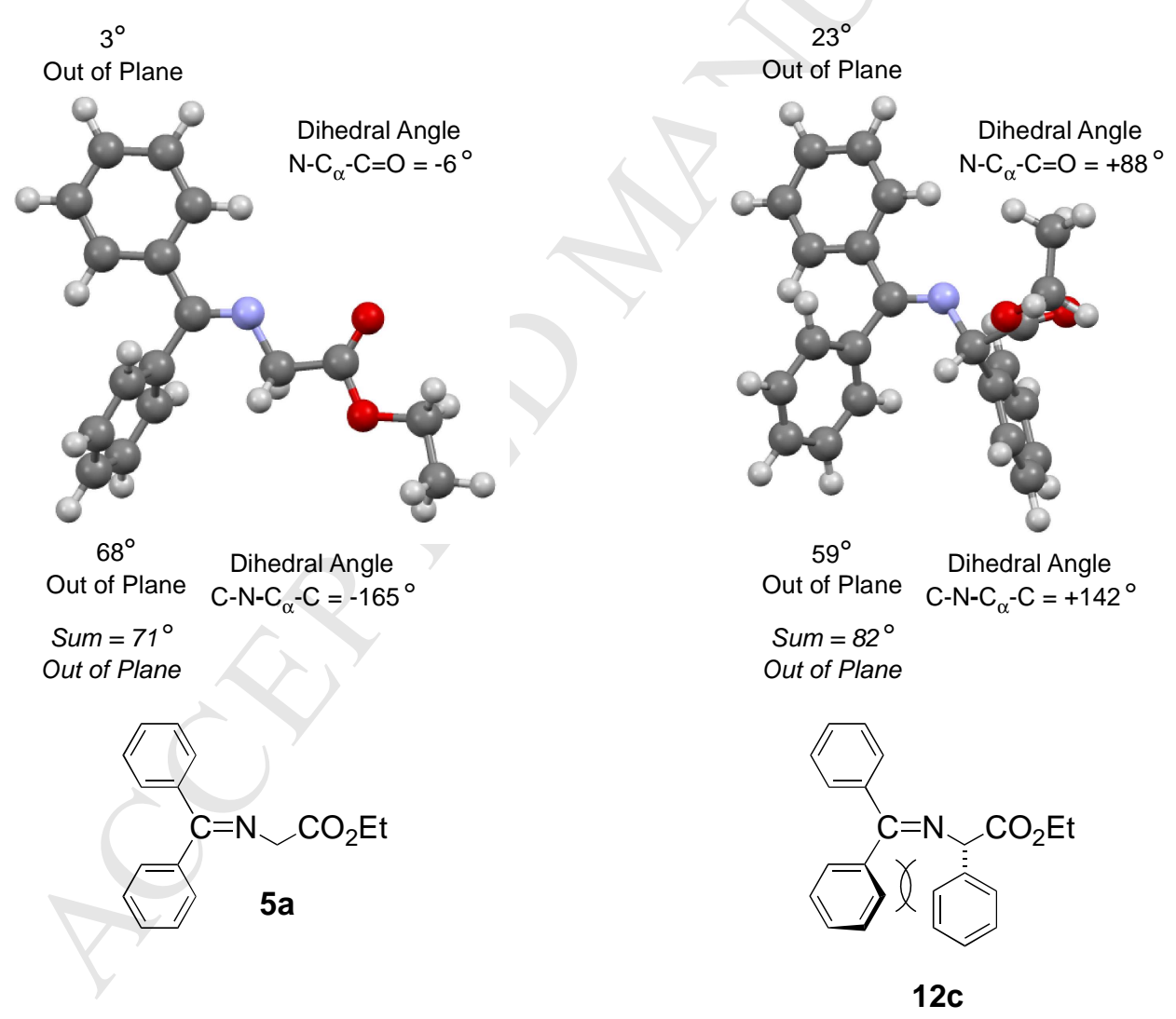

Figure 3. X-Ray Structures of the Benzophenone Imines of Glycine Ethyl Ester and Phenylglycine Ethyl Ester.

The X-ray structures of the glycine Schiff base 5a and the Schiff base of phenylglycine (12c) are also informative (Figure 3). The degree to which the phenyls in the ketimine are in or 
out of planarity gives a measure of the amount or lack of resonance stabilization in the anions of these two molecules based on the $\mathrm{Ph}_{2} \mathrm{C}=\mathrm{N}$ group. The sum of out of planarity in the glycine derivative $5 \mathbf{a}$ is $71^{\circ}$ while that in the phenylglycine derivative $12 \mathbf{c}$ is $82^{\circ}\left(11^{\circ}\right.$ more). Additionally, the dihedral angles demonstrate that in glycine 5a the carbonyl system is considerably closer to planarity with the imine than in the phenylglycine 12c. Both of these effects will be important in determining the decrease of acidity in $\mathbf{1 2 c}$ vs. 5a. ${ }^{35 a}$

Based on acidity differences and structures between reaction partners, it is expected that monoalkylation/monophenylation of the benzophenone imine of glycine (5a) would be facile while dialkylation of its monoalkylation/monoarylation products 12a-12c would require stronger basic or reaction conditions (vide infra). In contrast, both monoalkylation and dialkylation should occur under similar basic conditions with the aldimine of glycine ethyl ester (4b). ${ }^{35 a}$

\section{Amino acid amide PTC alkylations}

Alkylation of the benzophenone Schiff base of alanine amide (26a) presents the potential problem of multiple sites of deprotonation/alkylation (Scheme 11). ${ }^{38,39}$ The monomethylation of 26a was carried out using the ion-pair extraction method to yield $\mathbf{2 7} \mathbf{a}(84 \%)$ and was uneventful.

The second alkylation, with allyl bromide, gave all six possible products: starting material 27a, desired product 28a, N-alkylation 29a, C,N-dialkylation 30a, N,N-dialkylation 31a, and C,N,N-trialkylation 32a. Ten model reactions with variable bases, additive, solvents, temperature and time were carried out to find the optimal conditions for the second alkylation: 27a $(2 \mathrm{mmol})$, the stronger base $\mathrm{KOtBu}(2.4 \mathrm{mmol})$, allyl bromide $(2.4 \mathrm{mmol}){ }^{38}$ 
ODonnell Benzophenone Schiff Bases MS Ghosez Revd 031419.doc

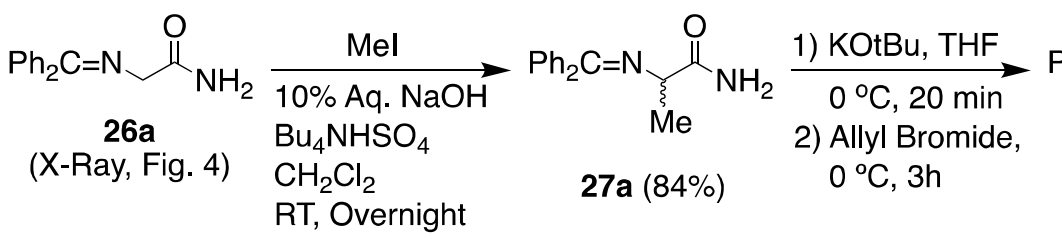

Variables for Model Reaction

Bases: $10 \% \mathrm{NaOH}^{\star}, 50 \% \mathrm{NaOH}^{\star}, \mathrm{NaOEt}^{\star}$, BTPP ${ }^{\star \star}$, LDA, LiHMDS, KHMDS, KOtBu.

Additive with Base*: $\mathrm{nBu}_{4} \mathrm{NHSO}_{4}$.

Solvents: $\mathrm{CH}_{2} \mathrm{Cl}_{2}$, THF.

Temperature: $\mathrm{RT}, 0 \mathrm{C},-78 \mathrm{C}$.

Time: $3 \mathrm{~h}$ or $18 \mathrm{~h}$.

${ }^{*}$ Schwesinger Base (vide infra).

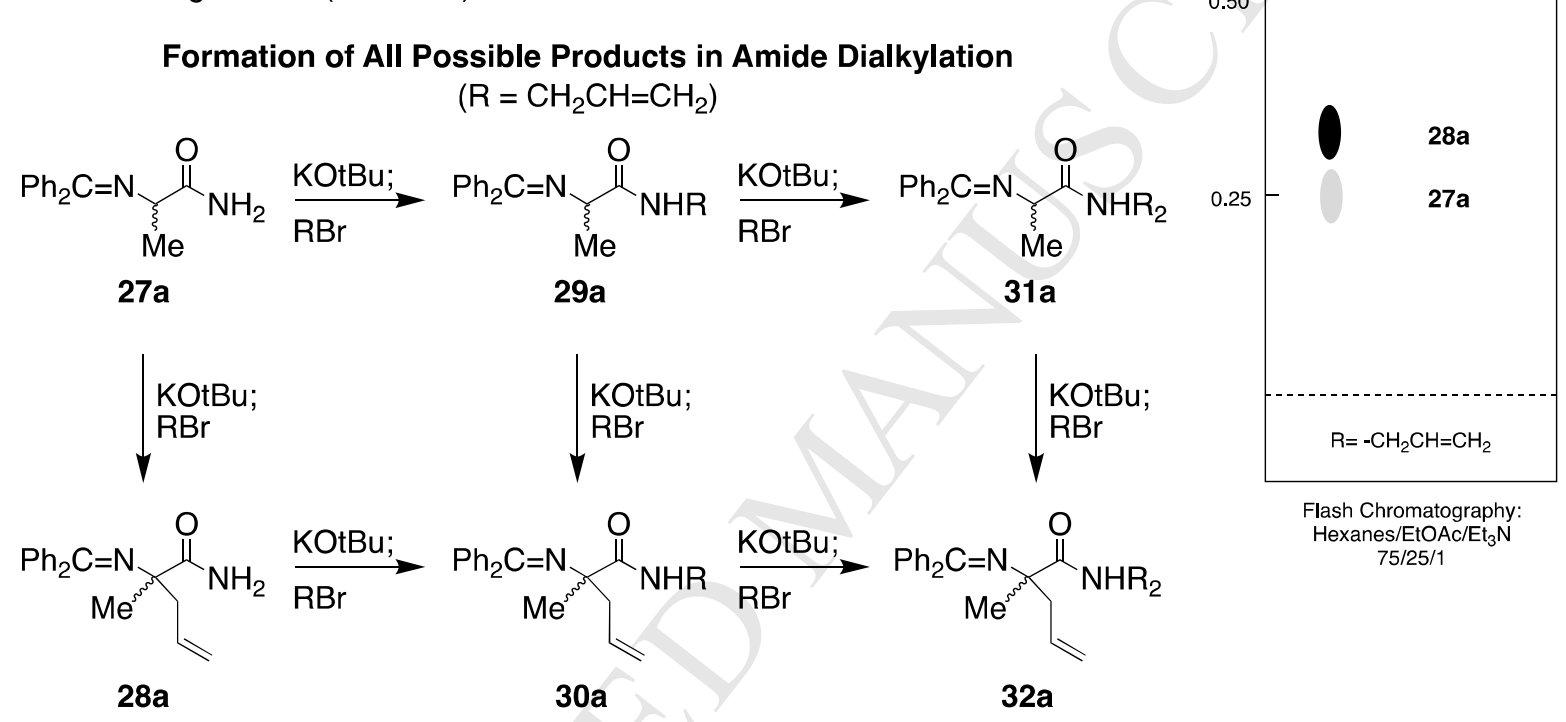

Scheme 11. Selective Mono- and Dialkylations of the Benzophenone Imine of Glycine Amide.

The two possible orders of addition to make the dialkylated product 28a from a benzylic halide (4-Cl-benzyl bromide) and an allyl halide (allyl bromide) were studied. The yield of the product derived from adding allyl bromide last was higher $(25 \%)$ compared with adding 4chlorobenzyl bromide last (10\%), likely due to steric hindrance in the latter case. Michael addition to $27 \mathbf{a}$ with $\mathrm{t}$-butyl acrylate gave the disubstituted derivative in $32 \%{ }^{38}$

Crystal structures were obtained for the starting material 26a, the mono-C-allyl product 27b and $\alpha$-allyl- $\alpha$-methyl dialkylation product 28b (Figure 4). ${ }^{38}$ Several interesting points confirm earlier discussions about the effect of steric hindrance on the reactivity of mono- and dialkylated derivatives (27b and $\mathbf{2 8 b}$ ). The cis-phenyl group on the imine is considerably farther out of planarity with the imine double bond than is the trans-phenyl, which is due to allylic $(1,3)$ strain. $^{37}$ 
ODonnell Benzophenone Schiff Bases MS Ghosez Revd 031419.doc

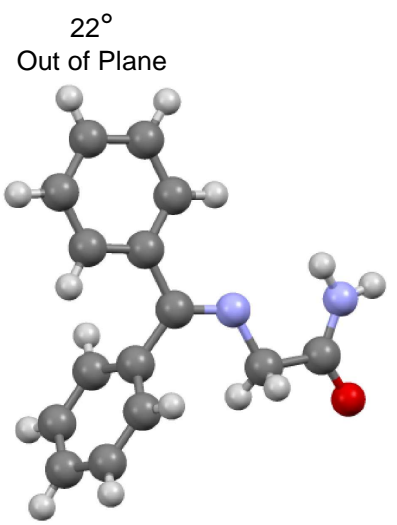

$66^{\circ}$

Out of Plane

Sum $=88^{\circ}$

Out of Plane<smiles>NC(=O)CN=C=Cc1ccccc1</smiles>

26a

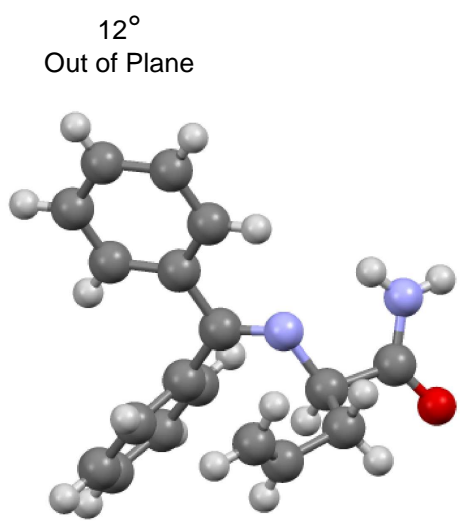

$80^{\circ}$

Out of Plane

Sum $=92^{\circ}$

Out of Plane

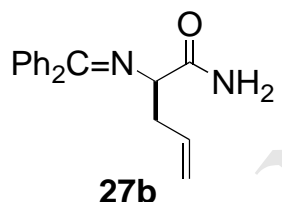

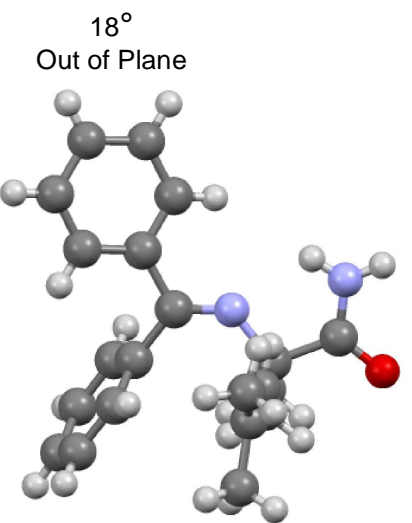

$81^{\circ}$

Out of Plane

Sum $=99^{\circ}$

Out of Plane

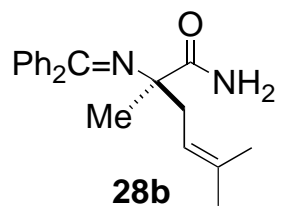

Figure 4. X-Ray Structures of the Benzophenone Imines of Glycine Amide and its Mono- and Dialkylated Derivatives.

\section{Phenylation and diphenylation for the preparation of aryl amino acids}

Phenylation of $\mathbf{5 b}$ with $\mathrm{Ph}_{3} \mathrm{BiCO}_{3}$ (2 eq.) followed by hydrolysis of the imine gave a $60 \%$ yield of phenylglycine hydrochloride (12c) (Scheme 12). ${ }^{40}$ Selective monophenylation was predicted based on the acidity of $\mathbf{1 2 c}(\mathrm{pKa}=21.2$, Figure 2$) .{ }^{35 a, 40}$ A second phenylation was achieved by phenylation of the aldimine esters 19 under the same conditions followed by complete hydrolysis to yield $\alpha, \alpha$-diphenylglycine (24d) or $\alpha$-alkyl- $\alpha$-phenylglycines (24e24I). ${ }^{41,42}$ 
ODonnell Benzophenone Schiff Bases MS Ghosez Revd 031419.doc

Selective Monophenylation - No Diphenylation!

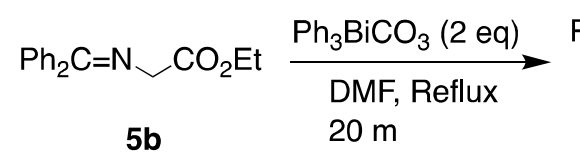

$5 b$

*Yields after hydrolysis to amino ester hydrochloride (2N HCl, Et ${ }_{2} \mathrm{O}, \mathrm{RT}, 20 \mathrm{~m}$ )
${ }^{\star \star} \alpha$-Phenylation: $\propto$-Phenyl , $\propto-\mathbf{R}^{1}$-Products<smiles>CCOC(N=Cc1ccccc1)c1ccccc1</smiles>

$12 \mathrm{c}(60 \%)^{*}$<smiles>[R]OC(=NC)C([R])N=C</smiles>

19 $(\mathrm{Ar}=4-\mathrm{CIPh})$

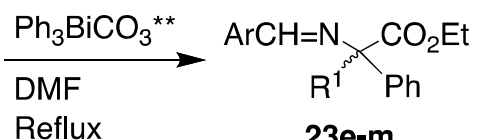

Reflux

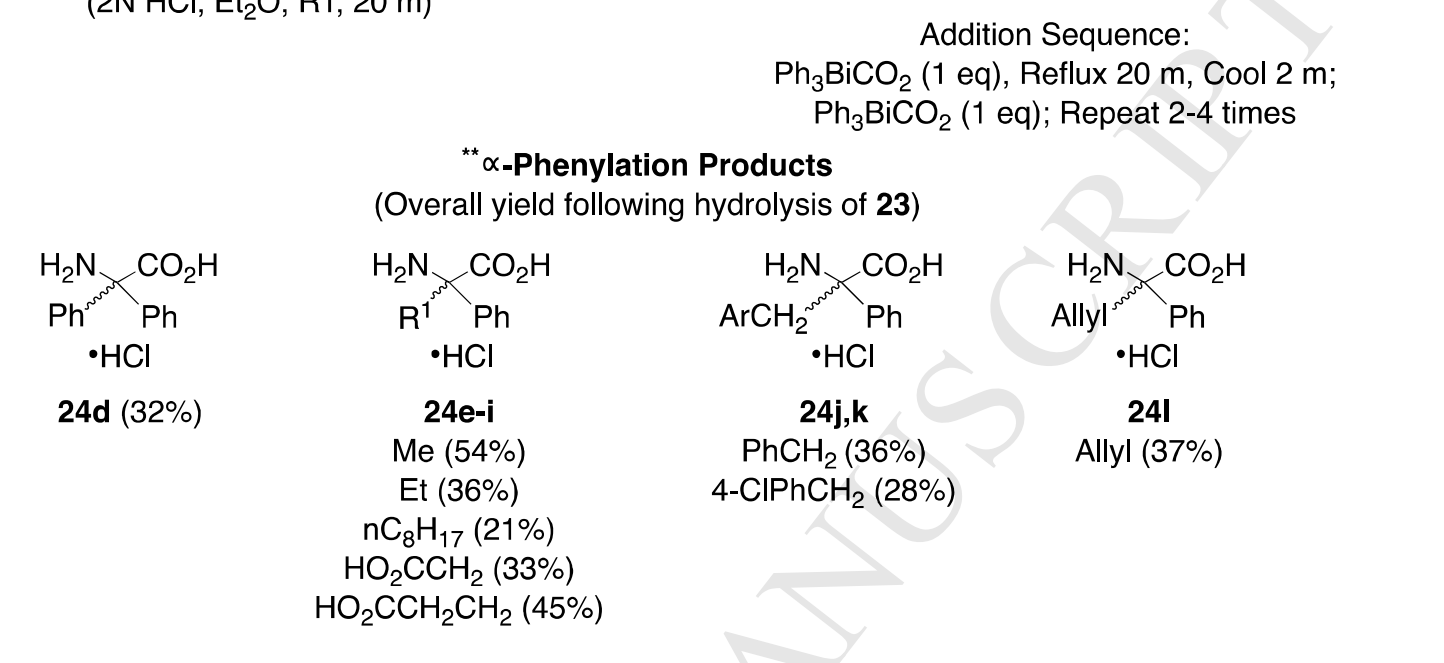

Scheme 12. Selective Phenylation and Diphenylations of the Benzophenone Imine and Aldimines of Glycine and other amino acid Esters.

\section{Selective alkylation of dipeptides by PTC}

Peptides with modified amino acid residues are important targets for drug development and therapeutic applications. Three chemical synthesis approaches for preparation of modified peptides are: incorporation of modified amino acids into peptides, modification of the side chains of intact peptide structures or modification of the backbone of a peptide.

An interest in introducing new side chains into dipeptides prompted study of the selective modification of the N-terminal residue of dipeptides by phase-transfer alkylation (Scheme 13). ${ }^{43,44}$ Since the initial step in the alkylation reaction is deprotonation, our earlier acidity studies with Bordwell ${ }^{35 a}$ (Figure 2) were instrumental in understanding the ability to functionalize dipeptides. Additionally, it was estimated that, based on the acidities of $\mathrm{N}$ methylacetamide (pKa 25.9) and N-phenylacetamide (pKa 21.5), ${ }^{35 a}$ removal of the $\mathrm{NH}$ proton in the model protected dipeptide 33a would not be problematic. 


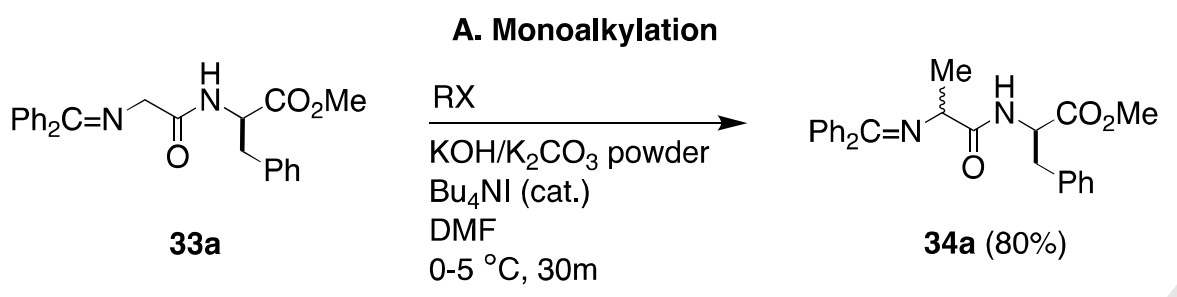<smiles>COC(=O)C(Cc1ccccc1)NC(=O)C(Cc1ccccc1)N=Cc1ccccc1</smiles>

34b (61\%)<smiles>CC(=O)C(CC(C)C)NC(=O)C(Cc1ccccc1)N=C=[Ge]</smiles><smiles>C=CC[C@H](N=Cc1ccccc1)C(=O)NC(COCCOCCOCCOC)C(OC)OCc1ccccc1</smiles>

34c (90\%)

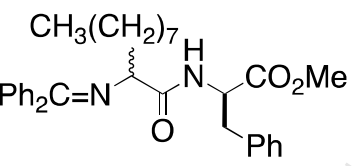

34d $(85 \%)$

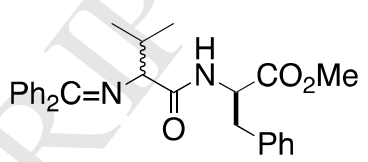

34e $(69 \%)$

B. Dialkylation

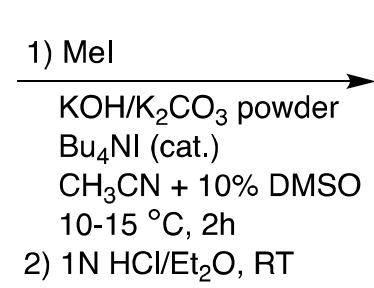

Retention at C-Terminal $\alpha-\mathbf{C}$ and No Diastereoselectivity

Scheme 13. Selective N-Terminal Monoalkylation and Dialkylation of Dipeptides Activated as Their Imine Esters.

An extensive study of the variables in the monoalkylation of 33a led to optimal conditions that involved a solid/liquid PTC with powdered $\mathrm{KOH} / \mathrm{K}_{2} \mathrm{CO}_{3}$ as base, tetrabutylammonium iodide (0.24 eq.) in DMF at $0-5{ }^{\circ} \mathrm{C}$ for 30 minutes to give the Schiff base of rac-Ala-D $(R)$-Phe methyl ester (34a) in $80 \%$ yield (Scheme 13). Four other alkylation products (34b-34e) were obtained in good to excellent yields. There was no detectable diastereoselectivity in these alkylations. $^{43}$

Based on earlier dialkylation studies (Schemes 6-8), the 4-chlorobenzaldehye imine of $\mathrm{L}(S)$-Phe-L $(S)$-LeuOMe (34f) was used for N-terminal dialkylation studies. Hydrolysis of the aldimine product gave the $\mathrm{N}$-terminal dialkylated product 35a. Again, diastereoselectivity at the $\mathrm{N}$-terminal $\alpha$-carbon did not occur. The stereochemical fate of the $\mathrm{C}$-terminal $\alpha$-carbon was determined by hydrolysis of $\mathbf{3 5 a}$ to its corresponding amino acids, which were converted to their GITC (2,3,4,6-tetra-O-acetyl- $\beta$-D-glucopyanosyl isothiocyanate) derivatives. The mixture was analyzed by C-18 HPLC under conditions that gave complete separation of GITC-L $(S)$-Leu and GITC-D $(R)$-Leu. There was no GITC-D $(R)$-Leu detected in the mixture (detection limit $0.2 \%$ ). Thus, there is retention of configuration at the C-terminal $\alpha$-carbon. ${ }^{43}$

In collaboration with colleague Bill Scott, the solution-phase synthesis of unnatural amino acids (Schemes 1, 2, 3, 5-9, 11, 12) and dipeptides (Scheme 13) was adapted (see Scheme 22 for bases used in solid-phase chemistry) and extended to permit the solid-phase synthesis of a large number of amino acids derivatives, peptidomimetics and unnatural peptides. ${ }^{45-49}$ Access to these structures is essential to the success of the Distributed Drug Discovery (D3) program, which seeks to educate global students while they do research synthesizing molecules for the 
discovery of drugs to treat neglected diseases. While the D3 research program is not a focus of this review, some of the fundamental methodology reported here, when adapted to solid-phase, was essential to providing simple, inexpensive, reproducible and powerful synthetic routes to the biomimetic molecules required by the $\mathrm{D} 3$ program.

\section{First enantioselective PTC alkylation and Cinchona alkaloid organocatalysts}

In 1984 the Dolling group at Merck reported the groundbreaking example of a catalytic, enantioselective synthesis by phase-transfer catalysis. ${ }^{50,51}$ A key to the success of this work was use of a chiral, non-racemic quaternary ammonium salt $\mathbf{4 0}$ derived by benzylation of the Cinchona alkaloid cinchonine (Scheme 14, Figure 5). ${ }^{52}$ An important benefit of these natural product, alkaloid-derived catalyst precursors is that they are readily available and relatively inexpensive (Figure 5).<smiles>COc1cc2c(c(Cl)c1Cl)C(=O)C(c1ccccc1)C2</smiles>

36

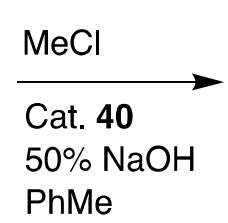

$\mathrm{RT}, 18 \mathrm{~h}$

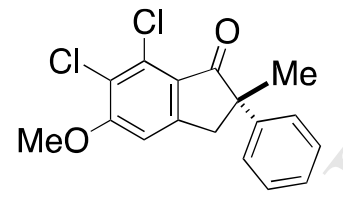

37

(95\%, 92\% ee)

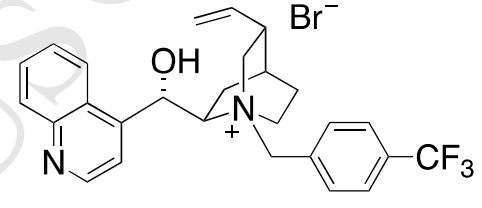

40

Cinchonine-Derived

Scheme 14. First Catalytic, Enantioselective PTC Alkylation.

The monosubstituted phenyl indanone $\mathbf{3 6}$ was methylated using liquid-liquid PTC conditions to yield indanone $\mathbf{3 7}$ containing a new quaternary carbon in $95 \%$ yield and $92 \%$ ee (Scheme 14) ${ }^{50 a}$. The mechanism of induction was proposed to involve ion-pairing between the anion of $\mathbf{3 6}$ and the quaternary ammonium salt. Further studies from the group reported an enantioselective Robinson annelation ${ }^{50 b}$ and a detailed kinetic and mechanistic analysis of the enantioselective indanone reaction by Hughes. ${ }^{50 \mathrm{c}}$ 


\section{Cinchona Alkaloids}<smiles>C=CC1C2CCN1C([B]C(O)c1ccnc3ccccc13)C2</smiles>

38

Cinchonine (CnOH)

Merck Catalyst

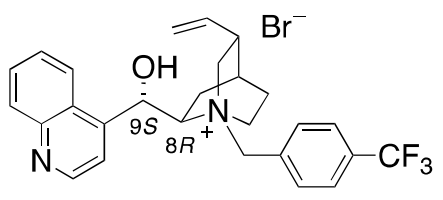

40

Cinchonine-Derived

Dolling, 1984

\section{2nd Generation $Q^{*} X$}

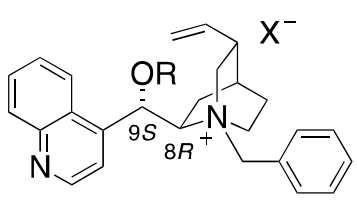

43

(R=Allyl 43a)

(R=Benzyl 43b)

Cinchonine-Derived

O'Donnell, 1994

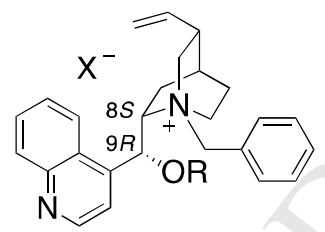

44

(R=Allyl 44a)

(R=Benzyl 44b)

Cinchonidine-Derived

O’Donnell, 1994<smiles>C=CC1CC2CCN1C2[C@H](O)c1ccnc2ccccc12</smiles>

39

Cinchonidine (CdOH)

Figure 5. Cinchona Alkaloids and Derived Quaternary Ammonium Phase-Transfer Catalysts.

\section{Enantioselective PTC monoalkylation of benzophenone imines of glycine esters}

We reported the catalytic enantioselective PTC alkylation of the benzophenone imine of glycine t-butyl ester in 1989 (Scheme 15). ${ }^{18,53}$ Complicating factors with this acyclic system are the need to selectively monoalkylate 5c without dialkylation and, following alkylation, to avoid racemization of the monoalkylated product $(\boldsymbol{R})-\mathbf{1 2 m}$. Our earlier studies concerning the pKa's and structures of various Schiff base derivatives (Figure 2) led us to believe that both of these goal could be realized. 
ODonnell Benzophenone Schiff Bases MS Ghosez Revd 031419.doc

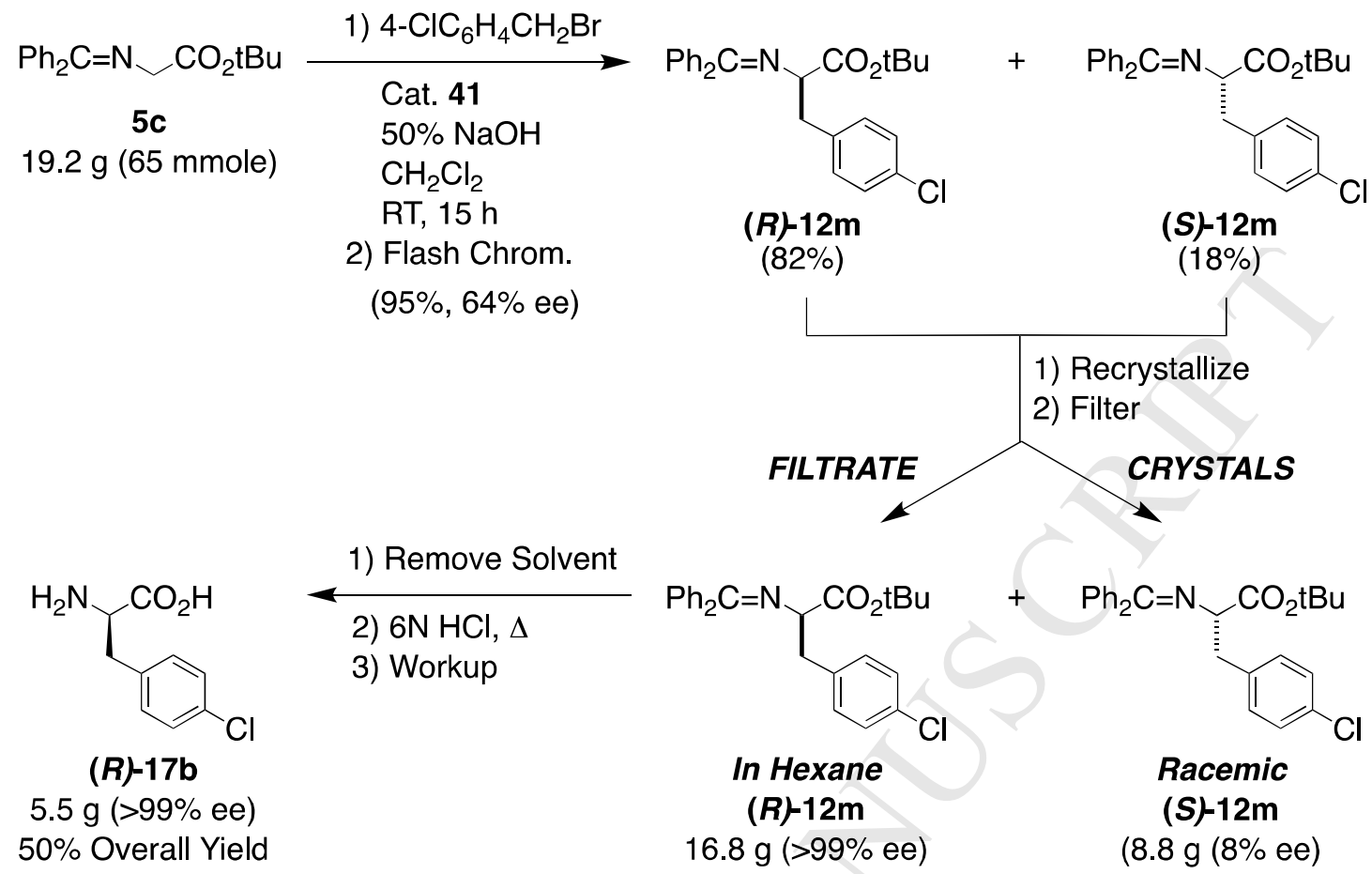

Scheme 15. First Catalytic Enantioselective PTC Monoalkylation of a Glycine Derivative.

An initial, small-scale experiment in toluene resulted in alkylation with a good chemical yield but only a 5\% ee! Changing the solvent to methylene chloride increased the $\%$ ee to $28 \%$. Systematic modification of a number of additional variables (nature of the ester group in $\mathbf{5}$, types of alkyl halides, amounts and concentrations of reagents and aqueous base, catalyst counterion, nature of the leaving group, reaction time and catalyst $\mathbf{4 1}$ or $\mathbf{4 2}$ ) led to products from different types of alkyl halides (\% ee catalyst 41, 42): 4-chlorobenzyl bromide (66\% ee, $62 \%$ ee), allyl bromide (66\% ee, $62 \%$ ee), methyl bromide ( $42 \%$ ee, --), n-butyl bromide (54\% ee, --). The cinchonine-derived catalyst $\mathbf{4 1}$ typically led to products with the unnatural $[(R)$ or D] absolute configuration while those from the cinchonidine-derived catalyst $\mathbf{4 2}$ gave the natural $[(S)$ or $\mathrm{L}]$ products in slightly lower \% ee (Scheme 15).

A large scale alkylation $(19.2 \mathrm{~g}, 65 \mathrm{mmol})$ of $\mathbf{5 c}$ with 4-chlorobenzyl bromide was carried out with results similar to the small-scale model reaction. The enantiomeric products $(\boldsymbol{R})-\mathbf{1 2 m}$ $(82 \%)$ and $(S)-12 m(18 \%)$ were separated by a single recrystallization and the major enantiomer remained in the filtrate to yield, on solvent evaporation, $16.8 \mathrm{~g}$ of 4-chloro-D-phenylalanine $(\boldsymbol{R})$ $\mathbf{1 2} \mathbf{m}$ in $>99 \%$ ee! Hydrolysis of $(\boldsymbol{R})-\mathbf{1 2} \mathbf{m}$ gave the amino acid $(\boldsymbol{R})-\mathbf{1 7 b}$ in $50 \%$ overall yield $(5.5$ $\mathrm{g},>99 \%)$ (Scheme 15). 
ODonnell Benzophenone Schiff Bases MS Ghosez Revd 031419.doc

\section{Mechanistic and molecular recognition studies of enantioselective PTC}

A study of the molecular recognition between the ion pairs of the Schiff base substrate $\mathbf{5 c}$ and the Cinchona alkaloid-derived catalyst $\mathbf{4 2}$ was conducted in collaboration with my colleague K. B. Lipkowitz. ${ }^{54}$ A model of the complex between $\mathbf{4 2}$ and the Z-enolate of $\mathbf{5 c}$ together with the potential energy surface was proposed. It was found that the likely binding region for the enolate is on the front side of the $N$-benzyl cinchoninium ion. The flat potential energy surface suggests that solvent and temperature should be important in these asymmetric alkylation. Since this early analysis, a number of other theoretical and mechanistic studies have been conducted to predict the origin of the enantioselectivity in these phase-transfer alkylations. ${ }^{51 \mathrm{c}, 55}$

\section{Enantioselective PTC dialkylation of an $\alpha$-substituted aldimine ester}

Based on the earlier successful racemic dialkylations of the aldimine esters of $\alpha$-amino acids (Schemes 6-8) and the enantioselective monoalkylations of the benzophenone imines of glycine esters (Scheme 15), attention was turned to the enantioselective PTC dialkylation of the protected/activated aldimine t-butyl ester of alanine $(\boldsymbol{S})$-19f (Scheme 16). ${ }^{56}$ A number of variables were explored. The cinchonine-derived catalyst $\mathbf{4 1}$ gave the model product $(\boldsymbol{R})-\mathbf{2 3 c}$ in $48 \%$ ee while the pseudoenantiomeric cinchonidine catalyst $\mathbf{4 2}$ yielded $(\boldsymbol{S})$-23c in only $24 \%$ ee. This is in contrast with the enantioselective monoalkylation, which gave only slightly better results for cinchonine catalyst 41 (66\% ee vs. 62\% ee, respectively (Scheme 15).

Other variables explored: (a) base: $50 \% \mathrm{NaOH}$, powdered $\mathrm{NaOH}$, powdered $\mathrm{KOH}$, powdered $\mathrm{KOH} / \mathrm{K}_{2} \mathrm{CO}_{3}$, powdered $\mathrm{KOH} / \mathrm{K}_{2} \mathrm{CO}_{3}$ melted and (b) aryl in starting material $(\boldsymbol{S})-\mathbf{1 9 f}$ : 4-ClPh-, 4-MeOPh-, Ph-, 1-naphthyl-, 2-naphthyl, 2,4,6-Cl ${ }_{3} \mathrm{Ph}$ -

Active alkyl halides (benzylic and allylic) gave good results in the alkylation (Scheme 16). However, a less reactive alkyl halide (iBuBr) gave only partial conversion from starting material to product (related references ${ }^{57,58}$ ).
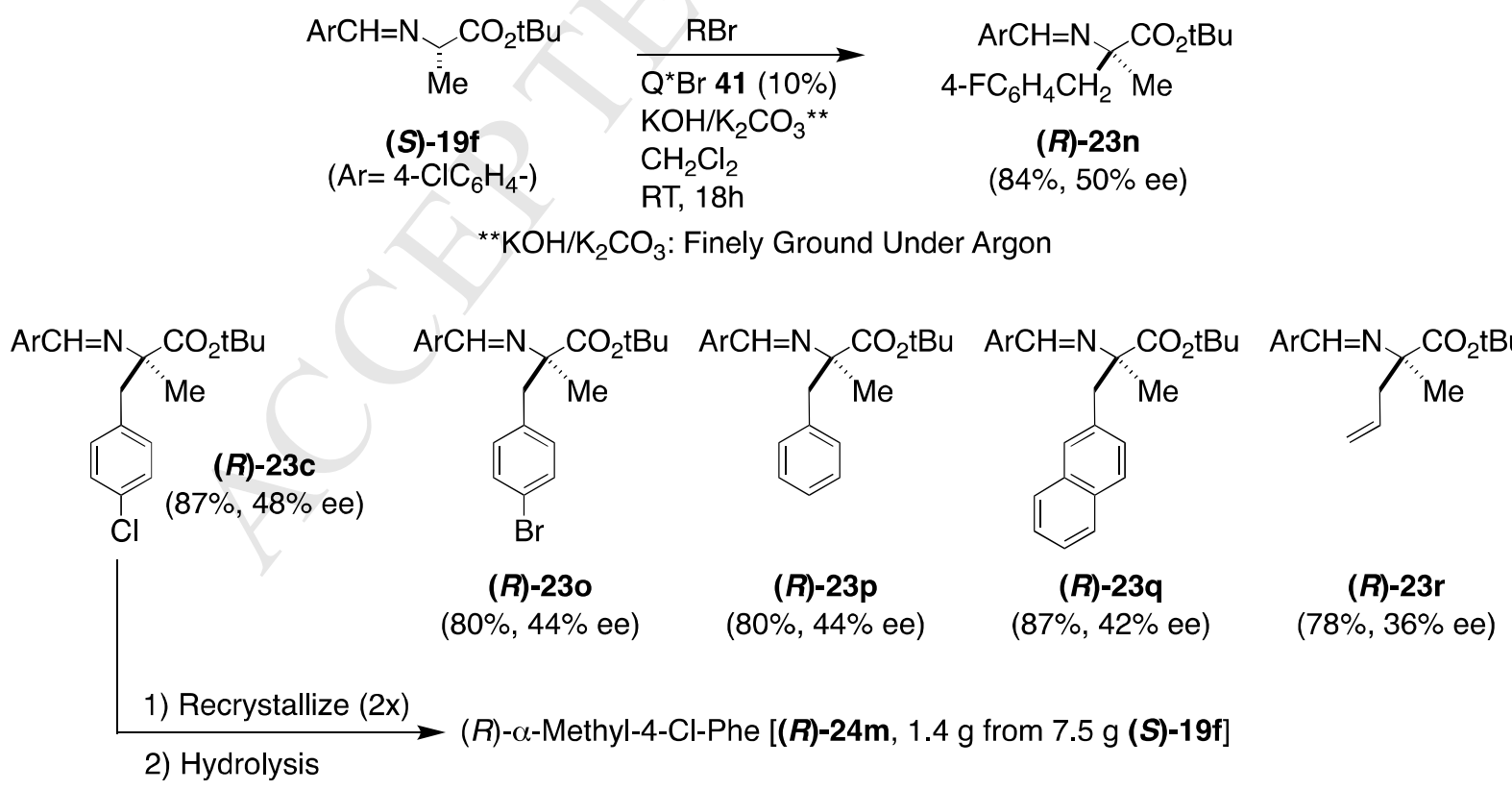

Scheme 16. Enantioselective PTC Dialkylation of the Aldimine of Alanine t-Butyl Ester. 
Interestingly, recrystallization to improve the $\%$ ee of a crude dialkylated product was also successful in the single case attempted: $(\boldsymbol{R})-\mathbf{6 8}$ was prepared on moderate scale from 19c $(7.5 \mathrm{~g})$, the crude product was recrystallized twice and then hydrolyzed to yield $\alpha$-methyl-4chlorophenylalanine ((R)1.4 g, 23\% overall yield, $>97 \%$ ee).

\section{A new active catalyst species for enantioselective alkylation by PTC}<smiles>CCCOC(=O)C(Cc1ccccc1)N=Cc1ccccc1</smiles>

$(S)-12 b$

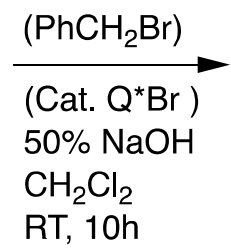<smiles>CCOC(=O)C(Cc1ccccc1)N=Cc1ccccc1</smiles>

(S)-12b<smiles>CCOC(=O)C(Cc1ccccc1)N=Cc1ccccc1</smiles>

$(R)-12 b$

Scheme 17. Racemization Studies to Determine the Nature of the Active Catalyst.

In an attempt to understand the mechanism of the enantioselective phase-transfer catalyzed reaction (Scheme 15) and the nature of the active catalyst, racemization studies of the optically pure product $(\boldsymbol{S}) \mathbf{- 1 2 b}$ that would be formed by enantiospecific benzylation of $\mathbf{5 b}$ were carried out in the presence/absence of a number of variables with the following results (Schemes 17 and 18$):^{59}$

(a) No $Q X$, no $R X \rightarrow 100 \%(S)$, 0\% racemization of $(\mathbf{S})-12 b$. Interpretation: the stereochemistry of reaction product $(\mathbf{S})-12 \boldsymbol{b}$ was not affected in the absence of $Q X$ and $R X$.

(b) Neutral quaternary ammonium salt $\left(n B u_{4} N^{+} \mathrm{Br}^{-}\right)$and no $R X(R=B n) \rightarrow 100 \%(S), 0 \%$ racemization of $(S)-12 b$. Interpretation: the quaternary ammonium salt did not have an $\mathrm{OH}$ group and, therefore, could not be converted into an anionic species by deprotonation.

(c) $\mathrm{CdOR}$ Quat $(\mathbf{4 4 b})$, no $R X \rightarrow 100 \%(S), 0 \%$ racemization of $(\boldsymbol{S})-\mathbf{1 2 b}$. Interpretation: the use of premade $O$-alkylated quaternary ammonium salt $\mathbf{6 2 b}$ under the reaction conditions did not affect the stereochemistry of product $(\boldsymbol{S})-\mathbf{1 2 b}$.

(d) $\mathrm{CdOH}$ Quat (42), $+\mathrm{RX} \rightarrow 100 \%(\mathrm{~S}), 0 \%$ racemization of $(\mathbf{S})-\mathbf{1 2 b}$. Interpretation: since the optically pure product $(\boldsymbol{S})-12 b$ was not racemized under these conditions, this implies that the initial quaternary salt was converted into another non-basic compound, first by deprotonation to the alkoxide 47 and then by a fast $O$-alkylation to the non-basic 44.

In summary, none of the four of the above reaction conditions $[(a)-(d)]$ led to racemization of product $(\mathbf{S})-\mathbf{1 2 b}$. In contrast, the following two experiments each led to partial racemization of optically pure product $(\mathbf{S})-\mathbf{1 2 b}$ :

(e) $\mathrm{CnOH}$ Quat $(\mathbf{4 1})$, no $\mathrm{RX} \rightarrow 64 \%(S), 72 \%$ racemization of $(\boldsymbol{S})-\mathbf{1 2 b}$.

(f) $\overline{C d O H ~ Q u a t ~(42), ~ n o ~} R X \rightarrow 65 \%(S), 70 \%$ racemization of $(\boldsymbol{S})-\mathbf{1 2 b}$. Interpretation of experiments $(e)$ and $(f):$ in the absence of alkyl halide, the cinchoninium salt $\mathbf{4 1}$ or the pseudoenantiomeric cinchonidinium salt 42 was converted into its corresponding alkoxide $\mathbf{4 7}$ that partially racemized the product, $(\mathbf{S})-\mathbf{1 2 b}$.

Taken together, these six experiments imply that the initially-formed base is the alkoxide $\left(\mathrm{Q}^{+} \mathrm{O}^{-}\right.$ 47) that is then O-alkylated to form the active catalyst 44 (Scheme 18). ${ }^{59}$ 
ODonnell Benzophenone Schiff Bases MS Ghosez Revd 031419.doc<smiles>C=CC1CC2CCN1C(Cc1ccccc1)[C@H]2[C@H](O)c1ccnc2ccccc12</smiles>

42

Cinchonindine-Derived

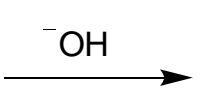

1

47

Organic-Soluble Base

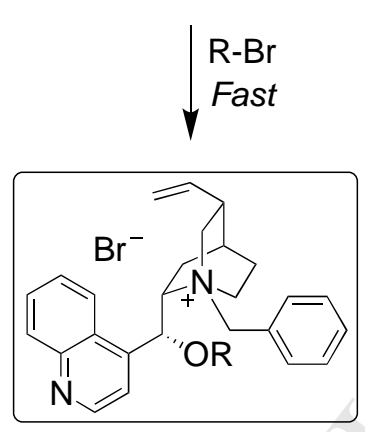

44

Active Catalyst
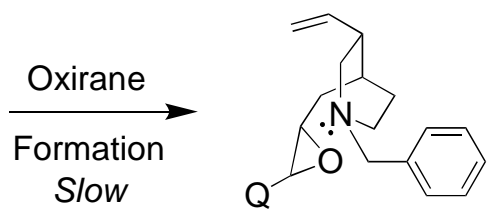

48

Oxirane

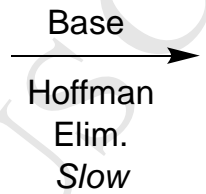

Slow

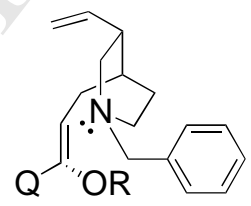

49

Scheme 18. Catalyst Decomposition Studies and Identification of the Active Catalyst.

The above results can be rationalized by a catalyst degradation mechanism (Scheme 18), which is similar to that proposed by Hughes at Merck. ${ }^{50 c}$ If the initial catalyst (41 or 42) contains an $\mathrm{OH}$ [experiments (e)-(f) above] it can be deprotonated to its alkoxide (e.g. here 47 from 41), which can undergo one of three reactions provided $\mathrm{R}-\mathrm{Br}$ is present: (i) 47 is a lipophilic organic base that could deprotonate (racemize) "product" $(\boldsymbol{S})$-12b (Scheme 17); (ii) slow formation of oxirane 48; or (iii) a fast O-alkylation of $\mathbf{4 7}$ to $\mathbf{4 3}$ (the active catalyst), which can undergo a slow Hofmann elimination to 49. Thus, as long as there is excess RX or, preferably, if the catalyst is already in its ether form (43) there will be slow degradation of the active catalyst 43 to 49 and the active catalyst 43 will have a reasonable lifetime. ${ }^{59}$

Based on these findings and to explore the nature of the alkyl group in the catalysts, two quaternary ammonium catalysts 44a (N-benzyl-O-allylcinchonidinium bromide) and $\mathbf{4 4 b}(\mathrm{N}, \mathrm{O}-$ dibenzylcinchonidinium bromide) were prepared and used in the allylation of $\mathbf{5 c}$ to prepare the monoallylated product $(\boldsymbol{S}) \mathbf{- 1 2 m}$ (Scheme 19). The O-allyl catalyst 44a gave slightly higher enantioselectivity than the O-benzyl one $\mathbf{4 4 b}$ (59\% ee vs. $54 \%$ ee) and, therefore, was chosen as the optimal catalyst for this reaction. ${ }^{59}$

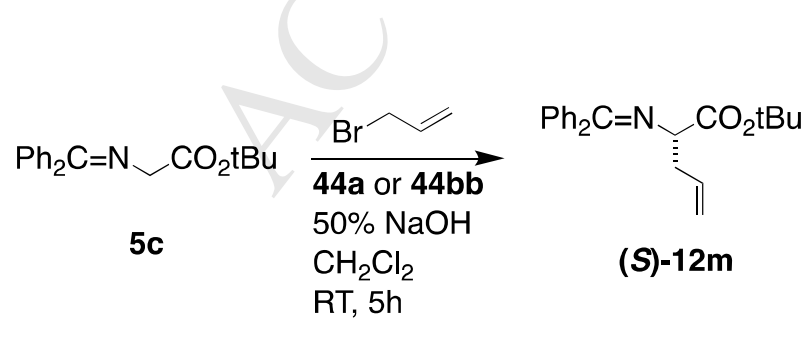

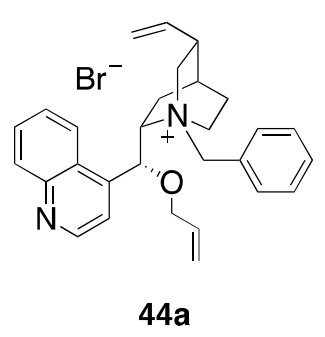

$59 \%$ ee $(S)$

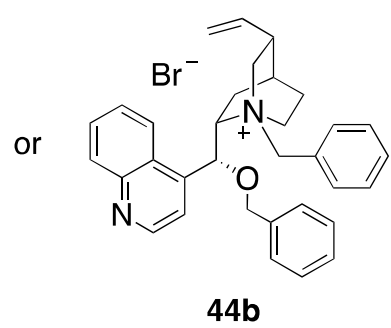

$54 \%$ ee $(S)$

Scheme 19. Optimization of New Catalyst System from Catalyst Degradation Studies. 


\section{Optimization of the catalytic enantioselective alkylation by PTC}

Based on the above observations, a detailed study was undertaken to optimize the reaction conditions for the catalytic enantioselective PTC benzylation of the benzophenone imine of glycine t-butyl ester $(\mathbf{5 c})$. The product $(\boldsymbol{S})$-12b was prepared in $81 \%$ ee with the secondgeneration catalyst 44b using solid-liquid PTC in the 7:3 toluene/dichloromethane mixed solvent system at $5{ }^{\circ} \mathrm{C}$ for 30 minutes (Scheme 20). ${ }^{9 \mathrm{~h}}$

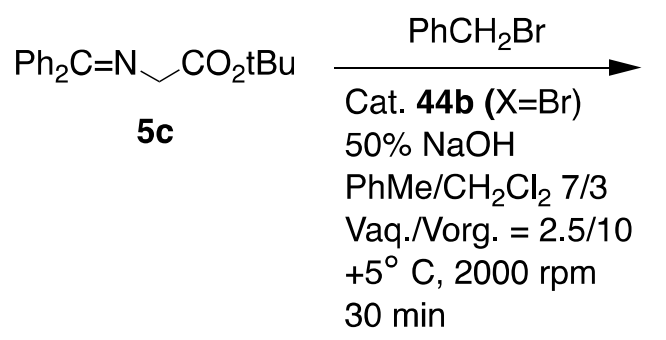

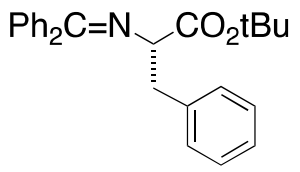

(S)-12b

$(87 \%, 81 \%$ ee $)$

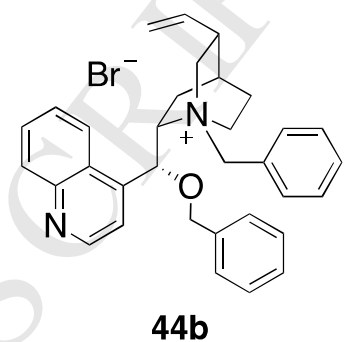

Cinchonindine-Derived

Scheme 20. Optimal Conditions for the Catalytic Enantioselective PTC Alkylation to Prepare (S)-65 (81\% ee).

\section{Third generation Cinchona-based catalysts for enantioselective alkylations}

A third generation of chiral quaternary salts derived from the Cinchona alkaloids was reported independently in late 1997 from the groups of Corey ${ }^{60}$ and Lygo. ${ }^{61}$ These involved adding an anthracenylmethyl group instead of the earlier benzyl group as the quaternary group attached to nitrogen (catalysts $\mathbf{4 5}$ or $\mathbf{4 6}$ ). Both reports provided a significant increase in enantioselectivity over the second generation O-alkyl substituted catalysts.

The Corey system (Scheme 20A) with catalyst $\mathbf{4 5}$ used cesium hydroxide monohydrate as base to minimize water in the organic phase $\left(\mathrm{CH}_{2} \mathrm{Cl}_{2}\right)$. Reactions were conducted at $-50{ }^{\circ} \mathrm{C}$ for $28-36 \mathrm{~h}\left(71-82 \%, 97-99.5 \%\right.$ ee) for less reactive alkyl halides and $-78{ }^{\circ} \mathrm{C}$ for $18-24 \mathrm{~h}(67-91 \%$, 92-99.5 \% ee) for more reactive ones (11 total reactions). The basic test reaction, the benzylation of the benzophenone imine of glycine t-butyl ester, gave product $(\boldsymbol{S}) \mathbf{- 1 2 b}(87 \%$ yield, $94 \%$ ee). ${ }^{60}$

The Lygo reaction (Scheme 21B) with catalyst $\mathbf{4 6}$ used a liquid-liquid PTC method with $50 \% \mathrm{KOH}$ in PhMe and 1.2 equiv. RX. Reactions were run at room temperature for 3-18 hours with active and less active alkyl halides plus t-butyl 2-iodoacetate followed by imine hydrolysis to the amino acid t-butyl ester (12 total alkylations, 40-86\%, 67-91\% ee). The model reaction gave t-butyl phenylalaninate in $85 \%$ (to the amino acid) and $94 \% \%$ ee. The authors prepared both $(\boldsymbol{S})$-12b (shown) and $(R)$-enantiomers (using the pseudoenantiomeric cinchonine-derived catalyst) of each product. It is noteworthy that the free $\mathrm{OH}$ catalysts were used throughout in this study. 
ODonnell Benzophenone Schiff Bases MS Ghosez Revd 031419.doc

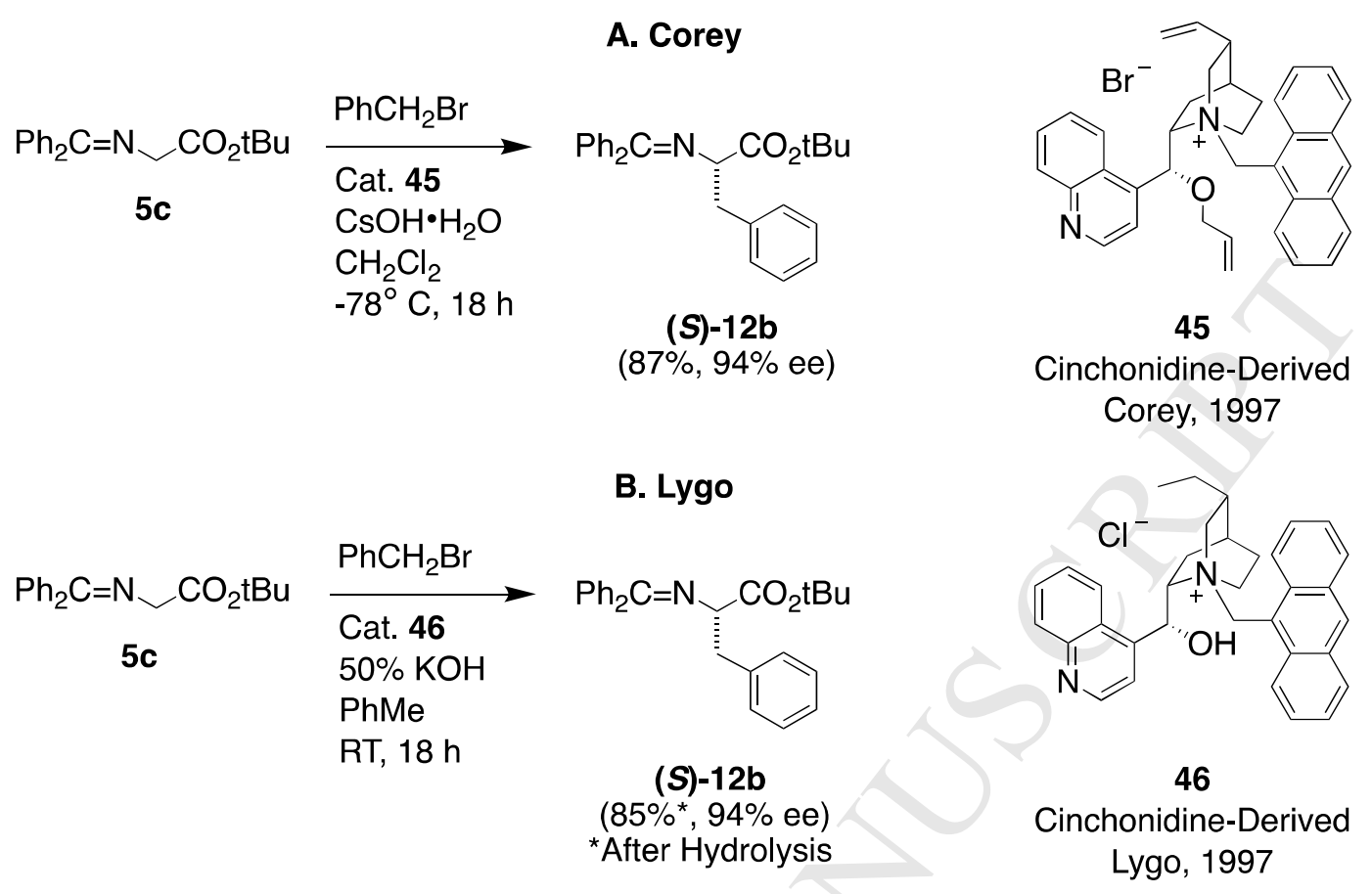

Scheme 21. Improved Enantioselectivities with Anthracenyl Salt Catalysts.

\section{Homogeneous enantioselective alkylation of the Schiff base ester of glycine}

An efficient homogeneous catalytic enantioselective synthesis of $\alpha$-amino acid derivatives was developed to overcome an inherent limitation in the two-phase systems. From a practical point of view, the need for efficient stirring can be problematic in PTC processes. While the levels of induction are not drastically affected by the rate of stirring, in order to achieve rapid reactions and minimize side reactions, effective stirring is crucial.

Catalytic asymmetric alkylation reactions were achieved by using the organic soluble, non-ionic phosphazene (Schwesinger bases) together with a chiral quaternary ammonium salt (Scheme 22). ${ }^{62}$ BEMP (50) and BTPP (51) are two relatively strong bases (super bases, pushpull bases, phosphazenes, Bronsted acid catalysts) that rely on protonation of the $\mathrm{sp}^{2}$ nitrogen that can then be delocalized through the resonance structures involving the other three $\mathrm{sp}^{3}$ nitrogens.

The acidity (pKa in DMSO) of the starting Schiff base ester 5c $(\mathrm{pKa}=19.7)$ and the conjugate acids of the Schwesinger bases (BEMP, $\mathrm{pKa}=16.2$ or BTPP, pKa 17.0) provides a qualitative estimation of the acid base reaction. Thus, deprotonation of $\mathbf{5 c}$ by either BEMP or BTPP would lead to formation of a small amount of the anion of 5c. This anion would then be alkylated and drive the reaction to completion by reestablishing the equilibrium for further alkylation. ${ }^{62}$

Homogeneous, enantioselective alkylation of $\mathbf{5 c}$ was achieved by its reaction with alkyl halides and base (BEMP, $-78{ }^{\circ} \mathrm{C}$ for active halides; BTPP, $-50^{\circ} \mathrm{C}$ for unreactive halides) in the presence of chiral catalysts $\mathbf{4 5}$ or $\mathbf{5 2}$ to yield products $(S)-\mathbf{1 2}$ or $(\boldsymbol{R})-\mathbf{1 2}$ in good to excellent yields and enantioselectivities (Scheme 22; see also later Figure 9 for related base systems). ${ }^{62}$ 
ODonnell Benzophenone Schiff Bases MS Ghosez Revd 031419.doc

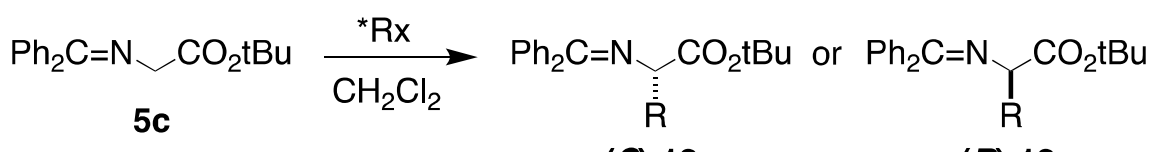

(S)-12

(Catalyst 45)
$(R)-12$

(Catalyst 52)

*Reaction Summary

Product Summary: 10 Previously Prepared; 10 New Products 12r-12aa

Products Stereochemistry: Both Enantiomers for Four Products BEMP, $-78^{\circ} \mathrm{C}, 4-7 \mathrm{~h}$, Active Halides, 13 Cases: $88-96 \%$, 83-94\%ee.*

**t-Butyl Bromoacetate, $-78^{\circ} \mathrm{C}, 4 \mathrm{~h}, 89 \%, 56 \%$ ee

BTPP, $-50^{\circ}$ C, 3.5-24 h,Non-Active Halides, 6 cases: $83-93 \%$, 85-97\%ee.

\section{Schwesinger Bases}

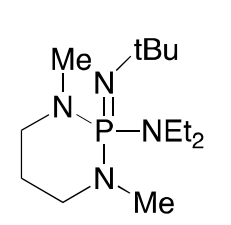

$$
\text { BEMP (50) }
$$$$
\mathrm{pKa}=16.2
$$

Active Halides Non-active Halides $-78^{\circ} \mathrm{C}$

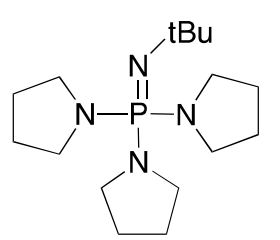

BTPP (51)

$$
\mathrm{pKa}=17.0
$$

$-50^{\circ} \mathrm{C}$

Pseudoenantiomeric Catalysts

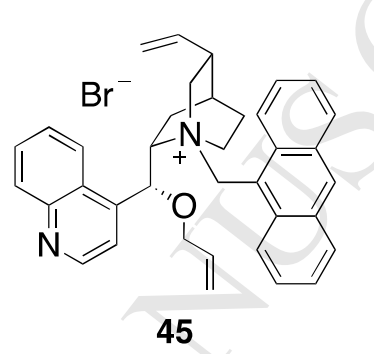

Cinchonidine-Derived

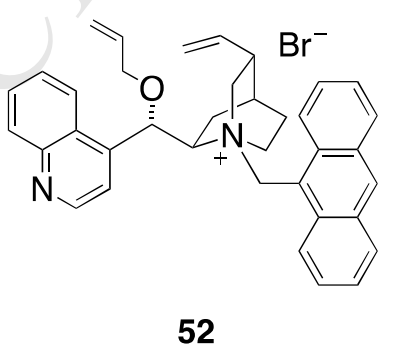

Cinchonine-Derived

Scheme 22. Schwesinger Bases for the Homogeneous Catalytic Asymmetric Synthesis of Amino Acid Derivatives.

\section{Homogeneous catalytic enantioselective Michael additions}

The methodology developed for the homogeneous alkylation of the glycine Schiff base ester 5c (Scheme 22) was extended to enantioselective Michael additions using the Schwesinger base BEMP together with Cinchona quaternary ammonium catalysts $\mathbf{4 5}$ and $\mathbf{5 2}$ (Scheme 23). ${ }^{63}$ The products [ $(\boldsymbol{S})$ - or $(\boldsymbol{R})$-ab-af] obtained from various Michael acceptors are simple analogs of glutamic acids The reactions proceeded at $-78^{\circ} \mathrm{C}$ in good yield and products with the natural $(S)$ configuration were obtained from catalyst $\mathbf{4 5}$ in better enantioselectivities than the $(R)$-products from catalyst $\mathbf{5 2}$. 
ODonnell Benzophenone Schiff Bases MS Ghosez Revd 031419.doc

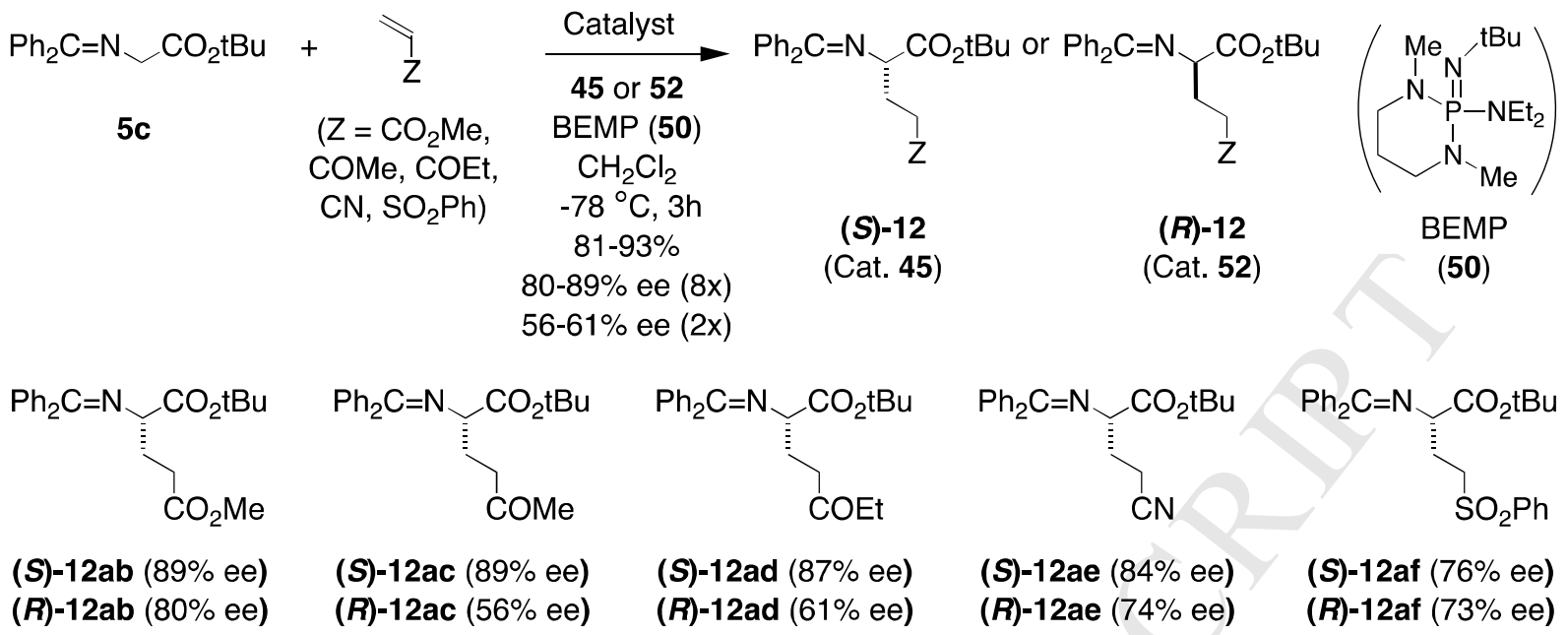

Scheme 23. Enantioselective Michael Additions of the Benzophenone Imine of Glycine t-Butyl Ester.

\section{Allylic acetates for the enantioselective synthesis of glutamic acids}

Derivatives of glutamic acid (Glu), a main excitatory amino acid in the CNS, are of current interest as potential therapeutic agents. Synthesis of a number of analogs of the 4substituted alkylidene glutamic acids was undertaken in collaboration with collaborator P. V. Ramachandran at Purdue (Scheme 24). ${ }^{64,65}$ The electrophiles were substituted allylic acetates (53) and the enantioselective phase-transfer $S_{N} 2$, alkylation was conducted using standard conditions with Cinchona alkaloid catalyst $\mathbf{4 5}$. Good to excellent yields of the products $(S)-54 a-$ $\mathbf{h}$ were obtained $(63-92 \%, 80-97 \%$ ee) and an X-Ray structure was obtained for $(\boldsymbol{S})$-54f. A representative product $[(\mathbf{S})-\mathbf{5 4 a})]$ was converted into the 4-substituted pyroglutamate $(\mathbf{2 S , 4 S )}$ 55a, which can be readily converted to 4 -substituted glutamic acids.

Use of the homogeneous catalytic enantioselective reaction developed earlier (Scheme $22),{ }^{62}$ with typical conditions (catalyst 45 , BEMP $(\mathbf{5 0}), \mathrm{CH}_{2} \mathrm{Cl}_{2},-78{ }^{\circ} \mathrm{C}, 24 \mathrm{~h}$ ) gave product (S)12ag $\left(90 \%, 79 \%\right.$ ee) but with poorer enantioselectivity. ${ }^{64}$ 
ODonnell Benzophenone Schiff Bases MS Ghosez Revd 031419.doc

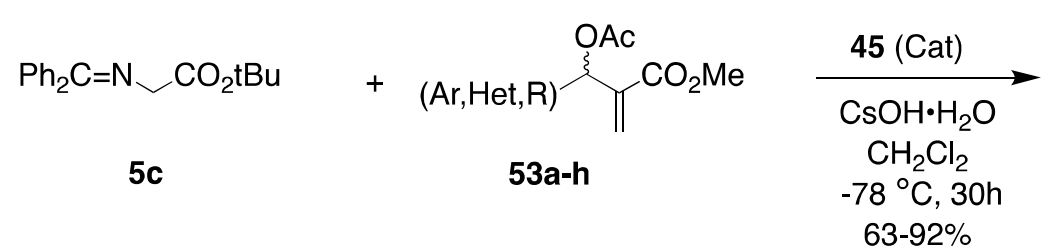

Other Conjuage Addition-Elimination Products

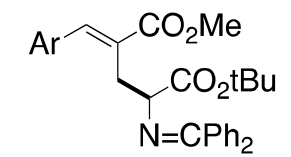

(S)-12ag-aj

Aryl Groups:

$\mathrm{Ph}(92 \%, 92 \%$ ee) $4-\mathrm{NO}_{2} \mathrm{Ph}(72 \%, 97 \%$ ee $)$

4-MePh $(63 \%, 89 \%$ ee $)$

$2,6-\mathrm{F}_{2} \mathrm{Ph}(68 \%, 80 \%$ ee $)$<smiles>COC(=O)C(=CCl)CC(OC(C)=O)C(=O)OCc1ccccc1</smiles>

(S)-12ak-al

Heteroyl Groups:

2-Pyridinyl (72\%, 82\% ee)

*2-Thienyl (90\%, 86\% ee)

${ }^{*}$ X-Ray<smiles>[R]/C=C(/CC(N=[PH2+])OC(C)=O)C(=O)OC</smiles>

(S)-12am-an Alkyl Groups: $n \operatorname{Pr}(82 \%, 82 \%$ ee $)$ tBu $(63 \%, 85 \%$ ee $)$<smiles>CCCCCCCCCC=CC(N=Cc1ccccc1)C(=O)OC</smiles>

(S)-12ag-an (8 Products) $63-92 \%, 80 \%-97 \%$ ee

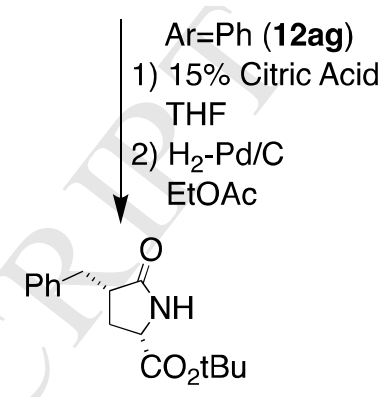

$(2 S, 4 S)-53 a(80 \%)$

Scheme 24. Catalytic Enantioselective Synthesis of Glutamic Acid Derivatives by Tandem Conjugate Addition-Elimination of Activated Allylic Acetates.

Based on the above methodology, a method for the preparation of fluorine-substituted glutamic acid derivatives was developed (Scheme 25). ${ }^{66}$ The starting fluorine-substituted allylic acetates 53 were prepared by vinylalumination of methyl propiolate (DIBAL-H, NMO), reaction of the intermediate product with a fluorinated aldehyde, then acetylation $\left(\mathrm{CH}_{3} \mathrm{COCl}\right.$, Pyr). Reaction of 5c with 53i-k gave glutamate derivatives 54i-k with the Cinchona-derived quaternary ammonium salt 45 while 5c with 53l-s gave racemic 54l-s. Product 54m was converted to the racemic pyroglutamate $\mathbf{5 5 b}\left(15 \%\right.$ aq. citric acid; $\left.\mathrm{H}_{2}-\mathrm{Pd} / \mathrm{C}\right)($ Scheme 25$){ }^{66}$

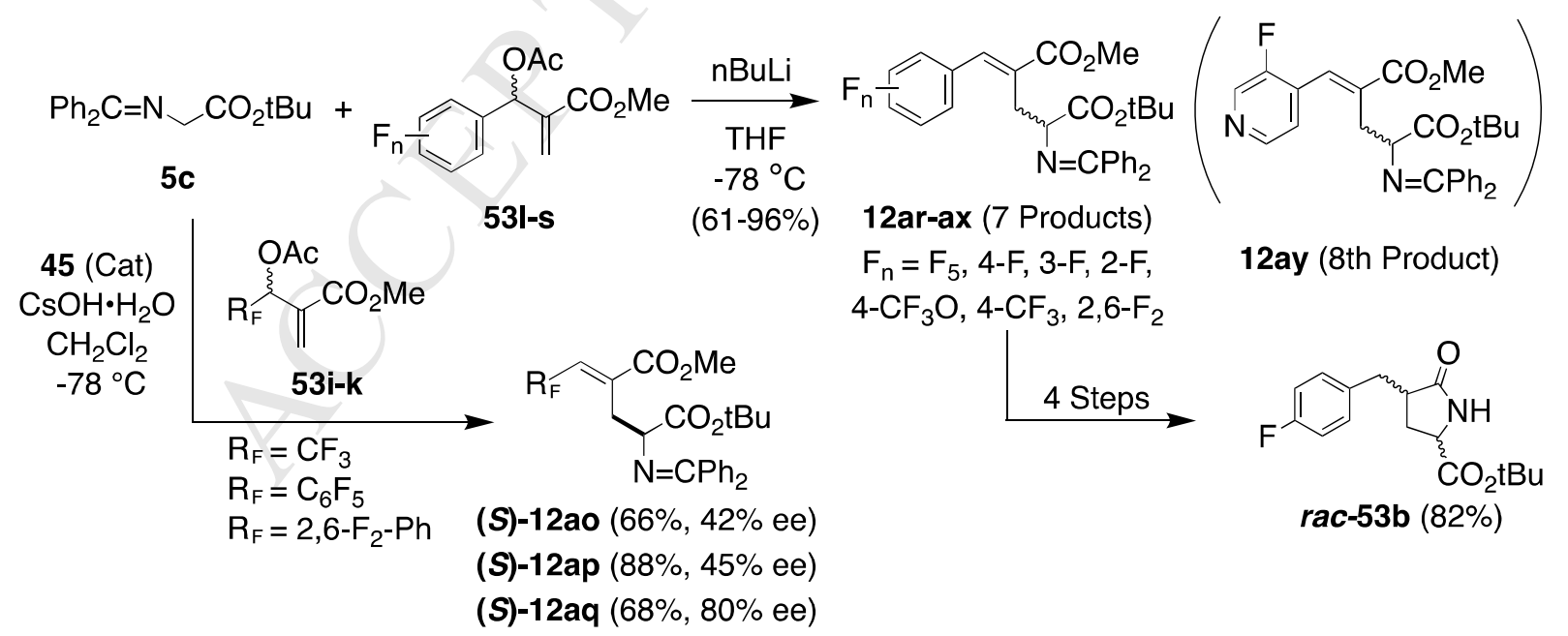

Scheme 25. Synthesis of Fluorinated Glutamic Acid Derivatives by Vinylalumination to Allylic Acetates followed by $\mathrm{S}_{\mathrm{N}} 2$ ' Alkylations. 


\section{Recrystallization of enantiomerically enriched products to higher optical purity}

One of our most effective examples to increase enantiomeric purity by recrystallization described synthesis of the Schiff base ester of 4-chlorophenylalanine (R)-17 (Scheme 15). An initial $64 \%$ ee ( $82 \%$ major enantiomer, $18 \%$ minor enantiomer) of product was obtained. After a single recrystallization, in which the major enantiomer remained in the filtrate, the optical purity was increased to $>99 \%$ ee. Several selected examples by our are presented (Figure 6). ${ }^{67,68}$ These have made use of recrystallization of optically enriched samples of the benzophenone imines (or aldimine $(\boldsymbol{R})-\mathbf{2 3 c}$ ) of amino acid esters for optical enrichment.

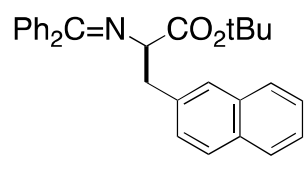

$(R)-12 y^{18}$

O'Donnell

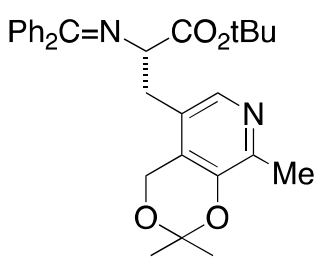

(S)-12bd ${ }^{69 c, d}$ Imperiali

$$
\begin{aligned}
\mathrm{Ph}_{2} \mathrm{C}=\mathrm{N} & \underset{\mathrm{C}}{\mathrm{C}} \mathrm{CO}\left(\mathrm{CO}_{2} \mathrm{tBu}\right)_{2}
\end{aligned}
$$

(S)-12ba/(S)-12bz ${ }^{98,99}$ O'Donnell

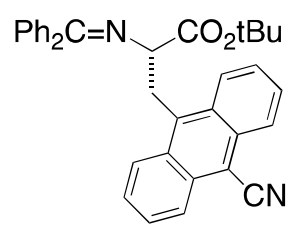

(S)-12be $\mathrm{e}^{69 \mathrm{e}}$ Imperiali<smiles>CCCCOC(=O)C(Cc1ccc(Br)cc1)N=CP</smiles>

(R)-12bb 69 Shioiri

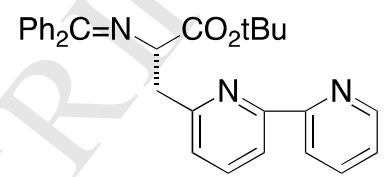

(S)-12bc ${ }^{69 b}$ Imperial

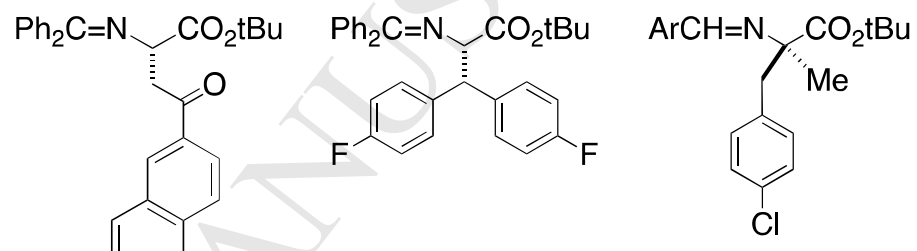

(S)-12bg ${ }^{83}$

Patterson
$(R)-23 c^{56}$

O'Donnell

(S) $-12 b f^{69 f}$

Imperiali

Figure 6. Recrystallization of Benzophenone Imines of Amino Esters to Higher Optical Purity.

An alternative method for improving the enantiomeric purity of these products is to convert the benzophenone imines of amino esters to their Fmoc derivatives 54 (15\% aq. citric acid, THF, RT; FmocCl, aq. $\mathrm{Na}_{2} \mathrm{CO}_{3}$, THF, RT) followed by recrystallization. (Figure 7). ${ }^{67}$

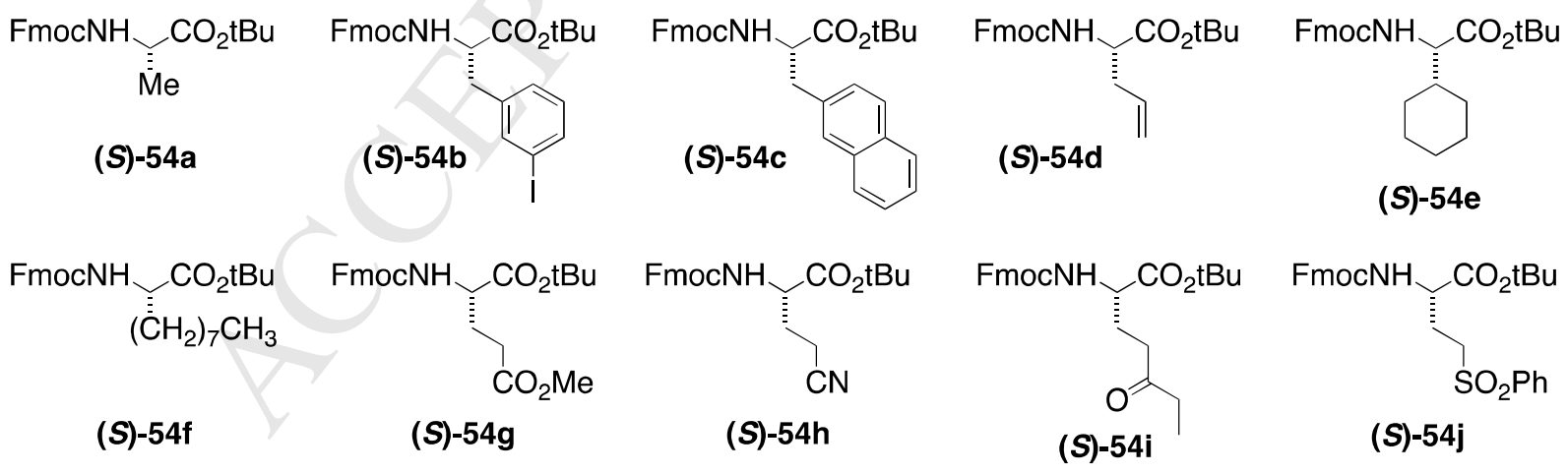

Figure 7. Recrystallization of Fmoc Derivatives of Amino Esters to Higher Optical Purity. 


\section{Amine diastereomer separations by conversion to their benzophenone imines}

An interesting use of benzophenone Schiff base derivatives was reported by Donaldson (Scheme 26). ${ }^{69}$ The amino ester diasts-55, a mixture of diastereomers, was an intermediate in the synthesis of conformationally restricted analogs of glutamate. When it was not possible to separate the mixture of diastereomers into its individual diastereomers, diasts-55 was converted into its benzophenone imine, which was readily separable by column chromatography to give the individual diastereomers (-)-55a and (+)-55b. This technique demonstrates an additional option for these and other Schiff base derivatives for the separation of diastereomeric mixtures of amines by conversion to their benzophenone imines.

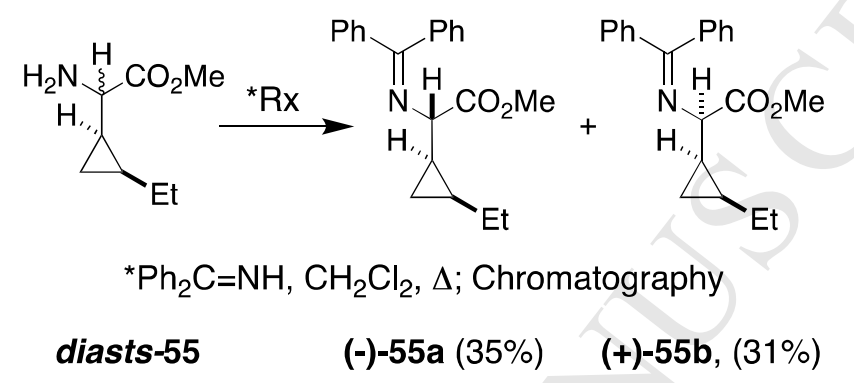

Scheme 26. Conversion of an Amine to its Benzophenone Imine for Separation of Diastereomers.

\section{Other quaternary ammonium salts and Schwesinger-type catalysts}

Since the early foundational efforts on enantioselective phase-transfer alkylation reactions in the 1980's, there have been numerous studies to extend this methodology to new reaction types (a non-inclusive list: Alkylation, Michael Addition, Aldol, Darzens, Neber Rearrangement, Horner-Wadsworth-Emmons, Cyclopropanation, Epoxidation, Aziridination, Oxidation, Reduction, Fluorination, Sulfenylation, Cyanation, Ring-Opening, Hydroxylation, Fluorination, Trifluoromethylation, Strecker) and catalysts. While many groups have contributed substantially to this effort in both articles and reviews, Maruoka has been a leader in developing new catalyst architectures such as $\mathbf{5 6}$ plus extension to new reactions. ${ }^{70}$ Four structural types of enantioselective phase-transfer catalysts are shown (Figure 8). Catalysts $\mathbf{5 6}^{70}$ and $\mathbf{5 7 ^ { 7 1 }}$ are based on non-natural precursors while $\mathbf{5 8}^{72}$ and $\mathbf{5 9}^{\mathbf{7 3}}$ and other catalysts ${ }^{74}$ (Figure 8) were derived from natural products (Cinchona alkaloids or tartaric acid).

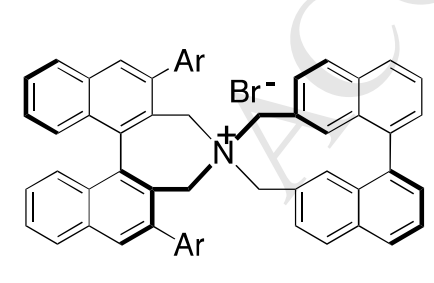

56

Maruoka

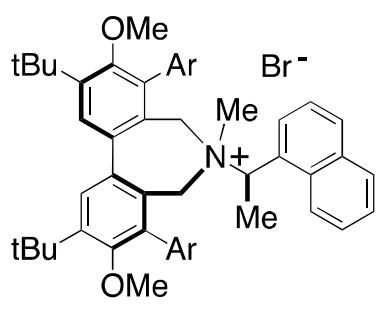

57

Lygo<smiles>C=CC1CN(Cc2cccc(F)c2F)CC1Cc1cccc2ncccc12</smiles>

58

Jew \& Park

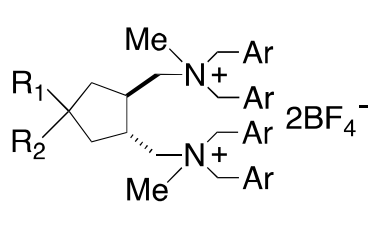

59

Shibasaki

Figure 8. Chiral Quaternary Salts as Phase-Transfer Catalysts for Enantioselective Reactions. 
ODonnell Benzophenone Schiff Bases MS Ghosez Revd 031419.doc

There has been a recent flurry of activity in the identification and study of structurally novel chiral, non-racemic phase-transfer type systems for various reactions with the benzophenone imine of glycine alkyl esters (60-64). While this review will not discuss this area in detail, a few examples have been selected and several reviews cited.

Particularly noteworthy are the extensive PTC studies by the Denmark group (catalyst development, mechanistic and stereochemical studies) to understand the factors affecting the alkylation reactions of $\mathbf{5 c}$ using quaternary ammonium salts such as $\mathbf{6 0} .^{75}$ The Lu group reported enantioselective alkylations and Michael additions using a simple amino acid-derived phosphonium salt 61 (Figure 9). ${ }^{76}$

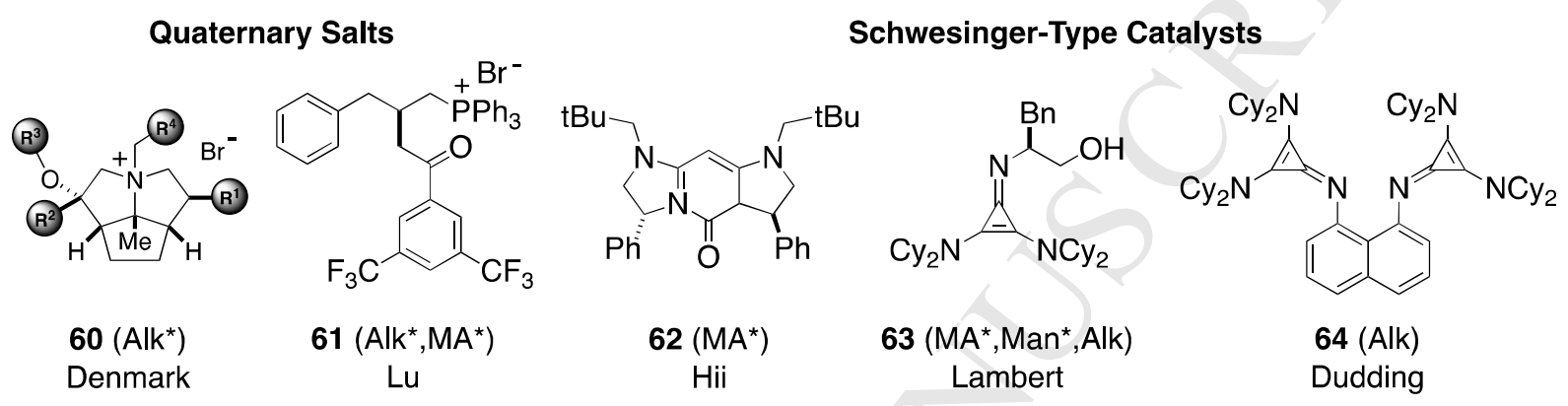

Types of Reactions ( ${ }^{*}=$ Chiral): Alk=Alkylation; $M A=$ Michael Acceptor; Mannich

Figure 9. Recent Chiral Quaternary Ammonium PTC Catalysts and Bronsted Acid Catalysts.

The remaining three catalysts are based on the principles of Schwesinger-type bases (super bases, push-pull bases, phosphazenes, Bronsted acid catalysts) (Scheme 22 and Figure 9). These serve as strong organic-soluble bases that undergo delocalization of the protonated species by an extended $\pi$ - or protonated aromatic system. ${ }^{77}$ Such systems are exemplified by the work

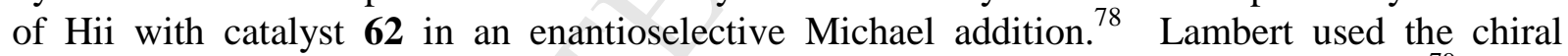
cyclopropenimine 63 in enantioselective Michael additions and a Mannich reaction, ${ }^{79}$ while Dudding extended this catalyst system to one involving achiral alkylation by a "proton sponge" 64. $^{80}$

\section{Large-scale synthesis of an optically active amino acid in $>99 \%$ ee}

Several examples of "large scale" phase-transfer reactions, either racemic or stereoselective, have been noted throughout this review and here. ${ }^{81}$ The large-scale synthesis with the Schiff base of glycine t-butyl ester (5c) in an enantioselective alkylation with 4,4'difluorobenzhydryl bromide by the Patterson group at GlaxoSmithKline that was carried out on a 6.1 molar scale of starting material (5c) is particularly impressive (Scheme 27). ${ }^{82,83}$ The salient features in the synthesis of $(\boldsymbol{S}) \mathbf{- 1 2 b g}$ by bromination of the benzhydrol then enantioselective PTC alkylation with $\mathbf{5 c}$ are outlined below: ${ }^{83}$

- 4,4'-Difluorobenzhydrol $(1.7 \mathrm{~kg}, 7.72 \mathrm{~mol})$ and $48 \% \mathrm{HBr}$ water $(5.1 \mathrm{~L})$ stirred $1 \mathrm{~h}$ at $25^{\circ} \mathrm{C}$

- Heated to $80{ }^{\circ} \mathrm{C}$ with stirring for $2 \mathrm{~h}$ then cooled to $25^{\circ} \mathrm{C}$

- Added $\mathrm{H}_{2} \mathrm{O}(6.8 \mathrm{~L})$ then $\mathrm{CH}_{2} \mathrm{Cl}_{2}(8.5 \mathrm{~L})$ and stirred then separated layers

- Washed with $\mathrm{H}_{2} \mathrm{O}(5.1 \mathrm{~L})$ then $5 \%$ aq. $\mathrm{NaHCO}_{3}(5.1 \mathrm{~L})$ 
- Concentrated organic layer at atmospheric pressure to $9.5 \mathrm{~L}$

- The 4,4'-difluorobenzhydryl bromide in $\mathrm{CH}_{2} \mathrm{Cl}_{2}$ added to $\mathbf{5 c}(1.8 \mathrm{~kg}, 6.10 \mathrm{~mol})$

- Catalyst 45 (0.185 kg, $0.30 \mathrm{~mol})$ added

- Dichloromethane $(1.8 \mathrm{~L})$ added and mixture cooled to $0{ }^{\circ} \mathrm{C}$ over $30 \mathrm{~min}$

- $45 \%$ aqueous $\mathrm{KOH}(7.6 \mathrm{~kg}, 60.9 \mathrm{~mol})$ added over $15-30 \mathrm{~min}$ with temperature $0-5{ }^{\circ} \mathrm{C}$

- Biphasic reaction stirred until reaction complete by TLC $(\sim 5 \mathrm{~h})$

- Water $(1.8 \mathrm{~L})$ added, layers separated and organic layer washed with brine $(5.4 \mathrm{~L})$

- Organic layer returned to reactor (rinse with $1.8 \mathrm{~L}$ of $\mathrm{CH}_{2} \mathrm{Cl}_{2}$ ) and concentrated to $10 \mathrm{~L}$

- Organic solution concentrated at atmospheric pressure to $10 \mathrm{~L}$

- $23 \%$ ethyl acetate in heptane $(9.1 \mathrm{~L})$ added, solution concentrated under vacuum to $14.5 \mathrm{~L}$

- Reaction seeded

- Vacuum distillation continued to $12.5 \mathrm{~L}$ volume, vacuum removed

- Reaction cooled to $20^{\circ} \mathrm{C}$ and maintained for $1-2 \mathrm{~h}$

- Solids collected by filtration, washed with $10 \%$ ethyl acetate in heptane $(3.6 \mathrm{~L})$

- Solids dried in $50{ }^{\circ} \mathrm{C}$ vacuum oven to constant weight

- Product $(\boldsymbol{S})$-12bg an off-white solid (1.72 kg, 56\%, > 99\% ee)

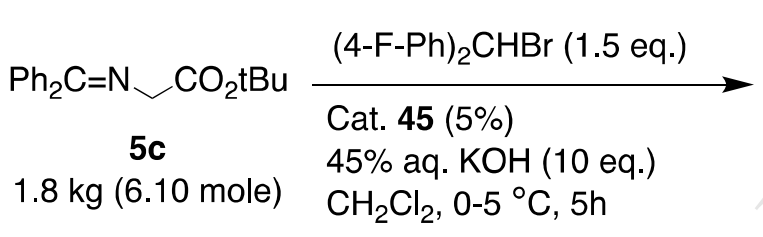

$(1.72 \mathrm{~kg}, 56 \%,>99 \%$ ee)

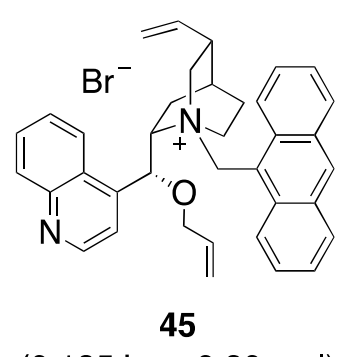

$(0.185 \mathrm{kgm} 0.30 \mathrm{~mol})$

Scheme 27. Large-Scale Enantioselective Catalytic Phase-Transfer Synthesis of an Amino Acid at GSK.

\section{Glycine cation vs. glycine anion equivalents}

Glycine anion equivalents $\mathbf{6 5}$ and those of $\alpha$-alkyl amino acids, which react with various electrophiles to give $\mathbf{6 6}$ and other derivatives have been the focus of the chemistry to this point. We now turn to their umpolung reagents, the cationic equivalents 67 , that react with nucleophiles to give products 68 . To date, the reactions of the cationic equivalents of amino acids have received considerably less attention than their anionic counterparts. Such methods can provide ready access to structural types of amino acids $\mathbf{6 8}$ not readily available from 65 .

\section{A. Glycine Anion Equivalent}

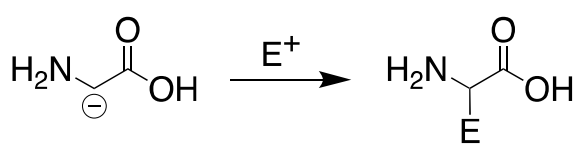

65
66
B. Glycine Cation Equivalent<smiles>NC(N)C(=O)OC=C[C@H](N)C(=O)O</smiles>

67 
Scheme 28. Glycine Anion Equivalents vs. Glycine Cation Equivalents.

\section{Cationic glycine: $\alpha$-Acetates of the benzophenone imines of glycine esters}

The synthesis of the cationic glycine equivalent 7a was first reported in $1985,{ }^{17}$ which was followed by two other routes to this important compound (Scheme 29). Reaction of the benzophenone imine of glycine ethyl ester 5a with N-bromosuccinimide in DMF with sodium acetate at room temperature gave $7 \mathbf{a} .{ }^{17}$ A more convenient and higher yielding procedure involved reaction of the t-butyl ester 5c (or many other esters) with lead tetraacetate in dichloromethane to give $7 \mathbf{c}^{84}$ In the third route the $\alpha$-keto derivative $\mathbf{6 9}$ (see Scheme 43 for preparation of $\mathbf{6 9}^{85}$ and further reactions) was reduced with super hydride followed by reaction with acetic anhydride to give 7c.

$$
\begin{aligned}
& \mathrm{Ph}_{2} \mathrm{C}=\mathrm{N} \smile \mathrm{CO}_{2} \mathrm{Et} \underset{\mathrm{NaOAc}, \mathrm{RT}}{\stackrel{\mathrm{NBS}, \mathrm{DMF}}{\longrightarrow}} \mathrm{Ph}_{2} \mathrm{C}=\mathrm{N}_{\text {OAC }} \mathrm{CO}_{2} \mathrm{Et} \\
& 5 a \\
& 7 a(71 \%)
\end{aligned}
$$

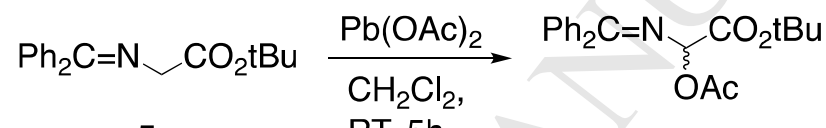

$$
\begin{aligned}
& \text { 5c } \quad \text { RT, } 5 h \quad \text { 7c (92\%) }
\end{aligned}
$$

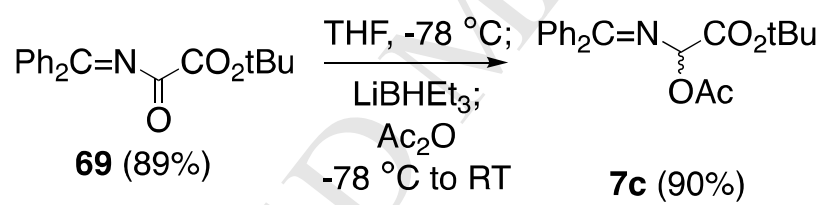

Scheme 29. Preparation of Glycine Cationic Equivalents.

\section{Cationic glycine: Reactions with neutral heteroatom nucleophiles}

Reaction of acetate 7a with neutral carbon nucleophiles (dimethylamine, thiophenol and primary or secondary alcohols) led to the racemic products $\mathbf{7 0 - 7 2}$ in $65-95 \%$ yield (Scheme $30){ }^{17,86}$ These products can be considered as further types of glycine cation equivalents. 
ODonnell Benzophenone Schiff Bases MS Ghosez Revd 031419.doc

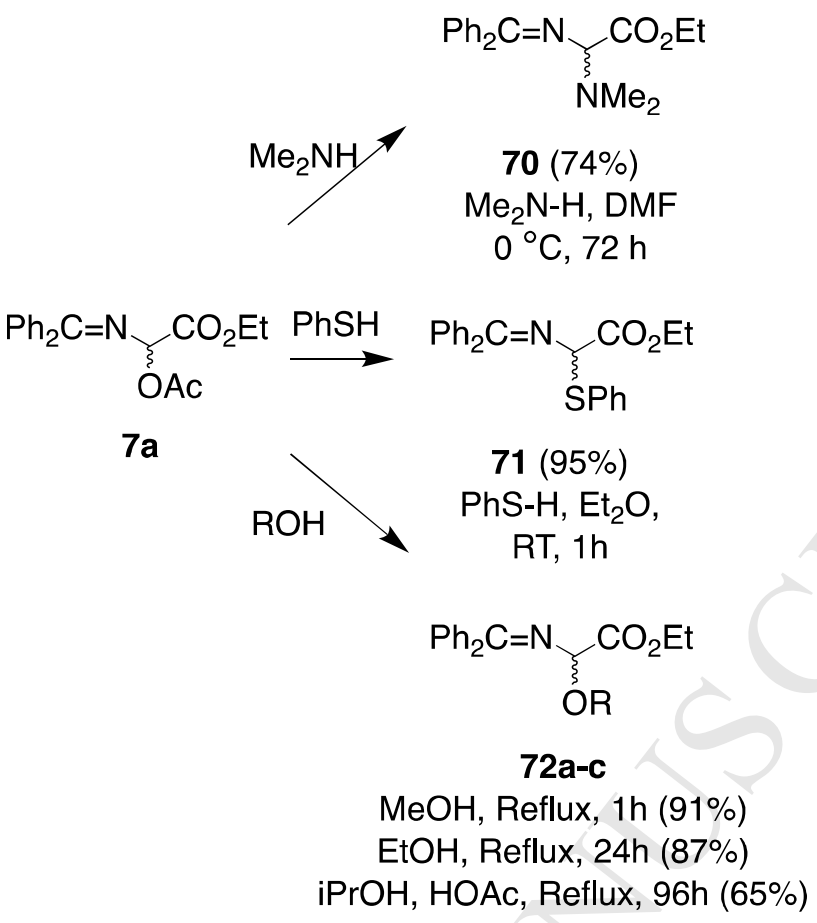

Scheme 30. Products from Reaction of Acetate with Neutral Nucleophiles.

\section{Cationic glycine: Reactions with organoboranes}

The acetate of benzophenone ethyl ester $\mathbf{7 a}$ is an $\alpha$-heteroatom-substituted ester. Since it is known that such compounds react with organoboranes, the reaction of $\mathbf{7 a}$ with organoboranes was developed to provide a general synthesis of amino acids (Scheme 31). ${ }^{87 a, b}$ The 9-alkyl/arylsubstituted-9-BBNs (73a-g) were prepared either by reaction of alkenes with 9-BBN (9borabicylco[3.3.1]nonane) or reaction of organometallics with 9-MeOBBN. Reaction of the 9$\mathrm{R} / \mathrm{Ar}-\mathrm{BBNs}$ with acetate $\mathbf{7 a}$ in the presence of the hindered phenoxide base gave the racemic protected amino acids $\mathbf{1 2}$ in moderate to excellent yield. With the exception of $\mathbf{1 2} \mathbf{b h}$, which is readily available by classical alkylation, the remaining products are difficult to prepare by this route either because of facile eliminations from the alkyl halides (12bi,bm) or difficult nucleophilic aromatic substitutions $(\mathbf{1 2 c}, \mathbf{b k}, \mathbf{b l})$. Products $\mathbf{1 2}$ were hydrolyzed to the amino acids $\left(1 \mathrm{~N} \mathrm{HCl}, \mathrm{Et}_{2} \mathrm{O} ; 6 \mathrm{~N} \mathrm{HCl}\right.$ Heat or $\left.\mathrm{LiOH}, \mathrm{H}_{2} \mathrm{O}\right)$ in $37-84 \%$ yield. 
ODonnell Benzophenone Schiff Bases MS Ghosez Revd 031419.doc

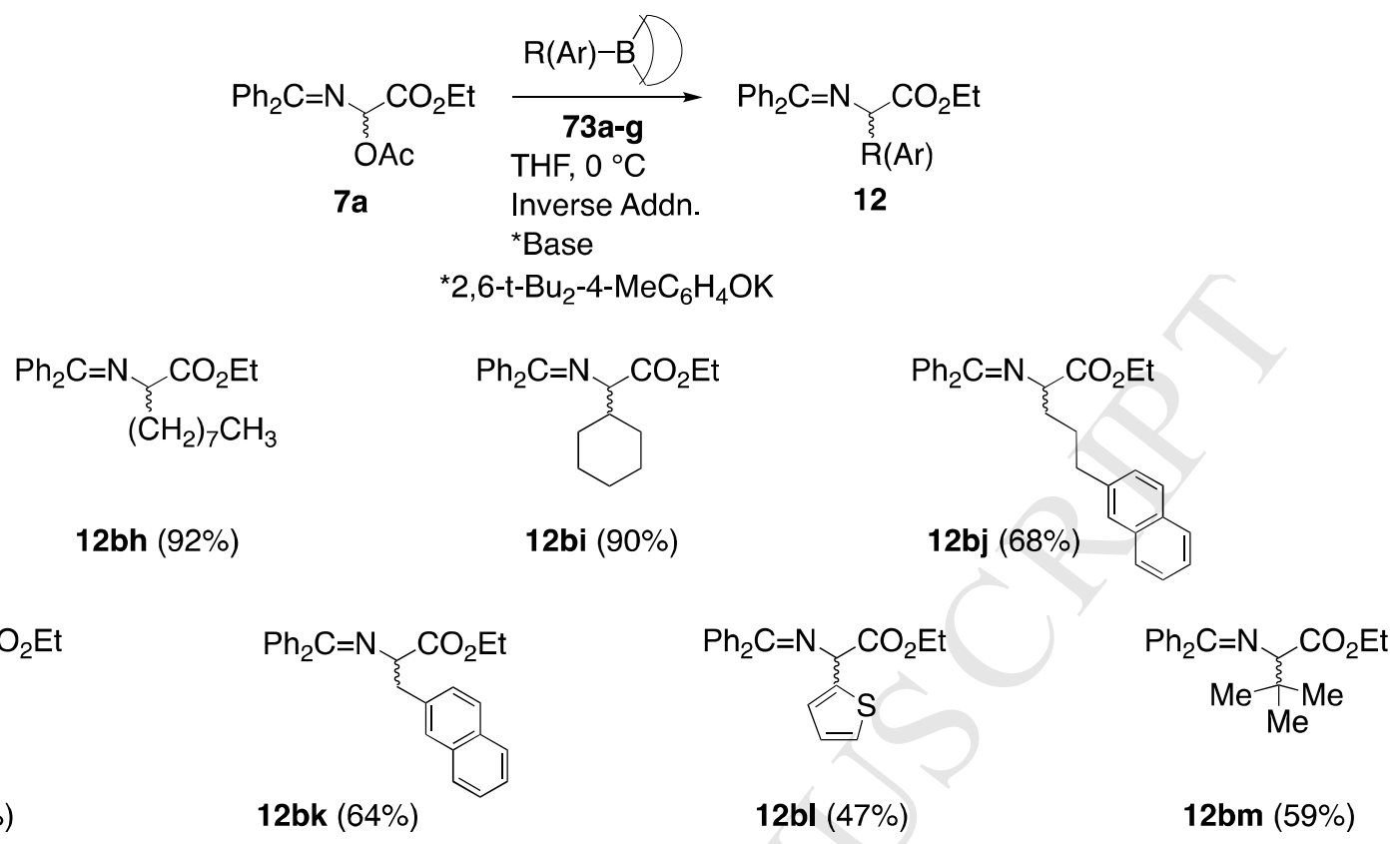

Scheme 31. Reaction of the Schiff Base Acetate of Glycine Ester with Organoboranes.

\section{Cationic glycine: Enantioselective syntheses with organoboranes}

The previous reaction of acetate 7a with 9-alkyl/aryl-9-BBNs (73) provided a method for appending the amino acid substructural unit onto alkenes or alkyl halides that can be readily converted into organoboranes (Scheme 31). The method was extended to the preparation of optically active $\alpha$-amino acids from $7 \mathbf{c}$ by using the inexpensive and readily available Cinchona alkaloids (Scheme 32). ${ }^{84 a}$ Model studies for the preparation of either enantiomer of the Schiff base esters of cyclohexyl glycine (12ba) were conducted without $\mathrm{LiCl}$ and both $(\mathbf{S}) \mathbf{- 1 2} \mathbf{b a}$ and $(\boldsymbol{R})$-12ba gave $61 \%$ ee. Addition of $\mathrm{LiCl}$ to the reaction mixture resulted in a dramatic increase in the selectivity (e.g., $(\boldsymbol{S})-\mathbf{1 2 b a})$ from $61 \%$ ee to $92 \%$ ee). 
ODonnell Benzophenone Schiff Bases MS Ghosez Revd 031419.doc

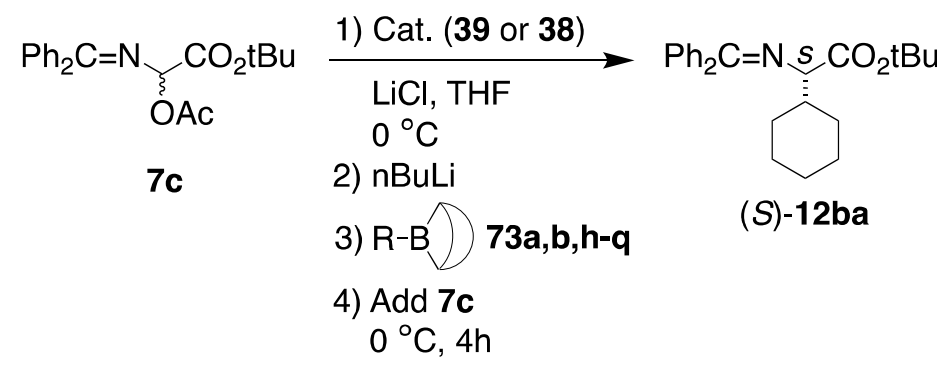

Products

$\mathrm{Ph}_{2} \mathrm{C}=\mathrm{N} s \mathrm{CO}_{2} \mathrm{tBu}$

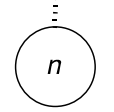

(S)-12ba $(n=6,84 \%, 92 \%$ ee)

(S)-12n ( $n=3,84 \%, 54 \%$ ee)

(S)-12bo ( $n=4,57 \%, 55 \%$ ee)

(S)-12bp ( $n=5,78 \%, 95 \%$ ee)

(R)-12bp (n=5, 80\%, 92\% ee)

(S)-12bq ( $n=7,81 \%, 89 \%$ ee)

(S)-12br ( $n=8,79 \%, 90 \%$ ee)
$\mathrm{Ph}_{2} \mathrm{C}=\mathrm{N} \leq \mathrm{CO}_{2} \mathrm{tBu}$

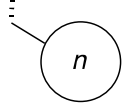

(S)-12bs ( $n=4,74 \%, 65 \%$ ee)

(S)-12bt ( $n=5,89 \%, 62 \%$ ee)

(S)-12bu ( $n=6,69 \%, 62 \%$ ee)

(R)-12bu ( $\mathrm{n}=6,83 \%, 59 \%$ ee)

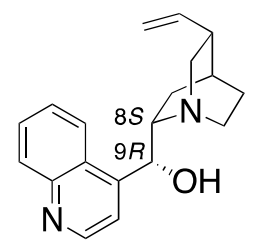

39

Cinchonindine $(\mathrm{CdOH})$

(S)-Products

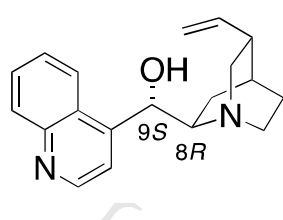

38

Cinchonine $(\mathrm{CnOH})$

(R)-Products
$\mathrm{Ph}_{2} \mathrm{C}=\mathrm{N} \underset{\Xi}{s} \mathrm{CO}_{2} \mathrm{tBu}$

$\left(\stackrel{\bar{C}}{\mathrm{H}_{2}}\right) \mathrm{nCH}_{3}$

(S)-12bv ( $\mathrm{n}=3,80 \%, 80 \%$ ee $)$

(S)-12bw ( $n=5,74 \%, 85 \%$ ee)

(R)-12bw ( $\mathrm{n}=5,85 \%, 82 \%$ ee)

(S)-12bh ( $n=7,92 \%, 75 \%$ ee)

Scheme 32. The Catalytic Enantioselective of $\alpha$-Amino Acid Derivatives from Organoboranes.

Using these optimal reaction conditions, seven cycloalkylglycine derivatives $(\boldsymbol{S})$-12ba.be-bi, were prepared. Although the enantioselectivity for the 3- and 4-membered ring analogs was only moderate, the remaining 5-through 8-membered products gave excellent enantio-selectivities $(89-95 \%$ ee). Cinchonidine (39) gave 2-3\% greater enantioselectivities than the pseudoenantiomeric cinchonine (38). The four homologous cycloalkylmethylglycine derivatives (S)-12bj-bl gave lower enantioselectivities (59-62\%) while those for the $\alpha$-alkylglycines (12q,bm,n) were intermediate (75-85\% ee).

A mechanism was presented in which the Cinchona alkaloid serves a dual role: first, as its alkoxide, to deprotonate the starting acetate $\mathbf{7 c}$ and, secondly, to protonate the final boron enolate intermediate in the key enantioselectivity-determining step to the final product.

\section{Cationic glycine: Enantio- and diastereoselective synthesis with organoboranes}

An acyclic stereoselective boron alkylation mediated by catalysts from the Cinchona alkaloids cinchonidine and cinchonine was used next in the stereoselective synthesis of the $\beta$ substituted $\alpha$-amino acid derivatives $\mathbf{1 2 b x}$ and 12by (Scheme 33). ${ }^{89,90}$

Starting organoborane $(\boldsymbol{R})-\mathbf{7 3 s} \quad(\mathrm{R}=\mathrm{Et})$ was prepared by Matteson's asymmetric homologation with BICHED boronic esters followed by Brown and Singaram's reduction/hydroboration of the boronic esters to set the latent $\beta$-stereocenters. Starting material $(\boldsymbol{R})-\mathbf{7 3 r}(\mathrm{R}=\mathrm{Phe})$ was prepared by the rhodium-catalyzed asymmetric hydroboration of styrene.

The stereochemistry of the reaction is determined by two factors: (a) the inherent diastereoselectivity (substrate control) favors formation of the syn-products and (b) the relative 
importance of the two steric control elements in the chiral protonation: the stereogenic $\beta$-center in 73r or 73s (substrate control) and the Cinchona alkaloids 39 or 38 (reagent control). The reaction occurred to give the matched pair of both products $(2 S, 3 R)-12 \mathrm{bn}$ and $(2 S, 3 R)-12 \mathrm{bo}$ in excellent enantio- and diastereoselectivity while the mismatched pair gave excellent selectivities for $(2 R, 3 R)-12$ by but eroded diastereoselectivity for $(2 R, 3 R)-12 b y$.

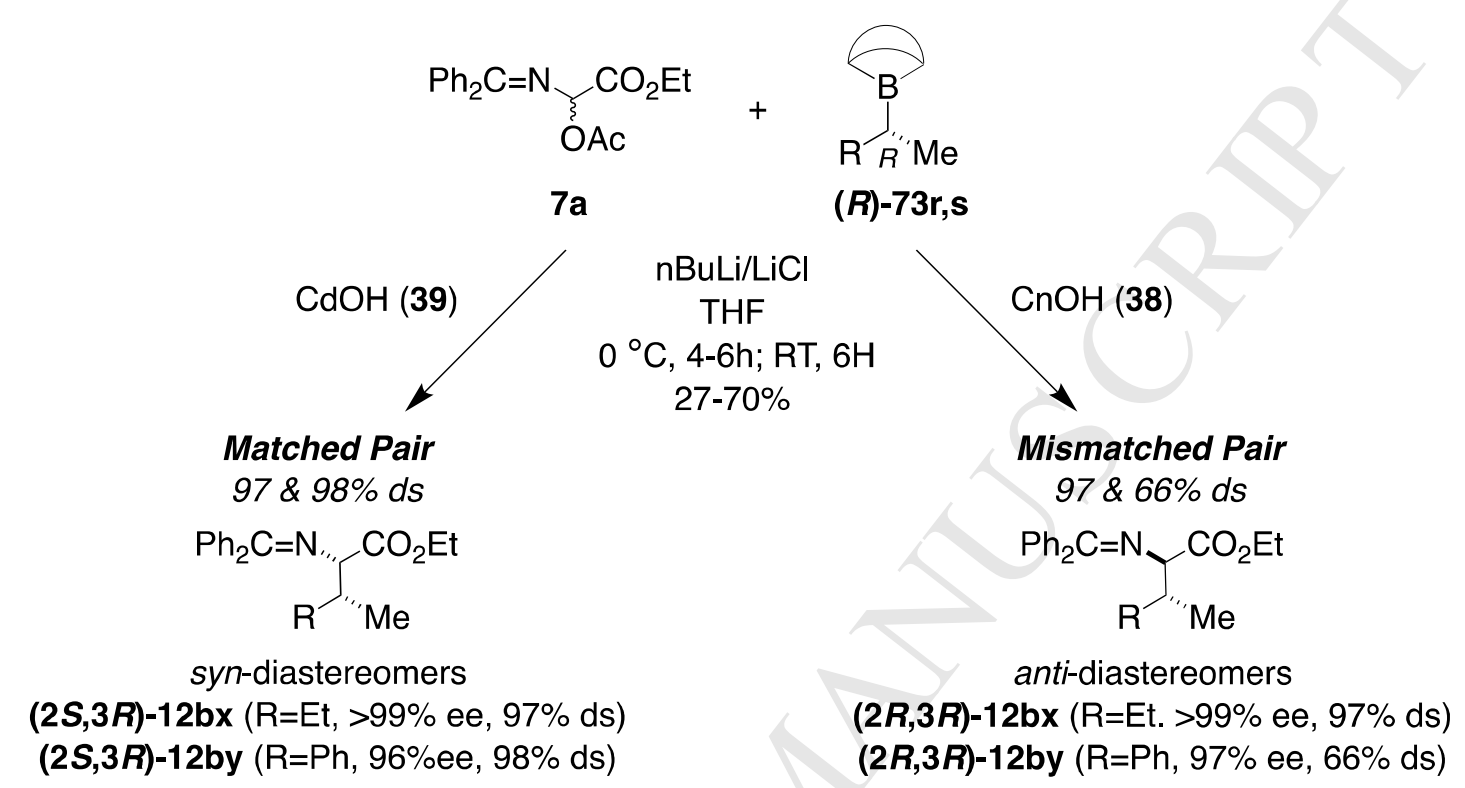

Scheme 33. Acyclic Stereoselective Boron Alkylation Reactions for the Asymmetric Synthesis of $\beta$-Substituted $\alpha$-Amino Acid Derivatives.

\section{Cationic glycine: Reactions with neutral carbon nucleophiles}

Further reactions were carried out with neutral carbon nucleophiles in the presence of varying amounts of the Lewis acid, $\mathrm{TiCl}_{4}$ with addition of the nucleophile last (Scheme 34). ${ }^{91}$ Active aromatics (furan, anisole, 2,4-dimethoxybenzene and indole) gave the corresponding protected products, which were hydrolyzed to the amino acids $(\mathbf{1 7} \mathbf{c - f}) .^{\mathbf{9 1 , 9 2 a , b}}$

Using similar, optimized conditions, the reactions of allysilanes 74a-c led to allylic $\gamma, \delta$ unsaturated amino acids (allylglycines) (12o,bp, bq) $)^{\mathbf{1 1 , 9 2 c}}$ while the silyl enol ether of acetophenone (75) gave the $\gamma$-keto amino acid 12br. ${ }^{\mathbf{9 0 , 9 2 d , e}}$ 
ODonnell Benzophenone Schiff Bases MS Ghosez Revd 031419.doc

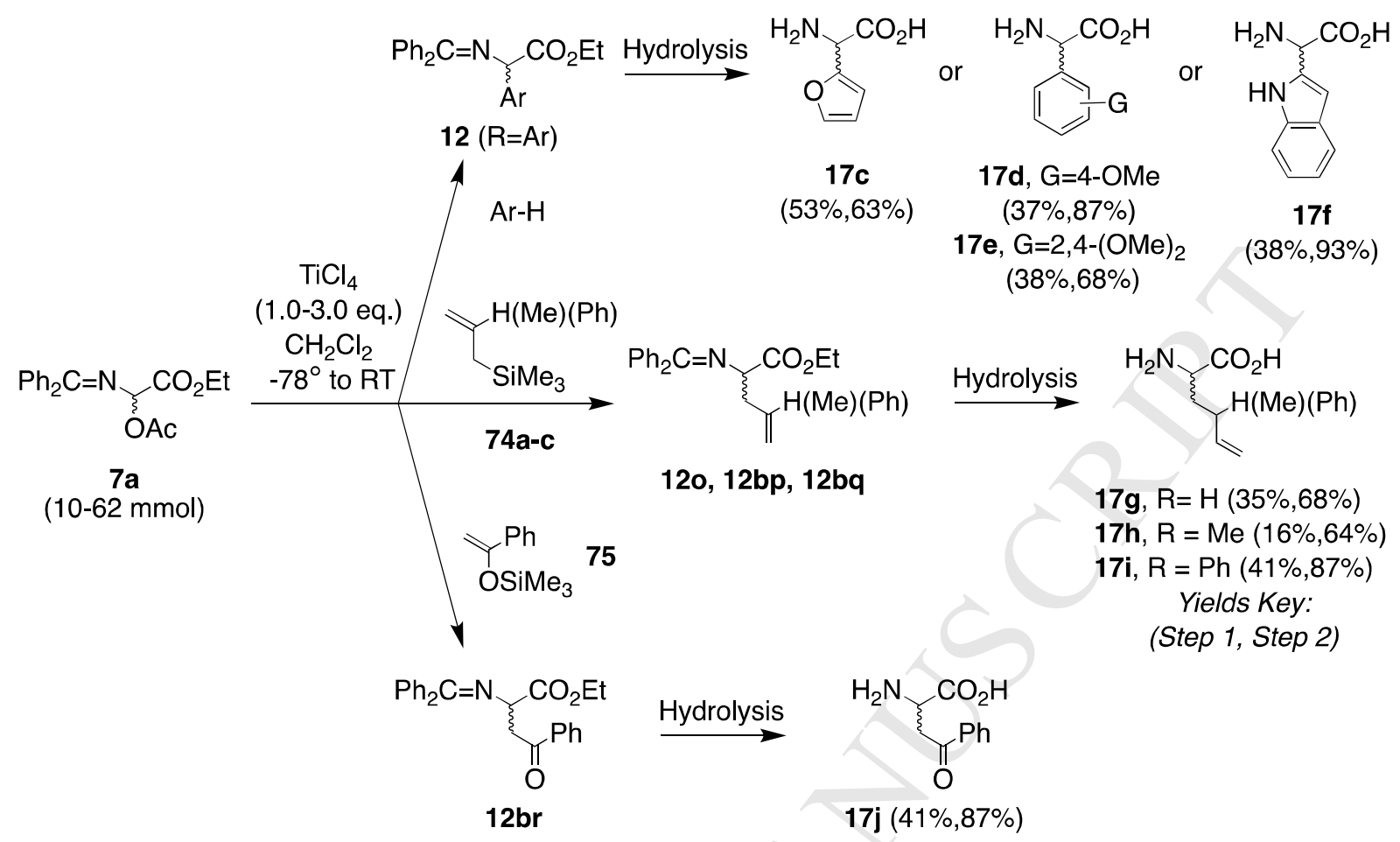

Scheme 34. Reactions of Neutral Carbon Nucleophiles with Organoboranes.

Reactions with acetate $\mathbf{7 a}$ gave only modest yields of the products $\mathbf{1 7} \mathbf{c}-\mathbf{f}, \mathbf{1 7} \mathbf{g}-\mathbf{i}$ and $\mathbf{1 7} \mathbf{j}$. Nonetheless, they can be readily scaled-up ( $3.25 \mathrm{~g}, 10 \mathrm{mmol}$ to $61.5 \mathrm{~g}, 61.5 \mathrm{mmol})$ with similar yields as the small scale model to obtain quantities of the desired products. Thus, this is an attractive route to these compounds based on the ready availability of acetate $\mathbf{7 a}$, the simple reaction procedure, workup, product purification and ease of reaction scale-up.

\section{Cationic glycine: Reactions with organometallics}

The formation of carbon-carbon bonds from the glycine cation equivalent $7 \mathbf{a}$ offers the potential for access to new structural types of amino acids not available through alkylation. For example, arylation is not typically possible by reactions of the glycine anion equivalents $\mathbf{6 5}$ nor are alkylations involving $2^{\circ}, 3^{\circ}$ or other alkyl halides prone to elimination under basic conditions.

Organocopper reagents are attractive carbon nucleophiles because of their potential for a wide range of reactivity and selectivity. Higher order mixed cuprates (76) were particularly suitable for these reactions (Scheme 35). ${ }^{93}$ Initial experiments demonstrated that these reactions were sensitive to temperature, solvent and mode of addition. The model racemic aryl-substituted glycinates [1-naphthylglycine (12bs) and 2-thienylglycine (12al)], a $3^{\circ}$ alkyl [t-butyl glycine (12bm)] and a $1^{\circ}$ alkylglycine [n-butyl glycine, norleucine (12q)] were prepared in 46-71\% yields and then converted to their respective amino acids. 


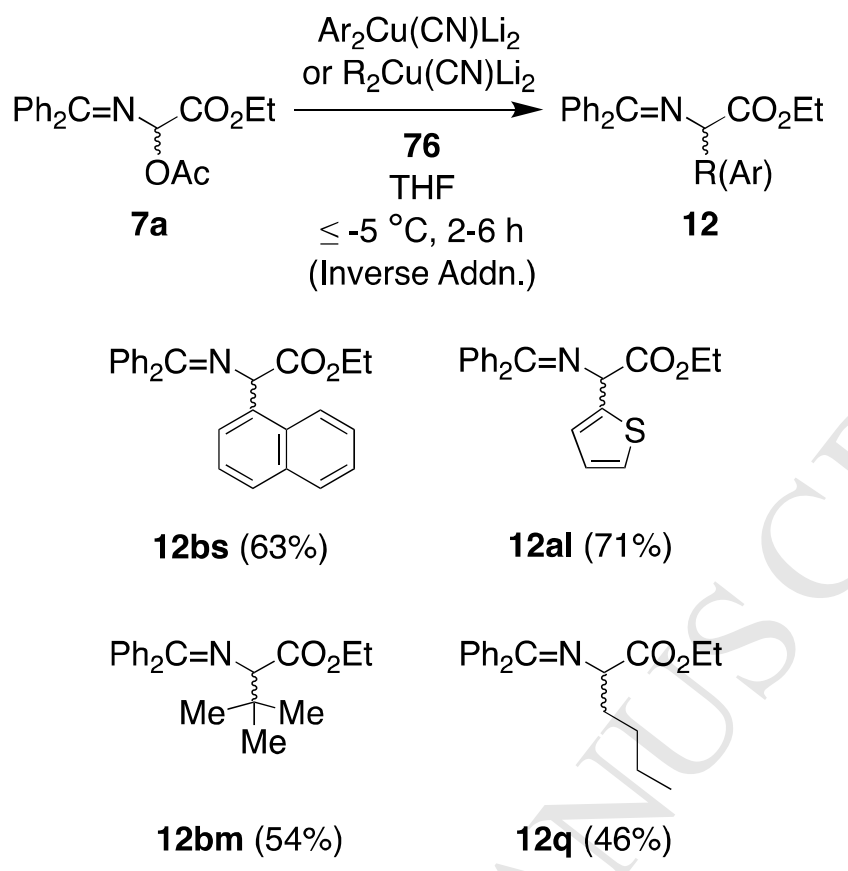

Scheme 35. Reaction of the Glycine Cation Equivalent with Organometallics.

This methodology has been extended by de Meijere to products containing cyclopropane rings (spiropentylglycine) and other derivatives. ${ }^{94}$ Lamaty, de Meijere and Knochel have used organozinc reagents in a similar fashion. ${ }^{95}$

\section{Cationic glycine: Malonate anions with palladium catalysis}

The rich chemistry of $\pi$-allyl palladium complexes has found widespread use in organic synthesis. While all carbon allylic systems have been studied extensively, the heteroatomsubstituted $\pi$-allyl palladium complexes are much less common. ${ }^{6}$ Our interest in these systems stems for their potential for use in amino acid synthesis by considering the acetates $\mathbf{7}$ as pseudo allylic acetates for reaction with nucleophiles such as malonate anions. In 1990 we reported the reaction of sodium dialkyl malonates with $\mathbf{7 b}, \mathbf{d}$ in the presence of $10 \%$ commercial tetrakis(triphenylphosphine)palladium(0) to give the protected $\beta$-carboxyaspartic acids (ASA) derivatives $\mathbf{1 2 b z}$, which could be deprotected to $\mathbf{1 7 c}$ or $\mathbf{1 7 d}$ (Scheme 36 ). ${ }^{96}$ 

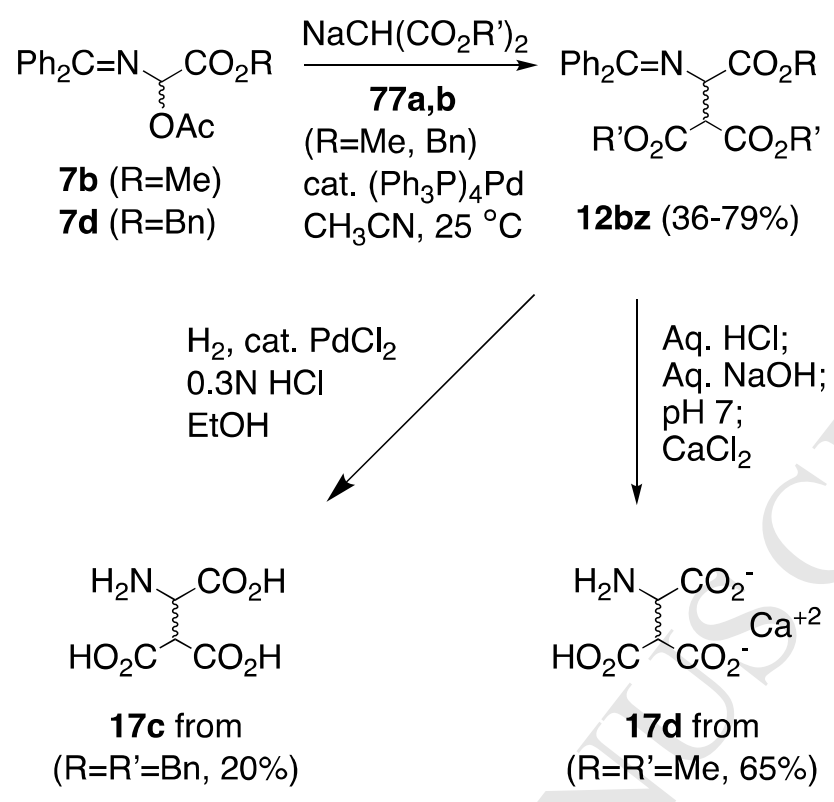

Scheme 36. Pd-Catalyzed Reaction of the Glycine Cation Equivalent with Malonate.

\section{Cationic glycine: Malonate anions and bis-phosphine tether length}

Improvements in the reaction were achieved in collaboration with Pher Andersson now at Stockholm University, by evaluating various bidentate phosphine ligands $\mathrm{Ph}_{2} \mathrm{P}\left(\mathrm{CH}_{2}\right)_{n} \mathrm{PPh}_{2}(\mathrm{n}=$ 2-6) and other variables in the reaction of sodium dimethyl malonate (77a) with the glycine cation equivalent $\mathbf{7 b}$ (Scheme 37). ${ }^{97}$ Optimal results were achieved with a tether length of four $(n=4)$. Additionally, in order to develop a catalytic enantioselective synthesis with chiral phosphine ligands, it was necessary to use a stable source of palladium that could be converted in situ to the active catalyst. This was accomplished by using $\operatorname{Pd}(\mathrm{OAc})_{2}$, which was converted to the active catalyst in situ in a larger scale synthesis ( $3 \mathrm{~g}$ of $\mathbf{7 b}$ ). Early studies using chiral bisphosphines with tether lengths of four, such as BPPM or BINAP gave low enantioselectivities (5-8\% ee or $27 \%$ ee, respectively). These results provided useful leads for further studies into catalytic enantioselective syntheses in these systems.

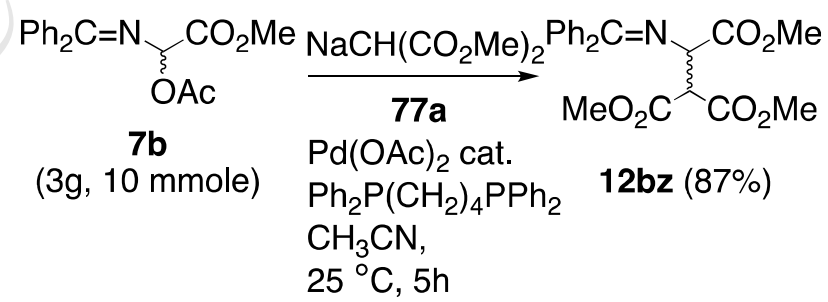

Scheme 37. Importance of Tether Length in Acetate Reaction with Malonate Anion. 


\section{Cationic glycine: Malonate anion enantioselective (BPPM) and $\beta$-alkylation}

Studies were undertaken to improve the initial low enantioselectivity obtained in the palladium catalyzed reaction of sodium dialkylmalonates with acetate $7 \mathbf{c}(7 \mathrm{~g})$ in the presence of the chiral ligand $(2 S, 4 S)$-BPPM (71). The product $(\boldsymbol{S})$-12bs, obtained following workup and flash chromatography, was a white solid $(8.5 \mathrm{~g}, 99 \%$ yield, $37 \%$ ee). A single recrystallization $\left(\mathrm{CH}_{2} \mathrm{Cl}_{2}\right.$, hexane) gave racemic crystals $12 \mathrm{bs}(4.4 \mathrm{~g})$. The filtrate was evaporated and dried to afford optically active $(\boldsymbol{S})-\mathbf{1 2 b s}(4.05 \mathrm{~g}, 48 \%$ yield, $77 \%$ ee) (Scheme 38$) .^{98}$

The utility of this reaction was extended to the preparation of $\beta$-substituted derivatives of $\beta$ carboxyaspartic acid by phase-transfer catalyzed alkylations of $(S)$-12bs in the presence of catalytic 18-crown-6. The reaction occurred with retention of configuration in product $(S)$-12cacd (90-99\% yield). Attempts to form (S)-12bt directly from 7c using sodium dimethyl methylmalonate (72) were less successful (40\%, 18\% ee).

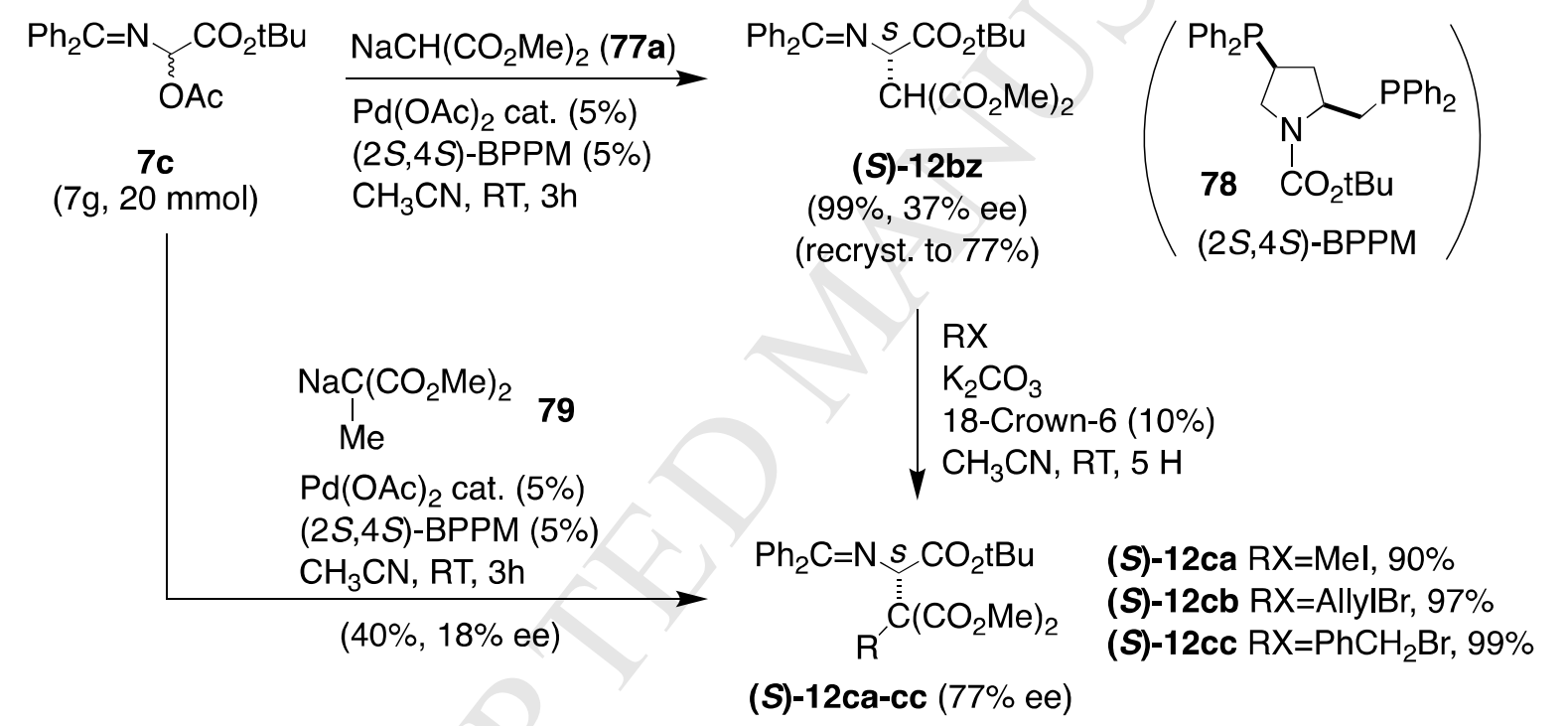

Scheme 38. Catalytic Enantioselective Reactions of Acetate with Malonate Anion and BPPM.

\section{Cationic glycine: Malonate anion enantioselective (BINAP) and recrystallization}

Our final study in the series was carried out in collaboration with Cliff Kubiak at Purdue. BINAP was used as the chiral ligand in the palladium-catalyzed reaction of the glycine cation equivalent 7c with malonate anion (Scheme 39). ${ }^{99,100}$ It included a systematic study of the substrate, nucleophile, additives and reaction conditions. Key findings were the preference for using the t-butyl ester of the acetate (7c) and the potassium salt of the malonate. The proposed $\eta^{3}$-azaallyl palladium intermediates were studied and isolation was attempted. A proposed mechanistic model for the reaction was presented.

The reaction was scaled up to provide, from $(R)$-BINAP $(\mathbf{8 0})$, the major enantiomer $(S)-\mathbf{1 2 b z}$ $(90 \%, 79 \%$ ee). Following flash chromatography and a single recrystallization, $(\boldsymbol{S})-\mathbf{1 2 b z}$ 
crystals were obtained $(62 \%, 95.5 \%$ ee). Selective deprotection of both the imine and t-butyl ester with $5 \mathrm{~N} \mathrm{HCl}$ gave $(\boldsymbol{S})-\mathbf{1 0 a}(48 \%, 93 \%$ ee) or just removal of the Schiff base with hydroxylamine hydrochloride yielded $(\boldsymbol{S})-\mathbf{1 0 b}(54 \%, 93 \%$ ee).

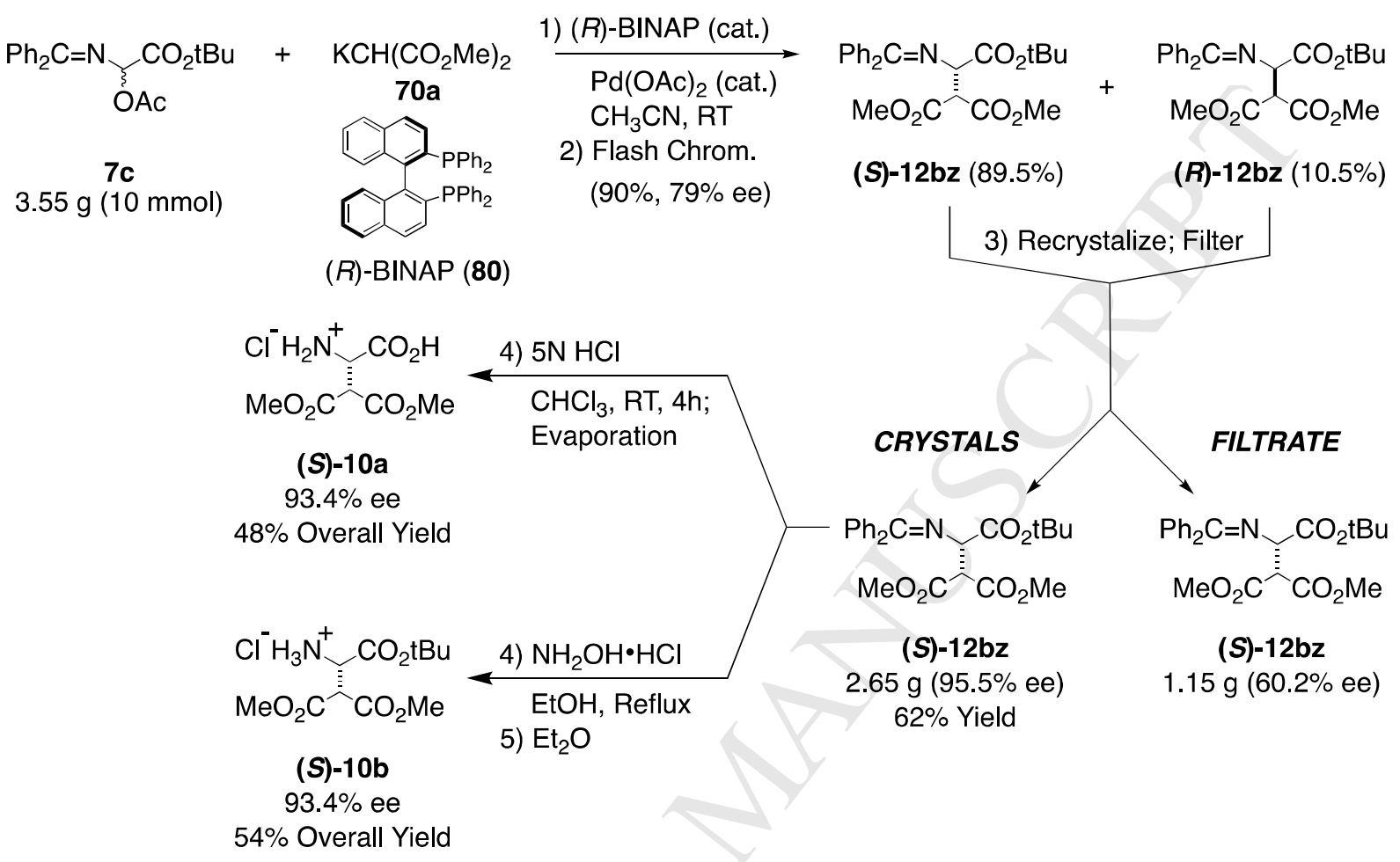

Scheme 39. Catalytic enantioselective reaction of acetate with malonate and BINAP.

\section{Cationic glycine: Reaction with vinyl anions to $\beta, \gamma$-unsaturated amino acids}

The previous reactions between acetates 7 and malonate anions can be considered a coupling between the soft malonate and a 2 -aza- $\pi$-allyl system. This concept was extended to coupling of a hard nucleophile (vinylalanes, 71) as a route to $\beta, \gamma$-unsaturated amino acid derivatives (vinylglycines, 12ca-cd) (Scheme 40). ${ }^{101,102}$ The vinylalane 81 was prepared by $\mathrm{Cp}_{2} \mathrm{ZrCl}_{2}$-catalyzed carboalumination of alkynes with $\mathrm{Me}_{3} \mathrm{Al}$. The coupling reaction of $\mathbf{7 b}$ and 81 with a catalytic amount of $\left(\mathrm{Ph}_{3} \mathrm{P}\right)_{4} \mathrm{Pd}$ in dioxane at room temperature gave tri- or tetrasubstituted vinylglycines in moderate yields. While the vinylalanes derived from less sterically demanding terminal alkynes coupled smoothly (12ca-cd), the vinylalane from tbutylacetylene gave no reaction. The vinylalane from a symmetrical internal alkyne (3-hexyne) gave a single coupling product (12cd) while, as expected, that from an unsymmetrical alkyne gave a mixture of regioisomers.

The product vinylglycine derivatives $12 \mathrm{ca}-\mathbf{c d}$ can be readily deprotected to their vinylglycine ester hydrochlorides $10 \mathrm{c}-\mathrm{f}$ ) by treatment with mild acid in a two-phase system (1N $\mathrm{HCl}, \mathrm{Et}_{2} \mathrm{O}, \mathrm{RT}, 15 \mathrm{~h}, 75-89 \%$ ). 
ODonnell Benzophenone Schiff Bases MS Ghosez Revd 031419.doc

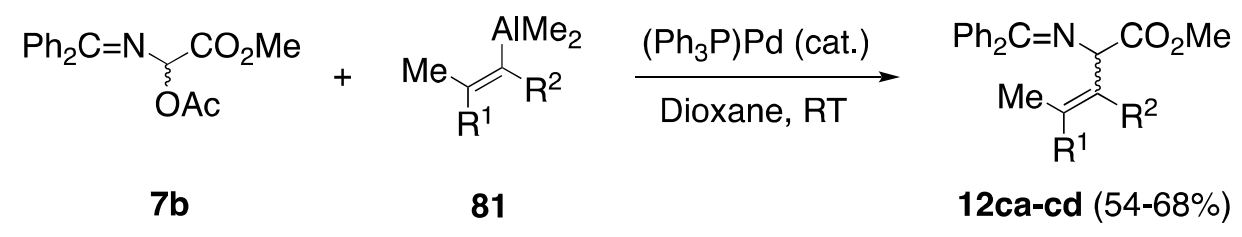<smiles>CCNC(C=O)C(C)=O</smiles>

$10 \mathrm{c}(68 \%)$<smiles>CCNC(C(C)=O)/C(C)=C/c1ccccc1</smiles>

$\operatorname{10d}(50 \%)$<smiles>CCNC(C)C(C)=C(C)C(C)C</smiles>

$10 \mathrm{e}(60 \%)$<smiles>CCNC(CC)C(CC)=C(C)C</smiles>

$10 f(54 \%)$

Scheme 40. Reaction of an Amino Acid Cation Equivalent with Vinylalanes and Palladium Catalysis to $\beta, \gamma$-Unsaturated Amino Acid Derivatives.

\section{Preparation and reactions of a cationic aminophosphonate equivalent with organoboranes}

A cationic equivalent of the $\alpha$-aminophosphonates $\mathbf{8 2}$ was developed to access phosphorous analogs of the $\alpha$-aminocarboxylates $\mathbf{8 4}$, derivatives not easily accessible by the anionic route (Scheme 41). ${ }^{103,104}$ Initial studies of this biologically interesting class of molecules focused on the nature of the leaving group on derivatives of the Schiff base ester 82. Since attempts to extend earlier success to prepare the acetate of $\mathbf{8 2}$ were unsuccessful, attention was focused on a sulfur-based leaving group. Treatment of the benzophenone imine of aminophosphonate $\mathbf{8 2}$ with 2,2'-dipyridyl disulfide gave the $\alpha$-thiopyridyl derivative $\mathbf{8 3}$. This group was selected because it possesses a combination of strong acidifying and good leaving group abilities. Thus, $\mathbf{8 3}$ is $4.3 \mathrm{pKa}$ units less acidic ( $\mathrm{pKa}=18.7$ in DMSO, statistically corrected by the number of acidic hydrogens) than its parent $82(\mathrm{pKa}=23.0)$ and has approximately the same acidity as $\mathrm{Ph}_{2} \mathrm{C}=\mathrm{NCH}_{2} \mathrm{CO}_{2} \mathrm{Et}(4, \mathrm{pKa}=18.7)$.

Reaction of $\mathbf{8 3}$ with organoboranes $\mathbf{6 7}$, in analogy with earlier studies with $\mathbf{7}$ (Schemes 30-33), readily gave $\alpha$-monosubstituted derivatives of the protected $\alpha$-aminophosphonates 84 . With the exception of the alkylation product $(\mathbf{8 4 e})$, the remaining products are difficult to obtain from the anionic equivalent by alkylation: an arylglycine $(\mathbf{8 4 a})$, the product from a hindered $3^{\circ}$ alkyl $(\mathbf{8 4 b})$, or other halides prone to elimination $(\mathbf{8 4 c , d})$. The organoboranes used for these reactions were derived from phenyl- or t-butyllithium and 9-MeOBBN or by hydroboration of the corresponding alkenes. The products $\mathbf{8 4}$ can be deprotected to either the $\alpha$-substituted- $\alpha$ aminophosphonates or phosphonic acids. 
ODonnell Benzophenone Schiff Bases MS Ghosez Revd 031419.doc

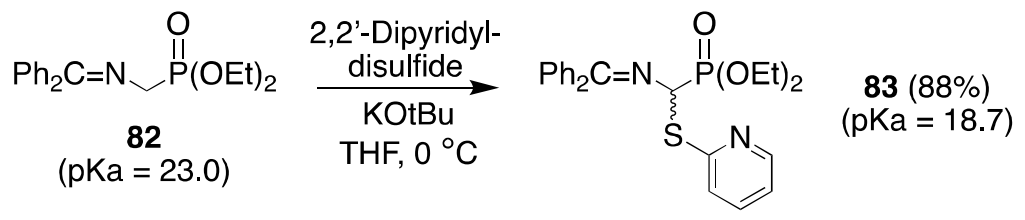<smiles>CCO[PH](=O)C(N=CPc1ccccc1)Sc1ccccn1</smiles>

83<smiles>CCOP(=O)(OCC)C(N=Cc1ccccc1)c1ccccc1</smiles>

$84 a(50 \%)$<smiles>CCOC(=O)C(C)(C)C(N=Cc1ccccc1)C(C)(C)C</smiles>

84b $(55 \%)$

Reactions with Organoboranes<smiles>[10B-]B1C=CC=C1</smiles>

67

$$
\frac{\mathrm{THF}, 0{ }^{\circ} \mathrm{C}}{\underset{\text { Inverse Addn }}{\text { Base* }}}
$$<smiles>[R10]C(N=C)[P+](=O)OCC</smiles>

*2,6-t-Bu2 $-4-\mathrm{MeC}_{6} \mathrm{H}_{4} \mathrm{OK}$

84

Scheme 41. Preparation and Reaction of an $\alpha$-Aminophosphonate Cation Equivalent with Organoboranes.

\section{Preparation and alkylation of the Weinreb amide of the benzophenone imine of glycine}

In addition to being important targets in their own right, derivatives of the amino acids and peptides such as amino aldehydes and ketones are of considerable interest. ${ }^{105}$ Our program in the solid-phase synthesis of amino acid and peptide derivatives led us to explore the use of a Weinreb amide as a surrogate for the Rink amide resin. ${ }^{106}$ In order to determine the appropriate base for deprotonation, a model solution-phase system was developed prior to extension to resinbound substrates. Since conventional resin-bound substrates add an additional solid phase to any synthesis, use of an organic-soluble, non-ionic base such as the Schwesinger bases BEMP (50) or BTPP (51) (Schemes 22 and 23) was envisioned (Scheme 42).

Starting Weinreb amide 86 was prepared from Boc-glycine (65) (Scheme 42). Alkylation of $\mathbf{8 6}$ was sluggish in BEMP (50), our first "base of choice." By using the slightly stronger base BTPP (51) the alkylation was successful to give the alkylated products $(\mathbf{8 7 a}, \mathbf{b})$. Although these were not used in a solution-phase synthesis of amino aldehydes or ketones, the methodology was applied successfully to prepare various amino and di- or tripeptide aldehydes and ketones on solid phase (24 total products in $27-87 \%$ yield). ${ }^{106}$ 
ODonnell Benzophenone Schiff Bases MS Ghosez Revd 031419.doc<smiles>O=C(O)CNCC(=O)O</smiles>

85
1) N-Methylmorpholine

2) $\mathrm{iBuOCOCl}$

3) $\mathrm{MeNHOMe} \cdot \mathrm{HCl}$ $-15{ }^{\circ} \mathrm{C}$ to $\mathrm{RT}$<smiles>CN(C)C(=O)N=Cc1ccccc1</smiles>

$86(54 \%)$
1) $\underset{T H F, R T}{\stackrel{1}{T}}$

2) $B T P P^{*}$<smiles>CN(C)C(=O)C(N=Cc1ccccc1)N(C)C</smiles>

87

Solution-Phase Model for

Solid-Phase Alkylation on Rink Resin

${ }^{*}$ BTPP (Base)

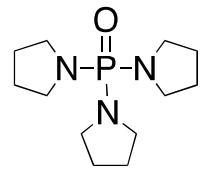

44
Alkylation Products

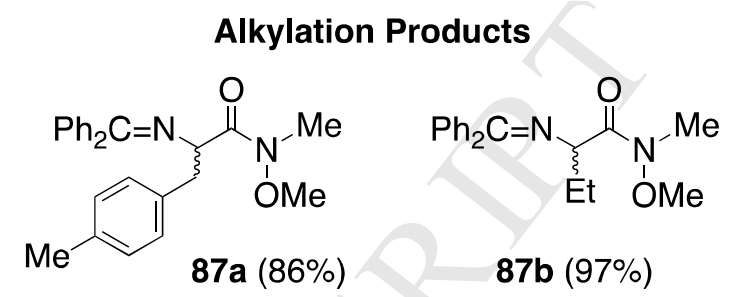

Scheme 42. Weinreb Amide Preparation and Alkylation.

\section{5. $\alpha$-Keto Schiff base esters for preparation of $\alpha, \beta$-didehydroamino acids}

Dehydroamino acid derivatives are an important class of compounds in biological systems. Typical construction of the $\alpha, \beta$-bond in these compounds is accomplished by a Wittig reaction, normally from the reaction of the Wittig reagent with aldehydes or ketones. Reaction with the reversed polarity, starting from an $\alpha$-keto amino acid and a Wittig reagent, is less common (Scheme 43). ${ }^{\mathbf{8 5}, 107}$

Preparation of the $\alpha$-keto amino acid derivative 69 was accomplished by reaction of the mixed ester-acid chloride from oxalyl chloride with benzophenone imine, which is stable for several weeks at $0{ }^{\circ} \mathrm{C}$ although it decomposes by decarbonylation at room temperature.

Reaction of 69 with Wittig reagents gave the dehydroamino acids 89a-f (78-90\% yield, with the given Z:E ratios). The major products were assigned the Z-configuration based on their small vicinal carbon-proton coupling constants and a crystal structure of the minor diastereomer of 89c confirmed the $E$-configuration. (Note: the first report of the Wittig olefination of the $\alpha$ keto amino acid derivative 69 appeared after our work was in progress ${ }^{107 a}$ ). 

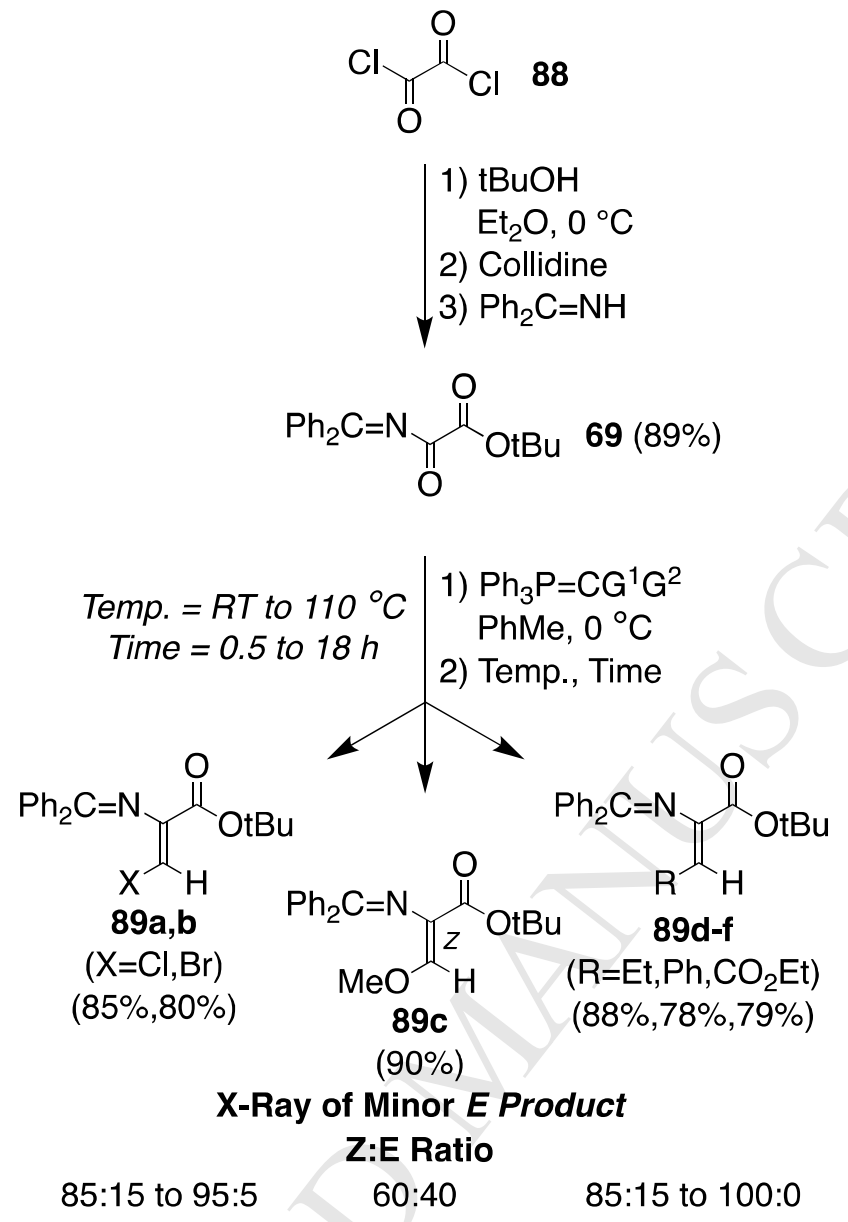

Scheme 43. Preparation of $\alpha, \beta$-Didehydroamino Acids Derivatives from $\alpha$-Keto Schiff Base.

\section{Transesterification of Schiff base esters of amino acids and dipeptides}

The protection and deprotection of carboxylic acids as their esters are key transformations in organic synthesis. This is especially true in amino acid and peptide chemistry and total synthesis where multifunctionalities and chirality are often present.

Many common methods for esterification of carboxylic acids cannot be used in the presence of a Schiff base because of the instability of a molecule that contains both an imine and a free carboxylic acid. We explored use of saponification followed by O-alkylation for conversion of the benzophenone imine of an amino acid methyl ester into its benzyl ester using a phase-transfer system (Scheme 44). ${ }^{108,109}$ Ion-pair extraction with a full equivalent of $\mathrm{Bu}_{4} \mathrm{NHSO}_{4}$ with aqueous $\mathrm{NaOH}$ in $\mathrm{CH}_{2} \mathrm{Cl}_{2}$ at room temperature was followed by separation of the layers and then addition of the alkyl halide to the organic phase. The benzophenone imines of $(S)$-phenylalanine methyl ester $(\boldsymbol{S})$-12b and phenylglycine methyl ester $(\boldsymbol{S})$-12c were chosen as models to test the propensity for racemization. Both starting materials gave "product" in good yield. However, while the phenylalanine $(S)$-12b gave retention of configuration in "product" $(S)$-12b, the phenylglycine $(\boldsymbol{S})$-12c gave "product" $(\boldsymbol{S})$-12c with $50 \%$ racemization. This result is not unexpected since the phenylalanine starting material $(\boldsymbol{S})-\mathbf{1 2 b}$ is expected to be less acidic (higher 
$\mathrm{pKa}$ ) than the phenylglycine one $(\boldsymbol{S}) \mathbf{- 1 2 c}$ (see Section 12, Figures 2 and 3, pKa= 23.2 for $\mathbf{1 2 b}$ vs. $\mathrm{pKa}=21.2$ for $\mathbf{1 2 c}$ ).

Application of this transesterification procedure to the conversion of the benzophenone imine dipeptide methyl ester of $(S)$-Val- $(S)$-Val into its benzyl ester resulted in retention of stereochemical integrity at both stereogenic centers of the resulting benzyl ester. ${ }^{109}$

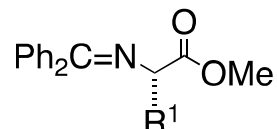

(S)-12b $\left(R^{1}=\mathrm{Bn}\right)$

(S)-12c $\left(\mathrm{R}^{1}=\mathrm{Ph}\right)$

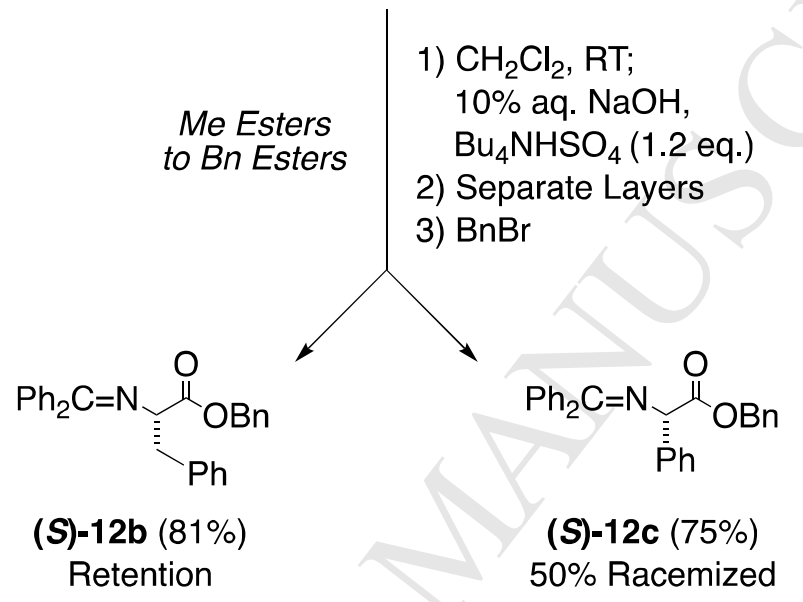

Scheme 44. Transesterification of Schiff Base Esters of Amino Acids and Dipeptides.

\section{Nitrogen alkylation for the preparation of $\mathrm{N}$-alkyl amino acids and a total synthesis}

N-Methyl amino acid are an important class of amino acids, as biologically active compounds, for the preparation of peptide analogs and in conformational studies of peptides. ${ }^{110}$ A major method for preparing N-methyl amino acids has been the nitrogen alkylation of a protected amino nitrogen (base, RX) from N-protected amino acids such as Boc or Cbz. An alternate route involves nitrogen alkylation of imine-type substrates, such as $(S)$-19 (aldimine) or (S)-90 (amidines) with electrophiles (Scheme 46). Synthesis of the N-alkyl amino acids involved preparation of amidines $(S)-90 a$ by reaction of the free amino ester from $10 \mathrm{~g}$ with dimethylformamide dimethyl acetal, followed directly by alkylation with either methyl triflate or dimethyl sulfate (Scheme 45). ${ }^{11}$

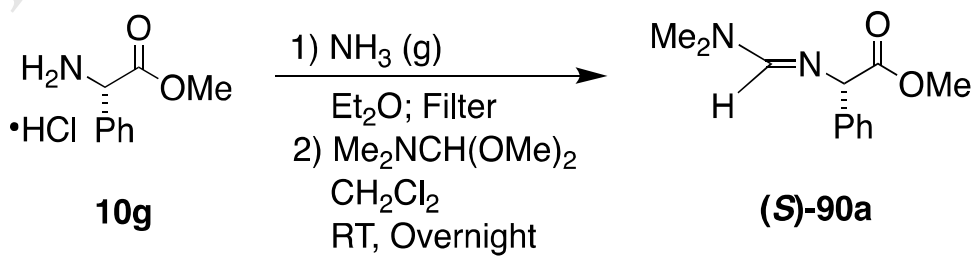

Scheme 45. Preparation of Amidine Esters of Phenylglycine. 
Alkylation of the Schiff bases esters $(\boldsymbol{S}) \mathbf{- 1 9 j}$ and their amidino counterparts $(\boldsymbol{S})-\mathbf{9 0 a}$ were compared in terms of reaction conditions and, especially, racemization at the $\alpha$-carbon (Scheme 46). Alkylation of the Schiff base ester of $(S)$-phenylalanine $(S)$-19j required forcing conditions with considerable erosion of the chiral center. In contract, the more basic/reactive amidino ester (S)-90a was alkylated with either methyl triflate for the racemization-prone derivative of phenylglycine or dimethyl sulfate for $\alpha$-alkyl $(S)$-91b-d or the $\alpha, \alpha$-dialkylamino acid derivative 92a. In cases $(S)-91 b$ and $(S)-91 c$ the reactions occurred with retention of configuration (Scheme 46). ${ }^{111}$

\section{Schiff Base Esters}

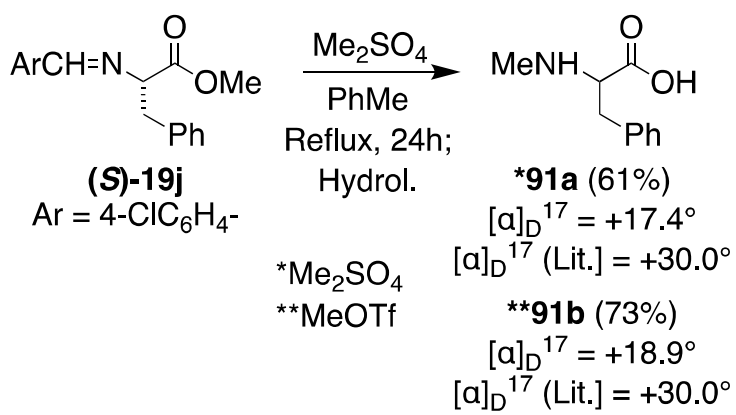

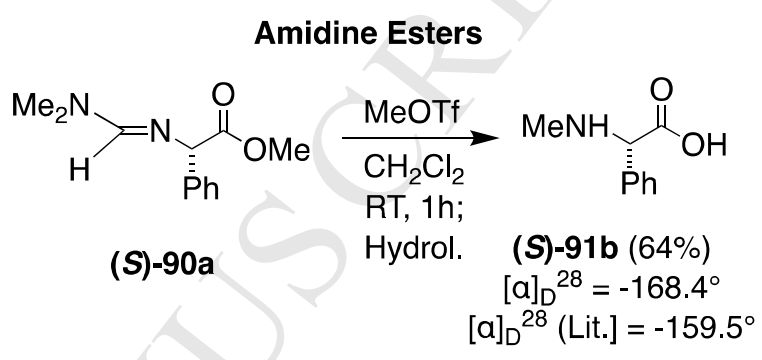

Other $\mathrm{Me}_{2} \mathrm{SO}_{4}$ Alkylations

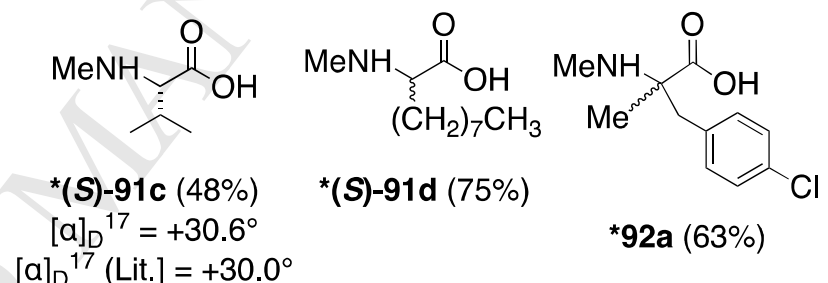

Scheme 46. N-Alkylation of Schiff Base and Amidine Amino Acid Esters.

Over the years, a number of very talented undergraduates have participated in undergraduate research in the group. Among these, Robin Polt contributed original ideas and research in a number of areas. ${ }^{17,19,35}$ One aspect in his early academic career at the University of Arizona was to develop a reductive route to the $\mathrm{N}$-alkyl amino acids from Schiff base esters. Reductive alkylation of $(\boldsymbol{S})-\mathbf{1 2}$ with $\mathrm{NaBH}_{3} \mathrm{CN}$ and aqueous formaldehyde followed by catalytic hydrogenation gave products $(\boldsymbol{S})-91 a-d$. Extension of the method by use of alkyl aldehydes gave longer chain N-alkyl derivatives (S)-95a-c (Scheme 47). ${ }^{12,113}$ 
ODonnell Benzophenone Schiff Bases MS Ghosez Revd 031419.doc<smiles>[R]OC(=[R])N=C=[PH+]</smiles>

$(S)-12$

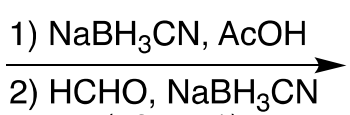
$(53-77 \%)$

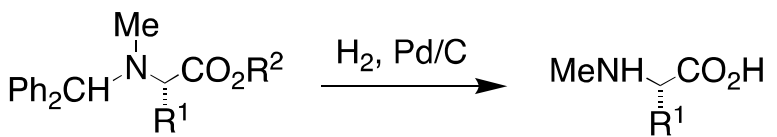

(S)-93a-d
(S)-91a-d (74-91\%)

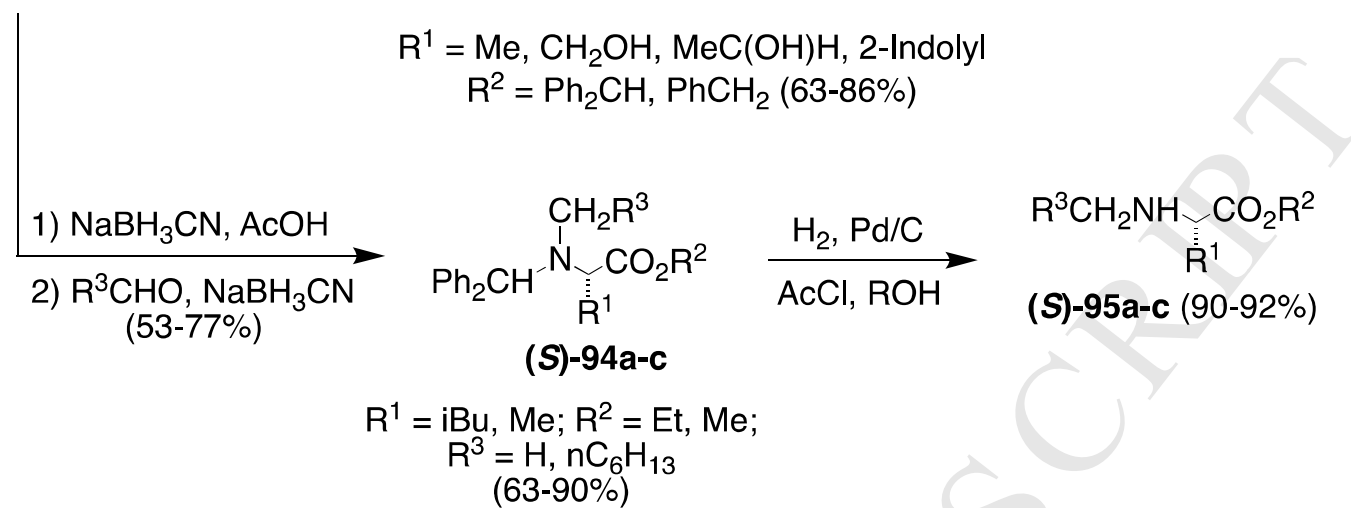

Scheme 47. Reductive Route to N-Alkyl Amino Acids from Schiff Base Esters.

The same group extended use of the benzophenone imines of glycine esters to the total synthesis of the "aza-sugar", L-Fuco-1-deoxy-nojirimycin (99) (Scheme 48). ${ }^{112-115}$ The synthesis involved addition of the an alkenyllithium with $\mathrm{iBu}_{5} \mathrm{Al}_{2} \mathrm{H}\left(\mathrm{iBu}_{3} \mathrm{Al} \cdot \mathrm{iBu}_{2} \mathrm{Al}-\mathrm{H}\right)$ to the ester $\mathbf{( S ) - 1 2 a}$ in a threo-selective tandem reduction-alkenylation, which was followed by $\mathrm{OH}$ protection to $\mathbf{9 7}$ [trichloroacetylisocyanate (TAI) was used to prepare cyclic derivatives of the initial reductionalkenylation adduct for NMR analysis]. Osmium-catalyzed cis-oxygenation of the double bond followed by Mom-protection of the resulting diol gave 97. This initial synthesis was completed by removal of the TBDMS group, oxidation to the aldehyde with a Swern oxidation, selective reduction of the Schiff base, saponification of the pivalate (with the quaternary ammonium salt $\mathrm{Bu}_{4} \mathrm{~N}^{+} \mathrm{OH}^{-}$), hydrogenolysis of the diphenylmethyl group and subsequent ring closure to yield LFuco-1-deoxy-nojirimycin (99) in 9 steps. The methodology was refined by the introduction of a TEMPO-catalyzed oxidation that was selective for the primary alcohol in the presence of two secondary alcohols, obviating the need for Mom-protection, and providing 99 in 8 steps in an overall yield of $20 \%$. Other amino sugars $(\mathbf{1 0 1})$ and aza-sugars (102) were synthesized using the same methodology. ${ }^{114,115}$ 
ODonnell Benzophenone Schiff Bases MS Ghosez Revd 031419.doc

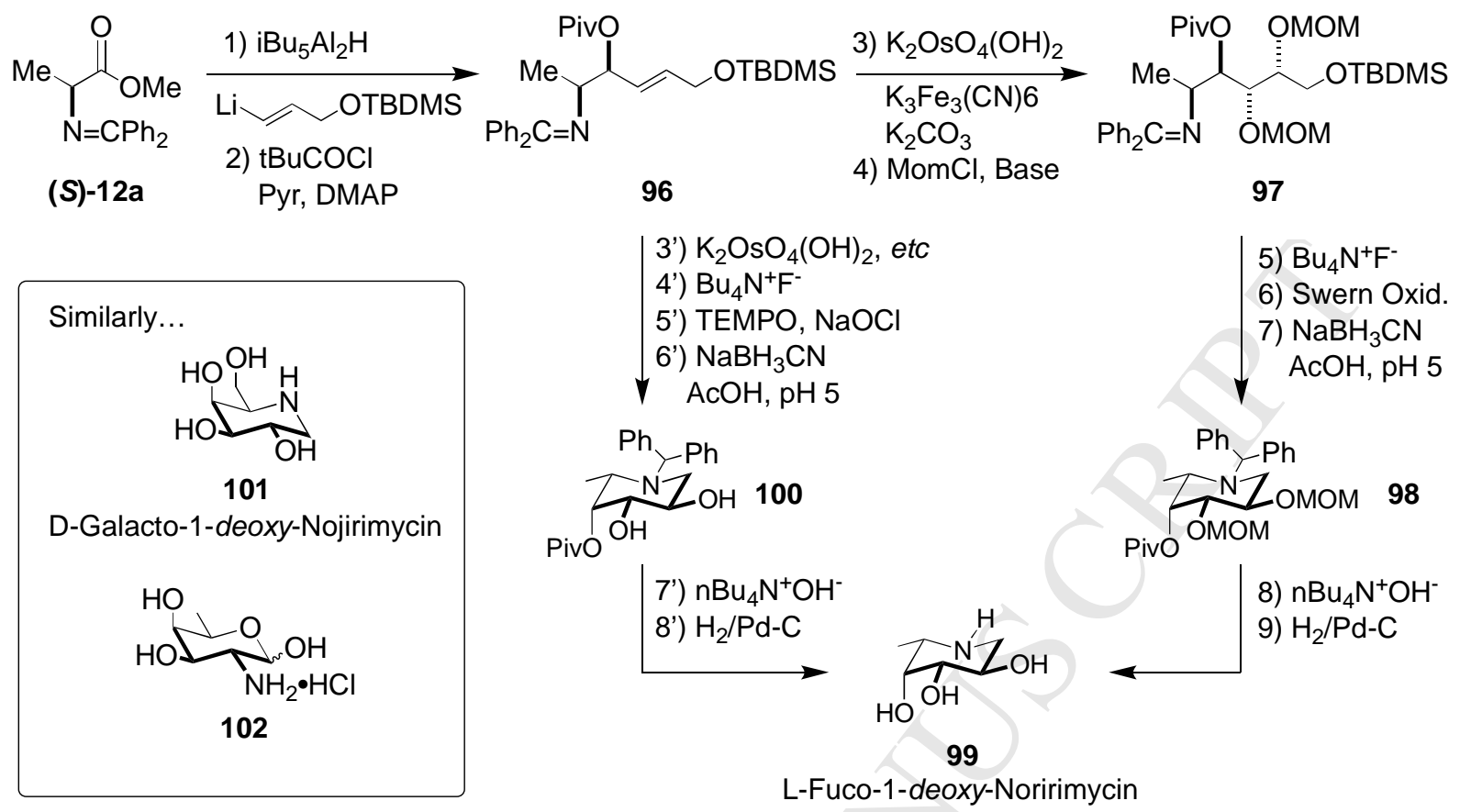

Scheme 48. Total Synthesis of Potential Glycosidase Inhibitors from the Benzophenone Imine of Alanine Ester by Polt.

\section{Conclusions}

The multiple uses of either the benzophenone imine esters of glycine, or the aldimine derivatives of monosubstituted amino acid esters, to synthesize either racemic or enantioenriched natural and unnatural amino acids has been reviewed. While the majority of the review covers our own contributions, the efforts of others are represented by the many reviews in the area. The field will continue to thrive as new catalysts, reactions types and conditions are explored and as the methodology finds further application in the total synthesis of complex molecules.

\section{Reflections}

In thinking back about my two-year postdoctoral experience in Belgium with Professor Ghosez, the first thoughts that come to mind are "remarkable scientist" and "ultimate host." My wife Kitty and I were immediately accepted with open arms into the larger Ghosez family and group, whether it was a dinner Chez Ghosez, a soiree at their home for the entire group or insight into a synthetic problem.

In early 1973 when I was finishing my PhD with Professor Kenneth Wiberg at Yale, I told Dr. Wiberg that I'd like to go to Europe for a postdoc and wondered if he had any recommendations. He said "Léon Ghosez" and added "he's a good man." How fortunate I was! The first day in lab, I knew I was being mentored by a gifted scientist and human being. Two years later, on finishing my postdoc, I discussed research plans for my upcoming academic position with the Patron; with a twinkle in his eye, he suggested I look into amino acid synthesis 
ODonnell Benzophenone Schiff Bases MS Ghosez Revd 031419.doc

because he thought it would be an important new area of research in the future. How right he was! His simple suggestion helped establish the trajectory of my career.

I have many fond memories of my time in Belgium. I remember the Saint Nicolas (Santa Claus) festivity in the lab in early December with the "Chef" being wheeled in on a cart for the celebration. Several visits to vacation homes with the Ghosez family were memorable. First, on the coast, where we were served waterzooie, the famed Belgian national soup of eggs, cream and fish. Since we thought there would be more courses to come after the soup, we didn't take the seconds that were offered...it was a hungry afternoon walking along the Belgian coast. Years later when we were on sabbatical in London in 1985, we visited the Ghosez family in northern France. We got lost, a workman showed us the way and Ghosez, of course, invited him to join us for lunch. Within fifteen minutes of our arrival our oldest son, Patrick, managed to step in a "cow pie." Mme. Ghosez was unfazed and took him right under her wing.

Léon Ghosez is a dear friend and colleague who has been instrumental in my own career and life. He introduced Kitty and me to the charms of the Continent and inspired me to always do my best work. I owe him more than I can say.

\section{Acknowledgements}

I am indebted to my many colleagues who have been part of this program: mentors, undergraduates, graduate students, postdocs, collaborators and friends. Special thanks go to my colleague Dr. William L. Scott. The many years of financial support from the National Institutes of Health (GM-28193) and Eli Lilly and Company are gratefully acknowledged. Finally, I want to thank my wife Kitty and our family for their continued love and understanding.

\section{References}

1. (a) Nájera C, Sansano JM. Chem. Rev. 2007; 107, 4584.

(b) Amino Acids, Peptides and Proteins in Organic Chemistry; Hughes AB, Ed.; WileyVCH: Weinheim, 2009; Vol. 1-5.

2. (a) Ager, D. J. In Amino Acids, Peptides and Proteins in Organic Chemistry; Hughes AB, Ed.; Wiley-VCH: Weinheim, 2009; Vol. 1, Chap. 12, p. 495.

(b) Jakubowska A, Kulig K. Curr. Org. Synth. 2013; 10: 547.

(c) Organic Chemistry, $2^{\text {nd }}$ Ed.; Clayden J, Greeves N, Warren S.; Oxford University Press: New York, 2012.

3. Campbell Biology, 11th Ed.; Urry LA, Cain ML, Wasserman SA, Minorsky PV, Reece JB; Pearson: New York, 2016.

4. Biochemistry, $4^{\text {th }}$ Ed.; Voet D, Voet JG; Wiley, Hoboken, NJ, 2011.

5. The Organic Chemistry of Drug Design and Drug Action, $3^{\text {rd }}$ Ed.; Silverman RB, Holladay MW; Academic Press: San Diego, 2014.

6. Tang S, Zhang X, Sun J, Niu D, Chruma JJ. Chem. Rev. 2018; 118, 10393.

7. O'Donnell MJ, Boniece JM, Earp SE. Tetrahedron Lett. 1978; 19, 2641.

8. O'Donnell MJ, Eckrich TM. Tetrahedron Lett. 1978; 19, 4625.

9. Reviews by the author:

(a) " $\alpha$-Amino Acid Synthesis," Tetrahedron Symposium-in-Print; O’Donnell, M. J., Ed.; 
ODonnell Benzophenone Schiff Bases MS Ghosez Revd 031419.doc

Pergamon Press: Oxford, 1988; 44, Issue 17: 5253-5614 .

(b) O'Donnell M. J. In Catalytic Asymmetric Synthesis; Ojima I., Ed.; Verlag Chemie: New York, 1993; Chap. 8, p. 389.

(c) O'Donnell M. J. In Encyclopedia of Reagents for Organic Synthesis; Paquette LA., Ed.; Wiley: New York, 1996; Vol. 4, p. 2435; e-EROS, 2001, 10.1002/047084289X.re063m.

(d) O'Donnell M. J. In Encyclopedia of Reagents for Organic Synthesis; Paquette LA., Ed.; Wiley: New York, 1996; Vol. 4, p. 2234; e-EROS, 2001, 10.1002/047084289X.re063f.

(e) O'Donnell M. J. In Encyclopedia of Reagents for Organic Synthesis; Paquette LA., Ed.; Wiley: New York, 1996; Vol. 4, p. 2230; e-EROS, 2001, 10.1002/047084289X.rd424m.

(f) O'Donnell M. J. In Encyclopedia of Reagents for Organic Synthesis; Paquette LA., Ed.; Wiley: New York, 1996; Vol. 1, p. 293; e-EROS, 2001, 10.1002/047084289X.rb031.

(g) O'Donnell M. J. In Encyclopedia of Reagents for Organic Synthesis; Paquette LA., Ed.; Wiley: New York, 1996; Vol. 3, p. 1771; e-EROS, 2001, 10.1002/047084289X.rd161m.

(h) Esikova I. A.; Nahreini T.S.; O'Donnell M. J. In Phase-Transfer Catalysis (ACS Symposium Series 659); Halpern M., Ed.; American Chemical Society: Washington, D. C., 1997; Chap. 7, p. 89, 1997.

(i) O'Donnell M. J.; Esikova I. A.; Mi A.; Shullenberger DF.; Wu, S. In Phase-Transfer Catalysis (ACS Symposium Series 659); Halpern M., Ed.; American Chemical Society: Washington, D. C., 1997; Chap. 10, p. 124, 1997.

(j) O'Donnell M. J. In Catalytic Asymmetric Synthesis; Second Edition, Ojima, I., Ed.; Wiley-VCH: New York, 2000; Chap. 10, p. 727.

(k) O'Donnell MJ. Aldrichimica Acta 2001; 34: 3.

(1) O’Donnell MJ. Acc. Chem. Res. 2004; 37: 518.

(m) O'Donnell M. J. “O'Donnell Amino Acid Synthesis," In Organic Syntheses Based on Name Reactions: A Practical Guide to 750 Reactions; Hassner, A.; Namboothiri, I., Eds.; Elsevier: Amsterdam, 2012; p. 351.

(n) O’Donnell M. J. “O'Donnell Amino Acid Synthesis," In Organic Chemistry Portal/Organic Reactions/Name Reactions; Taber DF, Mueller R., Eds.; https://www.organic-chemistry.org (accessed August 26, 2018). url: https://www.organicchemistry.org/namedreactions/o-donnell-amino-acid-synthesis.shtm (accessed 10 September 2018).

10. (a) Sörensen SPL. C. R. Trav. Lab. Carlsberg, Sér. Chim. 1903-1906; 6: 1

(b) Greenstein, J. P.; Winitz, M. Chemistry of the Amino Acids. John Wiley. New York, 1961, p. 709.

11. (a) Schiff H. Ann. Chem. Pharm. 1864; 131: 118.

(b) Dayagi, S.; Degani, Y. In The Chemistry of the Carbon-Nitrogen Double Bond; Patai, S., Ed.; Interscience: London: 1970, Chap. 2, p. 64.

12. Yamada S-I, Oguri T, Shioiri T. Chem. Commun. 1976; 136.

13. (a) Belokon' YN, Zel'tzer IE, Bakhmutov VI, Saporovskaya MB, Ryzhov MG, Yanovsky AI, Struchkov YT, Struchkov YT, Belikov VM. J. Am. Chem. Soc. 1983; 105: 2010.

(b) Gugkaeva ZT, Larionov VA, Moskalenko MA, Khrustalev VN, Nelyubina YV, Peregudov AS, Tsaloev AT, Maleev VI, Belokon YN. Synthesis. 2018; 50: 607.

14. Sorochinsky AE, Aceña JL, Moriwaki H, Sato T, Soloshonok VA. Amino Acids. 2013; 45: 691.

15. (a) Schöllkopf U, Hoppe D, Jentsch R. Angew. Chem. Int. Edit. 1971; 10: 331.

(b) Suzuki M, Miyahara T, Yoshioka R, Miyoshi M, Matsumoto K. Agr. Biol. Chem. 1974;

38: 1709 . 
ODonnell Benzophenone Schiff Bases MS Ghosez Revd 031419.doc

(c) Steglich W, Gruber P, Höfle G, König W. Angew. Chem. Int. Edit. 1971; 10: 653.

(d) Hoppe D. Angew. Chem. Int. Edit. 1975; 14: 426.

(e) Fitt JJ, Gschwend HW. J. Org. Chem. 1977; 42: 2639.

16. Stork G, Leong AYW, Touzin AM. J. Org. Chem. 1976; 41: 3491.

17. O'Donnell MJ, Bennett WD, Polt RL. Tetrahedron Lett. 1985; 26: 695.

18. O'Donnell MJ, Bennett WD, Wu S. J. Am. Chem. Soc. 1989; 111: 2353.

19. O’Donnell MJ, Polt RL. J. Org. Chem. 1982; 47: 2663.

20. (a) Brändström A, Junggren U. Acta Chem. Scand. 1969; 23: 2203.

(b) Brändström, A. In Preparative Ion Pair Extraction. An Introduction to Theory and Practice; Apotekarsocieteten/Hässle: Lakemedel, Sweden, 1974.

(c) Brändström A. Pure Appl. Chem. 1982; 54: 1769.

(d) Brändström A. J. Mol. Cat. 1983; 20: 93.

21. (a) Makosza M, Serafinowa. B. Rocz. Chem. 1965; 39: 1223.

(b) Makosza MM, Wawrzyniewicz M. Tetrahedron Lett. 1969; 10: 4659.

(c) Makosza M, Fedorynski M. Pol. J. Chem. 1996; 70: 1093.

(d) Makosza, M. In Phase-Transfer Catalysis: Mechanisms and Synthesis. Halpern M. E., Ed.; American Chemical Society: Washington, DC, 1997; Chap. 4, pp 41.

22. (a) Dehmlow, EV, Ezimora GC. Tetrahedron Lett. 1970; 11: 4047.

(b) Dehmlow EV; Dehmlow SS. In Phase Transfer Catalysis, $3^{\text {rd }}$ Ed.; VCW: Weinheim, 1993.

23. (a) Starks CM. J. Am. Chem. Soc. 1971; 93:195.

(b) Starks CM, Halpern ME, Ed.; American Chemical Society, Washington: DC; 1997; Chap. 2, p. 10.

24. Shioiri, T.; Ando, A.; Masui, M.; Miura, T.; Tatematsu, T.; Bohsako, A.; Higashiyama, M; Asakura, C. In Phase-Transfer Catalysis: Mechanisms and Synthesis; Halpern M. E., Ed.; American Chemical Society, Washington: DC; 1997; Chap. 11, p. 136.

25. O'Donnell MJ, Barney CL, McCarthy JR. Tetrahedron Lett. 1985; $26: 3067$.

26. Tsushima T, Kawada K, Nishikawa J, Sato T, Tori K, Tsuji T, Misaki S. J. Org. Chem. 1984; 49: 1163.

27. McCarthy JR, Barney CL, O'Donnell MJ, Huffman JC. Chem. Commun. 1987; 469.

28. (a) Brahms DLS, Dailey WP. Chem. Rev. 1996; 96: 1585.

(b) Khlebnikov, AF, Novikov MS, Kostikov RR. Synlett 1997; 929.

(c) Tsushima T, Kawada K, Nishikawa J, Sato T, Tori K, Tsuji T, Misaki S. J. Org. Chem. 1984; 49: 1163.

29. Ghosez L, Antoine J-P, Deffense E, Navarro M, Libert V, O'Donnell MJ, Bruder WA, Willey K, Wojciechowski K. Tetrahedron Lett. 1982; 23: 4255.

30. O'Donnell MJ, LeClef B, Rusterholz DB, Ghosez L, Antoine J-P, Navarro M. Tetrahedron Lett. 1982; 23: 4259.

31. O'Donnell MJ, Rusterholz DB. Synth. Commun. 1989; 19: 1157.

32. O'Donnell MJ, Wojciechowski K, Ghosez L, Navarro M, Sainte F, Antoine J-P. Synthesis; 1984: 313.

33. (a) Brackmann, F; de Meijere A. Chem. Rev. 2007; 107: 4493.

(b) Dian L, Marek I. Chem. Rev. 2018; 118: 8415.

34. O'Donnell MJ, Bruder WA, Eckrich TM, Shullenberger DF, Staten GS. Synthesis 1984; 127.

35. (a) O'Donnell MJ, Bennett WD, Bruder WA, Jacobsen WN, Knuth K, LeClef B, Polt RL, Bordwell FG, Mrozack SR, Cripe TR. J. Am. Chem. Soc. 1988; 110: 8520.

(b) Timofeeva DS, Ofial AR, Mayr H. Tetrahedron. 2019; 75: 459.

36. (a) Ripin, D. H.; Evans D. A. Evans pKa Table $\left(\mathrm{H}_{2} \mathrm{O}\right.$ \& DMSO) of 35 Organic and 
ODonnell Benzophenone Schiff Bases MS Ghosez Revd 031419.doc

Inorganic Structural Classes: http://ccc.chem.pitt.edu/wipf/MechOMs/evans_pKa_table.pdf (accessed 10 September 2018).

(b) Reich, H. J. Bordwell pKa Table (Acidity in DMSO):

http://www.chem.wisc.edu/areas/reich/pkatable/index.htm (accessed 10 September 2018).

(c) Evan's pKa Table plus DMSO Acidities of Common Heterocycles:

http://evans.rc.fas.harvard.edu/pdf/evans_pKa_table.pdf (accessed 10 September 2018). (Inorganic and Oxo-Acids; Nitrogen Acids; $\mathrm{CH}$ Bonds in Hydrocarbons and Carbonyl Compounds; $\mathrm{CH}$ Bonds at Nitriles, Heteroaromatic, and Sulfur Substituted Carbon; CH Bonds at Heteroatom Substituted Carbon; Acidities of Common Heterocycles.)

37. Hoffmann RW. Chem. Rev. 1989; 89: 1841.

38. O’Donnell MJ, Keeton JD, Khau VV, Bollinger JC. Can. J. Chem. 2006; 84: 1301.

39. Kumar S, Ramachandran U. Tetrahedron: Asymmetry. 2003; 14: 2539.

40. O'Donnell MJ, Bennett WD, Jacobsen WN, Ma Y-a, Huffman JC. Tetrahedron Lett. 1989; 30: 3909.

41. O'Donnell MJ, Bennett WD, Jacobsen WN, Ma Y-a. Tetrahedron Lett. 1989; 30: 3913.

42. (a) Williams RM, Hendrix JA. Chem. Rev. 1992; 92: 889.

(b) Lee S, Beare NA, Hartwig JF. J. Am. Chem. Soc. 2001; 123: 8410.

(c) Culkin DA, Hartwig JF. Acc. Chem. Res. 2003; 36: 234.

(d) Shirakawa S, Yamamoto K, Tokuda T, Maruoka K. Asian J. Org. Chem. 2014; 3: 433.

43. O'Donnell MJ, Burkholder TP, Khau VV, Roeske RW, Tian Z. Pol. J. Chem. 1994; 68: 2477.

44. (a) Pekošak A, Rotstein BH, Collier TL, Windhorst AD, Vasdev N, Poot AJ. Eur. J. Org. Chem. 2017; 1019.

(b) Filp U, Pekošak A, Poot AJ, Windhorst AD. Eur. J. Org. Chem. 2017; 5592.

(c) Reid CM, Sutherland A. In Amino Acids, Peptides and Proteins in Organic Chemistry; Hughes AB., Ed.; Wiley-VCH: Weinheim, 2009; Vol. 1, Chap. 11, p. 473.

45. O'Donnell MJ, Zhou C, Scott, WL. J. Am. Chem. Soc. 1996; 118: 6070.

46. Scott WL, Martynow JG, Huffman JC, O’Donnell MJ. J. Am. Chem. Soc. 2007; 129: 7077.

47. Scott WL, Zhou Z, Martynow JG, O’Donnell MJ. Org. Lett. 2009; 11: 3558.

48. Scott WL, O’Donnell MJ. J Comb Chem 2009; 11: 3.

49. Scott WL, Denton RE, Marrs KA, Durrant JD, Samaritoni JG, Abraham MM, Brown SP, Carnahan JM, Fischer LG, Glos CE, Sempsrott PJ, O’Donnell MJ. J. Chem. Educ. 2015; 92: 819.

50. (a) Dolling U-H, Davis P, Grabowski EJJ. J. Am. Chem. Soc. 1984; $106: 446$.

(b) Bhattacharya A, Dolling U-H, Grabowski EJJ, Karady S, Ryan KM, Weinstock LM. Angew. Chem. Int. Ed. Engl. 1986; 25: 476.

(c) Hughes DL, Dolling U-H, Ryan KM, Schoenewaldt EF, Grabowski EJJ. J. Org. Chem. 1987; 52: 4745.

51. (a) Berkessel, A.; Gröger, H. Asymmetric Organocatalysis: From Biomimetic Concepts to Applications in Asymmetric Synthesis; Wiley-VCH: Weinheim, 2005.

(b) Berkessel, A.; Gröger, H. In Asymmetric Organocatalysis: From Biomimetic Concepts to Applications in Asymmetric Synthesis; Berkessel, A., Gröger, H., Ed.; Wiley-VCH: Weinheim, 2005; Chap. 3, p. 13.

(c) Shirakawa S.; Maruoka K. In Catalytic Asymmetric Synthesis; Third Edition, Ojima I., Ed.; Wiley: New York, 2010; Chap. 2C, p. 95.

52. (a) Marcelli T, Hiemstra H. Synthesis. 2010; 1229-1279.

(b) Ingemann, S; Hiemstra, H. In Comprehensive Enantioselective Organocatalysis: Catalysis, Reactions, and Applications; Dalko, P. I.; Wiley-VCH: Weinheim, 2013; Chap. 6, p. 119. 
ODonnell Benzophenone Schiff Bases MS Ghosez Revd 031419.doc

(c) Ha, M. W.; Park, H-G. In R. S. C. Green Chem. North, M., Ed. Royal Society of Chemistry: London, 2016; Chap. 16, p. 82.

53. O’Donnell, M. J.; Wu, S.; Esikova, I.; Mi, A. U.S. Patent 5,554,753, 1996.

54. Lipkowitz KB, Cavanaugh MW, Baker B, O’Donnell MJ. J. Org. Chem. 1991; 56: 5181.

55. (a) Cannizzaro CE, Houk KN. J. Am. Chem. Soc. 2002; 124: 7163.

(b) Cook TC, Andrus MB, Ess DH. Org. Lett. 2012; 14: 5836.

(c) Petrova GP, Li H-B, Maruoka K, Morokuma K. J. Phys. Chem. B. 2014; $118: 5154$.

(d) Martins EF, Pliego, JR, Jr. J. Mol. Cat. A. 2016; 417:192.

(e) Kamachi T, Yoshizawa K. J. Chem. Inf. Model. 2016; 56: 347.

(f) Denmark SE, Henle JJ. Chem. Sci. 2015; 6: 2211.

(g) Engkvist O, Norrby P-O, Selmi N, Lam Y-h, Peng Z, Sherer EC, Amberg W, Erhard T, Smyth LA. Drug Disc. Today. 2018; 23: 1203.

56. O'Donnell MJ, Wu S. Tetrahedron: Asymmetry. 1992; 3: 591.

57. Lygo B, Crosby J, Peterson JA. Tetrahedron Lett. 1999; 40: 8671.

58. Belokon YN, Fuentes J, North M, Steed JW. Tetrahedron 2004; 60: 3191.

59. O'Donnell MJ, Wu S, Huffman JC. Tetrahedron. 1994; 50: 4507.

60. (a) Corey EJ, Xu F, Noe MC. J. Am. Chem. Soc. 1997; 119: 12414.

(b) Corey EJ, Noe MC. Org. Synth. 2003; 80: 38.

61. (a) Lygo B, Wainwright PG. Tetrahedron Lett. 1997; 38: 8595.

(b) Lygo B, Andrews BI. Acc. Chem. Res. 2004; 37: 518.

(c) Lygo B, Humphreys LD. Tetrahedron Lett. 2002; 43: 6677.

(d) Lygo B, Butt U, Cormack M. Org. Biomol. Chem. 2012; 10: 4968.

62. O'Donnell MJ, Delgado F, Hostettler C, Schwesinger R. Tetrahedron Lett. 1998; 39: 8775.

63. O'Donnell MJ, Delgado F, Dominguez E, de Blas J, Scott WL. Tetrahedron: Asymmetry. 2001; 12: 821.

64. Ramachandran PV, Madhi S, Bland-Berry L, Reddy MVR, O'Donnell MJ. J. Am. Chem. Soc. 2005; 127: 13450.

65. Yuan Y, Yu B, Bai X-F, Xu Z, Zheng Z-J, Cui Y-M, Cao J, Xu L-W. Org. Lett. 2017; 19: 4896.

66. Ramachandran PV, Madhi S, O’Donnell MJ. J. Fluor. Chem. 2007; 128: 78.

67. O'Donnell MJ, Delgado F. Tetrahedron. 2001; 57: 6641.

68. (a) Tohdo K, Hamada Y, Shioiri T. Synlett 1994; 247.

(b) Imperiali B, Fisher SL. J. Org. Chem.1992; 57: 757.

(c) Imperiali B, Roy RS. J. Am. Chem. Soc. 1994; 116: 12083.

(d) Imperiali B.; Roy, R. S. J. Org. Chem. 1995: 60: 1891.

(e) Torrado A, Imperiali B. J. Org. Chem. 1996; 61: 8940.

(f) Nitz M, Mezo AR, Ali MH, Imperiali, B. Chem. Commun. 2002; 1912.

69. Yun YK, Godula K, Cao Y, Donaldson WA. J. Org. Chem. 2003; 68: 901.

70. (a) Ooi T, Maruoka, K. Angew. Chem. Int. Ed. 2007; 46: 4222.

(b) Hashimoto T, Maruoka K. Chem. Rev. 2007; 107: 5656

(c) Shirakawa, S.; Maruoka, K. In Comprehensive Enantioselective Organocatalysis: Catalysts, Reactions, and Applications; Dalko P. I., Ed.; Wiley-VCH: Weinheim, 2013 Chap. 14, p. 365.

(d) Shirakawa S, Maruoka K. Angew. Chem. Int. Ed. 2013; 52: 4312.

(e) Kaneko S, Kumatabara Y, Shirakawa S. Org. Biomol. Chem. 2016; 14: 5367.

71. Lygo B, Beaumont DJ. Chimia 2007; 61: 257.

72. Jew S-s, Park H-g. Chem. Commun. 2009; 7090. 
ODonnell Benzophenone Schiff Bases MS Ghosez Revd 031419.doc

73. Okada A, Shibuguchi T, Ohshima T, Masu H, Yamaguchi K, Shibasaki M. Angew. Chem. Int. Ed. 2005; 44: 4564.

74. (a) Chinchilla R, Mazón P, Nájera C, Ortega FJ, Yus M. ARKIVOK 2005; 222.

(b) Andrus MB, Ye Z, Zhang J. Tetrahedron Lett. 2005; 46: 3839.

75. (a) Denmark SE, Gould ND, Wolf LM. J. Org. Chem. 2011; 76: 4260.

(b) Denmark SE, Gould ND, Wolf LM. J. Org. Chem. 2011; 76: 4337.

76. Wen S, Li X, Lu Y. Asian J. Org. Chem. 2016; 5: 1457.

77. (a) Kondo Y, Ueno M, Tanaka Y. Jap. Synth. Chem. 2005; 63: 453 (text in Japanese, good structures and English references).

(b) Gheewala CD, Collins BE, Lambert TH. Science. 2016; 351: 961.

(c) Raczyńska ED, Gal J-F, Maria P-C. Chem. Rev. 2016; 116: 13454.

(d) Lyons DJM, Crocker RD, Blümel M, Nguyen TV. Angew. Chem. Int. Ed. 2017; 56: 1466.

78. Sheshenev AE, Boltukhina EV, White AJP, Hii KK. Angew. Chem. Int. Ed. 2013; 52: 6988.

79. (a) Bandar JS, Lambert TH. J. Am. Chem. Soc. 2012; 134: 5552.

(b) Bandar JS, Lambert TH. Synthesis. 2013; 45: 2485.

(c) Bandar JS, Sauer GS, Wulff WD, Lambert TH, Vetticatt MJ. J. Am. Chem. Soc. 2014; 136: 10700 .

(d) Bandar JS, Barthelme A, Mazori AY. Lambert TH. Chem. Sci. 2015; 6: 1537.

(e) Bandar JS, Tanaset A, Lambert TH. Chem. Eur. J. 2015; 21: 7365.

80. (a) Mirabdolbaghi R, Dudding T, Stamatatos T. Org. Lett. 2014; 16: 2790.

(b) Belding L, Stoyanov P, Dudding T. J. Org. Chem. 2016; 81: 553.

81. (a) Qiu W, Soloshonok VA, Cai C, Tang X, Hruby VJ. Tetrahedron. 2000; 56: 2577.

(b) Hillier MC, Reider PJ. Drug Disc. Today. 2002; 7: 303.

(c) Grabowski, EJJ. Abdel-Magid, A. F., Ragan, J. A., Eds.; American Chemical Society: Washington DC, 2004; p. 1.

(d) Gröger, H. Ernst Schering Foundation Symposium Proceedings. 2008; 2: 141-158.

(e) Maruoka K. Org. Process Res. Dev. 2008; 12: 679.

(f) Nun P, Pérez V, Calmès M, Martinez J, Lamaty F. Chem. Eur. J. 2012; $18: 3773$.

(g) Tan J, Yasuda N. Org. Process Res. Dev. 2015; 19: 1731.

(h) Hughes DL. Org. Process Res. Dev. 2018; 22: 574.

82. Patterson DE, Xie S, Jones LA, Osterhout MH, Henry CG, Roper TD. Org. Process Res. Dev. 2007; 11: 624.

83. Patterson, DE, Xie S, Jones LA, Osterhout MH, Henry CG, Roper TD. In Asymmetric Catalysis on Industrial Scale: Challenges, Approaches, and Solutions, $2^{\text {nd }}$ Ed.; Blaser, H.-U; Federsel H.-J., Eds.; Wiley-VCH: Weinheim, 2010; Chap. 26, p. 473.

84. (a) O'Donnell MJ, Drew MD, Cooper JT, Delgado F, Zhou C. J. Am. Chem. Soc. 2002; 124; 9348.

(b) O'Donnell MJ, Delgado F, Drew MD, Pottorf RS, Zhou C, Scott WL. Tetrahedron Lett. 1999; 40: 5831.

85. O'Donnell MJ, Arasappan A, Hornback WJ, Huffman JC. Tetrahedron Lett. 1990; 31: 157.

86. Schörgenhumer J, Tiffner M, Waser M. Beilstein J. Org. Chem. 2017, 13, 1753.

87. (a) O'Donnell MJ, Falmagne J-B. Chem. Commun. 1985; 1168 (Corrigendum, Chem. Commun. 1986; 732).

88 King, GA III, Sweeny JG, Iacobucci GA. J. Agric. Food Chem. 1991; 39: 52.

89. O’Donnell MJ, Cooper JT, Mader MM. J. Am. Chem. Soc. 2003; 125: 2370.

90. (a) Crudden CM, Edwards D. Eur. J. Org. Chem. 2003; 4695.

(b) Crudden, CM, Glasspoole BW, Lata CJ. Chem. Commun. 2009; 6704.

(c) Michaux J, Niel G, Campagne J-M. Chem. Soc. Rev. 2009; 38: 2093. 
(d) Chen Y, Yudin AK. Tetrahedron Lett. 2003; 44: 4865.

(e) Kanayama T, Yoshida K, Miyabe H, Takemoto Y. Angew. Chem. Int. Ed. 2003; 42: 2054.

(f) Kanayama T, Yoshida K, Miyabe H, Kimachi T, Takemoto Y. J. Org. Chem. 2003; 68: 6197.

(g) Ooi T, Kato D, Inamura K, Ohmatsu K, Maruoka K. Org. Lett. 2007; 9: 3945.

91. O'Donnell MJ, Bennett WD. Tetrahedron. 1988; 44: 5389.

92. (a) Clark BP, Harris JR. Synth. Commun. 1997; 27: 4223.

(b) Jiang B, Huang Z-G, Synthesis, 2005; 2198.

(c) Liu Z, Mehta SJ, Hruby VJ. Org. Prep. Proced. Int. 2012; 44: 222.

(d) Lygo B, Andrews BI. Tetrahedron Lett. 2003; 44: 4499.

(e) Wang L, Murai, Y, Yoshida T, Okamoto M, Tachrim ZP, Hashidoko Y, Hashimoto, M. Molecules, 2014; 19: 6349.

93. O'Donnell MJ, Falmagne J-B. Tetrahedron Lett. 1985; 26: 699.

94. (a) Kozhushkov SI, Brandl M, Yufit DS, Machinek R, de Meijere A. Liebigs Ann./Recueil. 1997; 2197.

(b) de Meijere A, Ernst K, Zuck B, Brandl M, Kozhushkov SI, Tamm M, Yufit DS, Howard JAK, Labahn T. Eur. J. Org. Chem. 1999; 3105.

(c) de Meijere A, Kozhushkov SI. Chem. Rev. 2000; 100: 93.

95. (a) Lamaty F, Lazaro R, Martinez J. Tetrahedron Lett. 1997; 38: 3385.

(b) Brandl M, Kozhushkov SI, Bräse S, de Meijere A. Eur. J. Org. Chem. 1998; 453.

(c) Knochel P, Perea JAA, Jones P. Tetrahedron. 1998; 54: 8275.

(d) Knochel P, Schade MA, Bernhardt S, Manolikakes G, Metzger A, Piller FM, Rohbogner CJ, Mosrin M. Beilstein J. Org. Chem. 2011; 7: 1261.

96. O'Donnell MJ, Yang X, Li M. Tetrahedron Lett. 1990; 31: 5135.

97. O'Donnell MJ, Zhou C, Mi A, Chen N, Kyle JA, Andersson PG. Tetrahedron Lett. 1995; 36: 4205.

98. O'Donnell MJ, Zhou C, Chen N. Tetrahedron: Asymmetry, 1996; 7: 621.

99. O’Donnell MJ, Chen N, Zhou C, Murray A, Kubiak CP, Yang F, Stanley GG. J. Org. Chem. 1997; 62: 3962.

100. Yamaguchi M, Ohba K, Tomonaga H, Yamagishi T. J. Mol. Cat. A. 1999; 140: 255.

101. O'Donnell MJ, Li M, Bennett WD, Grote T. Tetrahedron Lett., 1994; 35: 9383.

102. (a) Negishi E-i, Hu Q, Huang Z, Qian M, Wang G. Aldrichimica Acta, 2005; 38: 71.

(b) Berkowitz, DB, Charette BD, Karukurichi, KR, McFadden JM. Tetrahedron: Asymmetry. 2006; 17: 869.

(c) Hang J, Deng L. Bioorg. Med. Chem. Lett. 2009; 19: 3856.

103. O'Donnell MJ, Lawley LK, Pushpavanam PR, Burger A, Bordwell FG, Zhang X-M. Tetrahedron Lett. 1994; 35: 6421.

104. (a) Genet JP, Uziel J, Juge S. Tetrahedron Lett. 1988; 29: 4559.

(b) Schrader T, Steglich W. Synthesis. 1989; 97.

(c) Baldwin IC, Williams JMJ, Beckett RP. Tetrahedron: Asymmetry. 1995; 6: 679.

(d) Jászay ZM, Németh G, Pham TS, Petneházy I, Grün A, Tőke L. Tetrahedron: Asymmetry. 2005; 16: 3837.

(e) Kukhar V. P.; Romanenko V. D. In Amino Acids, Peptides and Proteins in Organic Chemistry; Hughes, A.B. Ed.; Wiley-VCH: Weinheim, 2009; Vol. 2, Chap. 5, p. 189.

(f) Kudzin, ZH, Kudzin, MH, Drabowicz, J, Stevens, CV. Curr. Org. Chem. 2011; 15: 2015. 
ODonnell Benzophenone Schiff Bases MS Ghosez Revd 031419.doc

(g) Sevrain CM, Berchel M, Couthon H, Jaffrès P-A. Beilstein J. Org. Chem. 2017, 13, 2186.

105. (a) Jurczak J, Golebiowski A. Chem. Rev. 1989; 89: 149.

(b) Fisher LE, Muchowski JM. Org. Prep. Proced. Int. 1990; 22: 399.

(c) Khlestkin VK, Mazhukin DG. Curr. Org. Chem. 2003; 7: 967.

(d) Balasubramaniam S, Aidhen IS. Synthesis, 2008; 3707.

(e) Liebeskind LS, Yang H, Li H. Angew. Chem. Int. Ed. 2009; 48: 1417.

(f) Sun G, Wei M, Luo Z, Liu Y, Chen Z, Wang Z. Org. Process Res. Dev. 2016; 20; 2074.

106. O'Donnell MJ, Drew MD, Pottorf RS, Scott WL. J. Comb. Chem. 2000; 2: 172.

107. (a) Bazureau JP, Person D, Le Corre M. Tetrahedron Lett. 1989; 30: 3065.

(b) Murphy PJ, Lee SE. J. Chem. Soc., Perkin Trans. 1. 1999; 3049.

(c) Kazmaier, U. In Amino Acids, Peptides and Proteins in Organic Chemistry; Hughes, A.

B., Ed.; Wiley-VCH: Weinheim, 2009; Vol. 2, Chap. 1, p. 3.

108. O'Donnell MJ, Cook GK, Rusterholz DB. Synthesis. 1991; 989.

109. (a) Doecke CW, Staszak MA, Luke WD. Synthesis. 1991; 985.

(b) Hermann C, Pais GCG, Geyer A, Kühnert SM, Maier ME. Tetrahedron 2000; 56: 8461.

(c) Ikunaka M. Org. Process Res. Dev. 2008; 12: 698.

110. (a) Aurelio, L.; Brownlee, RTC, Hughes AB. Chem. Rev. 2004; 104: 5823.

(b) Aurelio, L.; Hughes, A. B. In Amino Acids, Peptides and Proteins in Organic Chemistry;

Hughes A. B., Ed.; Wiley-VCH: Weinheim, 2009; Vol. 1, Chap. 6, p. 245.

111. O'Donnell MJ, Bruder WA, Daugherty BW, Liu D. Wojciechowski K. Tetrahedron Lett., 1984; 25: 3651.

112. Chruma JJ, Sames D, Polt R. Tetrahedron Lett. 1997; 38: 5085.

113. Polt, R. L. In Amino Acid Derivatives: A Practical Approach; Barrett, G. C., Ed.; Oxford University Press: New York, 1999; Chap. 9, p. 101.

114. Polt R, Sames D, Chruma J. J. Org. Chem. 1999; 64: 6147.

115. Razavi H, Polt R. J. Org. Chem. 2000; 65: 5693.

Martin J. O'Donnell was born and raised in Williams, Iowa. He received his B.S. in Chemistry from the University of Iowa in 1968 and his Ph.D. from Yale University in 1973 with Professor Kenneth B. Wiberg. He did a postdoctoral fellowship with Professor Léon Ghosez at the Université Catholique de Louvain in Belgium (1973-1975). Marty's independent career started in 1975 at Indiana University Purdue University Indianapolis where he is Chancellor's Professor and Professor of Chemistry \& Chemical Biology. He is the recipient of several research and teaching awards, including the 1995 Chancellor's Award for Excellence in Teaching. His research involves the development and utilization of the enantioselective syntheses of amino acids by phase-transfer catalysis using Cinchona alkaloid derivatives, development of a cationic glycine equivalent for reactions with various nucleophiles and, more recently, the solid-phase synthesis of amino acids and peptides in a program entitled "Distributed Drug Discovery." 